\title{
PROBABILISTIC PRODUCTION FORECASTING AND RESERVES ESTIMATION IN WATERFLOODED OIL RESERVOIRS
}

\author{
A Thesis \\ by \\ MAKSIM Y. NAZARENKO \\ Submitted to the Office of Graduate and Professional Studies of \\ Texas A\&M University \\ in partial fulfillment of the requirements for the degree of \\ MASTER OF SCIENCE
}

$\begin{array}{ll}\begin{array}{l}\text { Chair of Committee, } \\ \text { Committee Members, }\end{array} & \begin{array}{l}\text { Duane McVay } \\ \text { Thomas Blasingame } \\ \text { Christine Ehlig-Economides }\end{array} \\ \text { Head of Department, } & \text { Daniel Hill }\end{array}$

May 2016

Major Subject: Petroleum Engineering

Copyright 2016 Maksim Nazarenko 


\begin{abstract}
The importance of uncertainty quantification and risks assessment in the petroleum industry cannot be overstated. Uncertainty will always be present in production forecasts and reserves estimates. Underestimation of uncertainty when estimating reserves and profitability of projects can lead to poor decision making and disappointment.
\end{abstract}

Water Displacement Curve (WDC) models allow engineers to estimate reserves and forecast production performance in waterflooded oil reservoirs taking into account either liquid or water production. Compared with Decline Curve Analysis (DCA), WDC models are expected to perform better in forecasting oil production in waterflooded oil fields.

In this study I applied Bayesian methodology and Markov Chain Monte Carlo (MCMC) methods with WDC models. I also developed a Multimodel approach based on eleven WDC models to quantify uncertainty in production forecasts by assessing differences in matches and forecasts provided by each model.

Both Multimodel and MCMC with WDC models were calibrated and compared to MCMC with DCA methods. Reliability of the developed methods was assessed using production history of 100 wells from actual waterflooded oil fields. I performed hindcast studies in which I assumed that some fraction of the actual historical production data is known (6, 12, 24 and 36 months) and the rest of the actual production is unknown (5 - 7 years). I then matched the assumed known production fraction of the history and forecasted production to the end of the actual historical period. The cumulative production at the end of the hindcast is compared to the actual cumulative production at this time to test the probabilistic reliability of the methodology when production history is limited. 
The study showed that

- WDC Multimodel, MCMC with WDC and MCMC with DCA are well-calibrated probabilistic methods

- WDC Multimodel performs more than 20 times faster than MCMC with WDC and MCMC with DCA techniques having the same level of reliability

- Compared with MCMC using DCA, WDC Multimodel and MCMC with WDC show more reliable results when the history matching period is less than 24 months

Computer software was developed during this research to make the process of calculations more convenient. 


\section{DEDICATION}

This thesis is dedicated to my parents for all love and support they have provided me with throughout my life. 


\section{ACKNOWLEDGEMENTS}

I would like to thank my committee chair, Dr. McVay, for his extensive support and continuous guidance during my studying, without him this research could not be completed. I also would like to thank my committee members, Dr. Blasingame, Dr. Valko and Dr. Ehlig-Economides, for providing valued insight and help throughout the course of this research.

I would like to express my deepest appreciation to Dr. Zhu and Dr. Zolotukhin for their guidance and support during my studying.

I want to extend my gratitude to LUKOIL Overseas for giving me financial support, without it my studying at Texas A\&M University would not have been possible. I also wish to thank my supervisor and Head of Reservoir Engineering Department at LUKOIL Overseas, Proshenkov A.G., for his extensive supervision and generous support during my studying.

Finally, thanks to my friends and colleagues and to the department faculty and staff for making my time at Texas A\&M University a great experience and unforgettable memories. 


\section{NOMENCLATURE}

a

b

bbl

$b_{D C A}$

CPOHP

DCA

$\mathrm{D} \infty$

$\widehat{D}$

$D_{\min }$

Di

EUR

$f_{o}$

$f_{w}$

$f(\mathrm{y} \mid \theta)$

GOR

$k_{\text {ro }}$

$k_{r w}$

K

$L_{p}$

MCMC

MBM

Mcf

$m$

$N_{p}$
WDC Constant, dimensionless

WDC Constant, dimensionless

Barrel (unit)

Exponential parameter of DCA model

Cumulative production of hindcast period, bbl

Decline Curve Analysis

Power-Law decline at infinite time constant, 1/month

Power-Law decline constant, 1/month

Minimum decline rate, 1/year

Initial decline rate, 1/year

Estimate Ultimate Recovery, bbl

Oil Content in produced liquid, $\%$

Water Content in produced liquid, $\%$

Likelihood function

Gas Oil Ratio

Oil relative permeability, dimensionless

Water relative permeability, dimensionless

Potential EUR without imposing economic limits, Mcf

Cumulative production of liquid, bbl

Markov Chain Monte Carlo

Modified Bootstrap Method

Thousand cubic feet

Slope of Duong's Model, dimensionless

Cumulative production of oil, bbl 


$\begin{array}{ll}N & \text { Exponent parameter or Power-Law model, } \\ N & \text { dimensionless } \\ \text { OOIP } & \text { Total number of months in history matching period } \\ \text { PPF } & \text { Oil Originally in Place, bbl } \\ \text { P10 } & \text { Probabilistic Production Forecasting Software } \\ \text { P50 } & 10^{\text {th }} \text { Percentile } \\ \text { P90 } & 50^{\text {th }} \text { Percentile } \\ q_{o i} & 90^{\text {th }} \text { Percentile } \\ q_{l} & \text { Actual oil production in month i, bbl/month } \\ q_{i} & \text { Actual liquid production in month i, bbl/month } \\ \widehat{q_{o l}} & \text { Initial rate, Volume/Month } \\ \text { TCP } & \text { Calculated monthly production in month i, bbl/month } \\ T_{0} & \text { Total Cumulative Production, bbl } \\ \text { T } & \text { Modified Arps' time, months } \\ \text { WOR } & \text { Time, months } \\ \text { WDC } & \text { Water Oil Ratio, dimensionless } \\ W_{p} & \text { Water Displacement Curve } \\ Y & \text { Cumulative production of water, bbl } \\ \alpha & \text { Monthly production, Volume } \\ a_{L} & \text { Constant, dimensionless } \\ \beta & \text { Time of Logistic Growth model at which half of the } \\ \delta_{D C A} & \text { potential EUR has been produced, months } \\ \delta_{W D C} & \text { Constant, dimensionless } \\ \delta_{l} & \text { Relative Error for oil production (DCA model) } \\ & \text { Relative Error for liquid production rate } \\ & \end{array}$


$\varepsilon$

$\theta j$

$\theta_{\text {lower }}$

$\theta_{\text {proposal }}$

$\theta_{\text {upper }}$

$\Theta$

$\pi(\theta)$

$\pi(\theta \mid y)$

$\sigma$

$\sigma_{\text {proposal }}$

$\Phi$

$\tau$

$n_{L}$

$\mathrm{H}$
Residual between actual production and calculated curve production

Potential candidate of the parameters

Lower boundary of proposal distribution

Parameters drawn from proposal distribution

Upper boundary of proposal distribution

One of the decline curve parameters

Prior or posterior probability

Posterior distribution

Sample variance from best fit

Sample variance from proposal parameters

Cumulative density function of standard normal distribution

Characteristic time parameter or Stretched Exponential

Production Decline Model (SEPD) model, months

Decline exponent parameter of Logistic Growth model, dimensionless

Exponent parameter or SEPD model, dimensionless 


\section{TABLE OF CONTENTS}

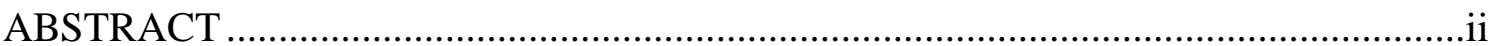

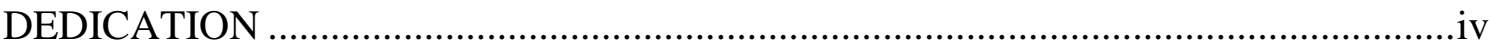

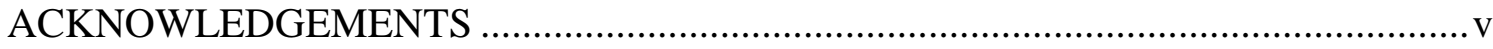

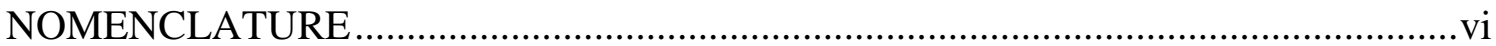

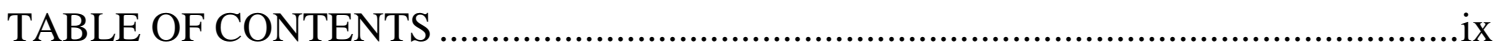

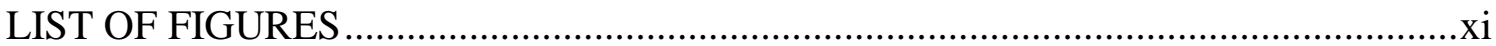

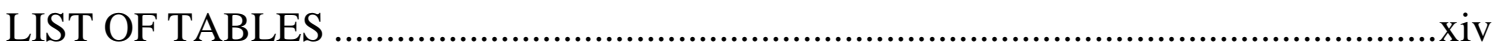

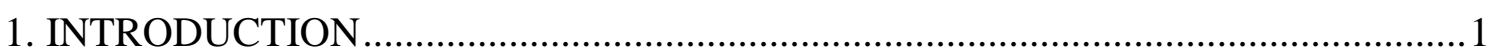

1.1 Statement and Significance of the Problem ..........................................................

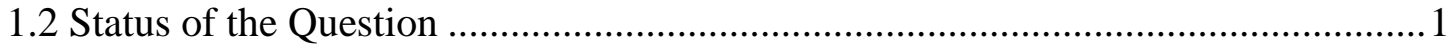

1.3 Research Objectives ......................................................................................

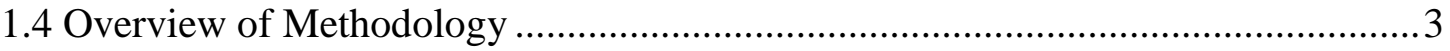

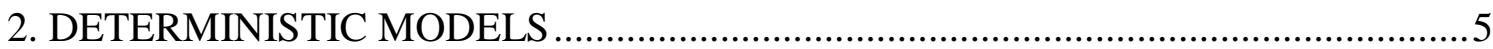

2.1 Water Displacement Curve (WDC) Models ...........................................................5

2.1.1 Application of WDC Models ..................................................................13

2.1.2 Overall Workflow for Deterministic WDC Modeling .................................25

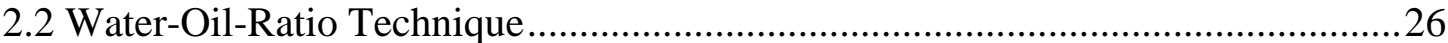

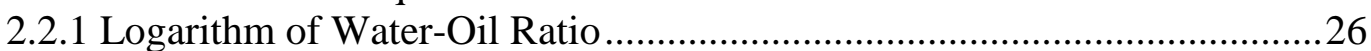

2.2.2 Mature Waterflood Forecasting .................................................................29

2.3 Decline Curve Analysis...................................................................................

2.3.1 DCA Models ........................................................................................

2.3.2 Overall Workflow ..................................................................................

3. PROBABILISTIC / STOCHASTIC METHODOLOGIES ………………………..........

3.1 Bayes' Theorem with Markov Chain Monte Carlo Methodology (MCMC) ..........34

3.1.1 Bayes' Theorem .......................................................................................

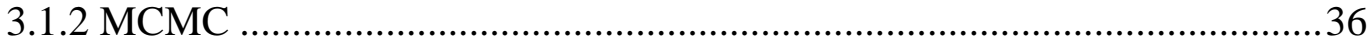


3.1.3 Application of Bayes Theorem and MCMC with DCA Models.................38

3.1.4 Overall Workflow ..............................................................................44

3.1.5 Application of Bayes Theorem and MCMC with WDC Models...............45

3.1.6 Overall Workflow ..............................................................................49

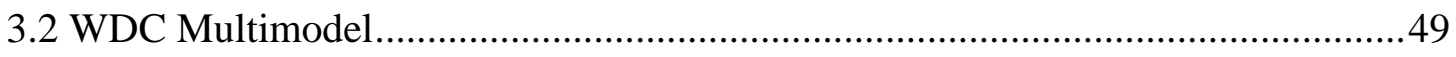

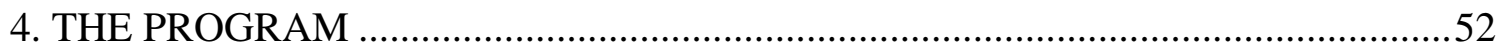

4.1 Additional Deterministic Methods Applied in the Program ..............................52

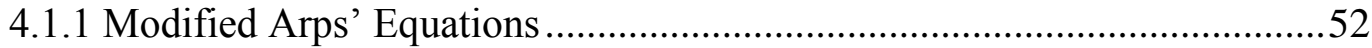

4.1.2 Power-Law Exponential Model ...........................................................53

4.1.3 Stretched Exponential Production Decline Model ..................................54

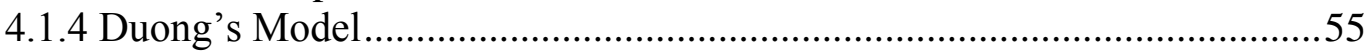

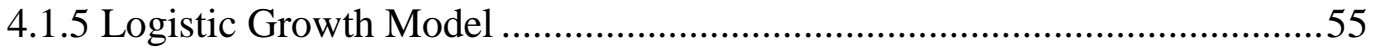

4.1.6 Pressure Depletion Model .......................................................................56

4.2 Additional Probabilistic Methods Applied in the Program ..................................58

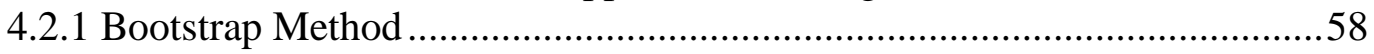

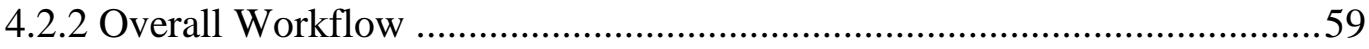

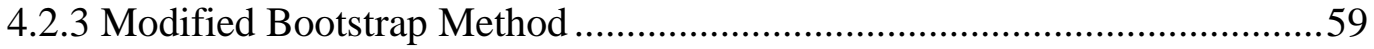

4.2.4 Overall Workflow ...............................................................................6 60

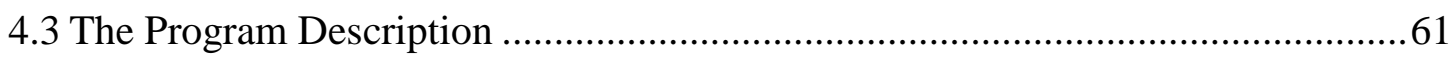

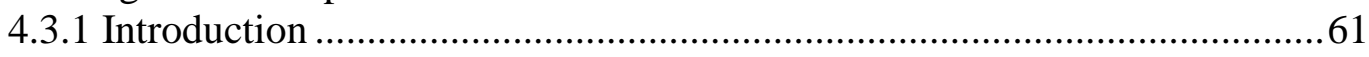

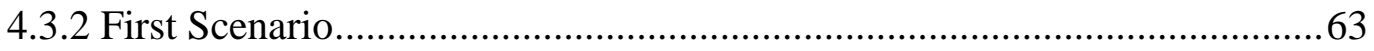

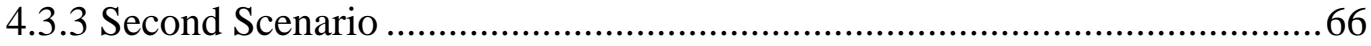

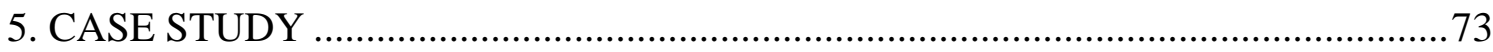

5.1 Case Study: Wilmington and Kumkol Waterflooded Oil Fields...........................73

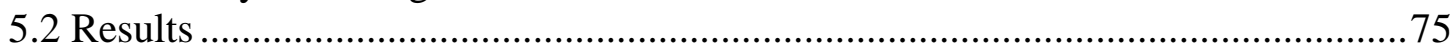

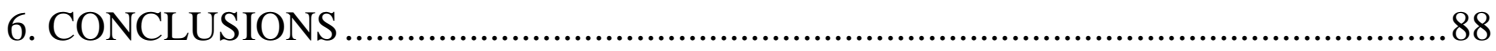

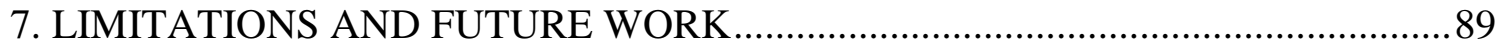

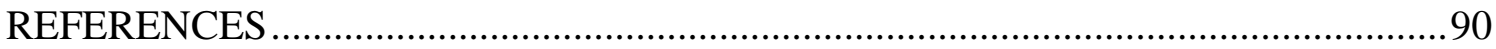




\section{LIST OF FIGURES}

Page

Fig. 1-Comparison of Maksimov and Sazonov Models (Savelyev et al., 2008) ............7

Fig. 2-Monthly and Cumulative Oil Production vs. Time

(Well A, Kumkol Oil Field).

Fig. 3-Monthly and Cumulative Liquid Production vs. Time

(Well A, Kumkol Oil Field)

Fig. 4-Watercut and Cumulative Water Production vs. Time

(Well A, Kumkol Oil Field) 15

Fig. 5-Sazonov WDC, Cumulative Oil Production vs. Natural Logarithm of

Cumulative Liquid Production (Well A, Kumkol Oil Field) 16

Fig. 6-Maksimov WDC, Cumulative Oil Production vs. Natural Logarithm of

Cumulative Water Production (Well A, Kumkol Oil Field). 17

Fig. 7-Cumulative Liquid Production vs. Time (Well A, Kumkol Oil Field) .20

Fig. 8-Cumulative Water Production vs. Time (Well A, Kumkol Oil Field)..... .21

Fig. 9-Reserves Forecast (Well A, Kumkol Oil Field) 24

Fig. 10-Monthly Production of Oil (Forecast) (Well A, Kumkol Oil Field)..... .24

Fig. 11-Monthly Watercut (Forecast) (Well A, Kumkol Oil Field) ...........................25

Fig. 12_WOR Technique (Well B, Kumkol Oil Field) ..........................................28

Fig. 13 -WOR Technique (Well B, Kumkol Oil Field) ..........................................29

Fig. 14-Iterative Algorithm of the Program Which Can Be Used to Forecast 30 


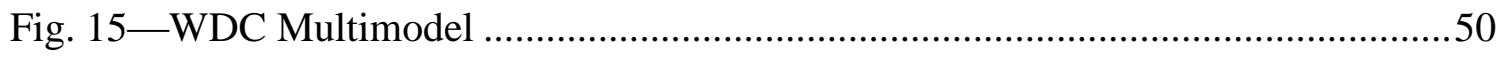

Fig. 16 - 11 WDC Models (Well C, Kumkol Oil Field) ..................................................51

Fig. 17—P10, P50 and P90 Curves (Well C, Kumkol Oil Field) .....................................51

Fig. 18-Start Window ……………………………........................................61

Fig. 19—DATA Spreadsheet (Well A, Wilmington Oil Field) .........................................62

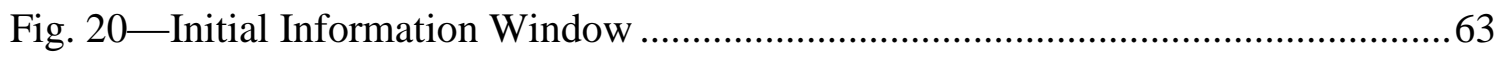

Fig. 21—First Scenario, First Window ……………………………….....................64

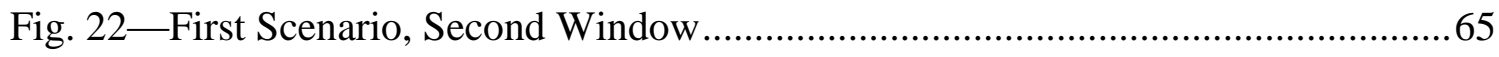

Fig. 23-Second Scenario, First Window ..................................................................66

Fig. 24-Second Scenario, Second Window ……………...........................................67

Fig. 25-Second Scenario, Third Window ……………...............................................68

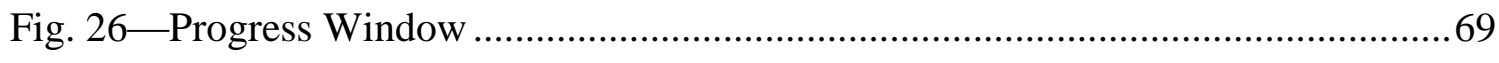

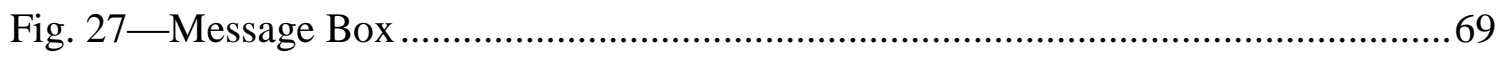

Fig. 28—Example of Result Graph, MCMC with WDC (Hindcast)

(Well A, Wilmington Oil Field) ………………….............................................

Fig. 29-Scheme of "No Water Production" Scenario ......................................................71

Fig. 30 - Scheme of "Water Production" Scenario .......................................................... 72

Fig. 31-Monthly Oil Production vs. Time (Well A, Wilmington Oil Field) ...................73

Fig. 32-Watercut vs. Time (Well A, Wilmington Oil Field) ...........................................74

Fig. 33-Probabilistic Hindcast, MCMC with WDC, Well A (Wilmington Oil Field) ..80

Fig. 34-Probabilistic Hindcast, WDC Multimodel, Well B (Wilmington Oil Field) ....80 
Fig. 35-Probabilistic Hindcast, MCMC with DCA, Well A (Wilmington Oil Field) ...81

Fig. 36 - Calibration Plot, MCMC with WDC ….................................................. 82

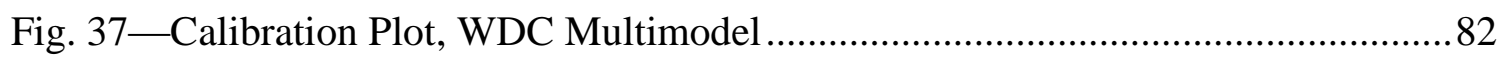

Fig. 38 - Calibration Plot, MCMC with DCA …................................................. 83

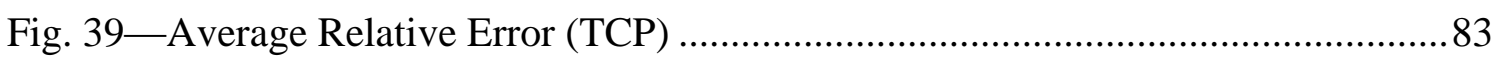

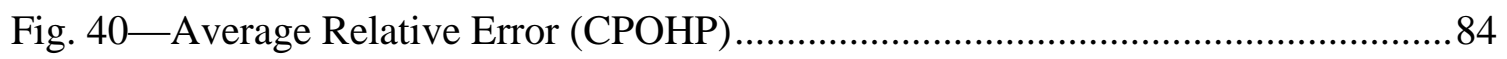

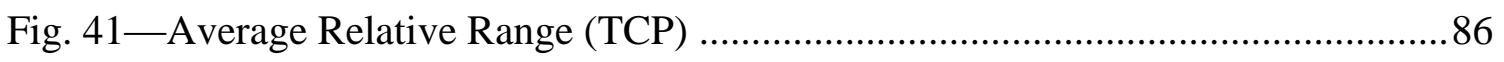

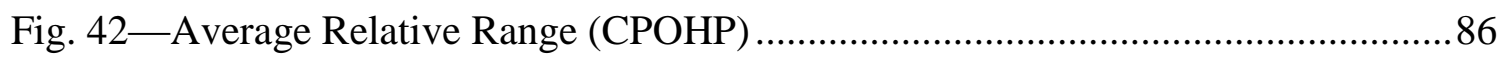




\section{LIST OF TABLES}

Page

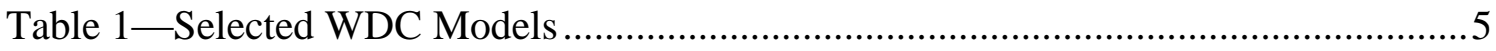

Table 2-Calculation of Production Parameters ..................................................... 13

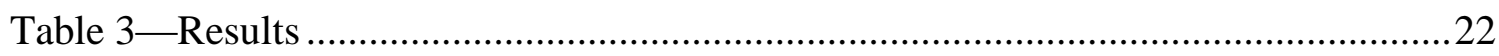

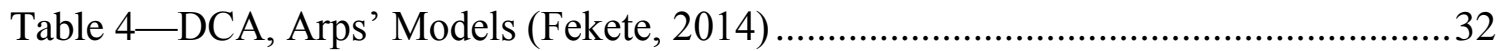

Table 5-DCA Parameters Limits (Gas), Suggested by Gonzalez et al. (2012) .............39

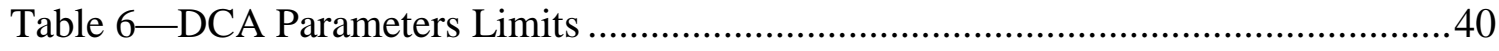

Table 7—Standard Deviations for DCA Models Parameters, ...................................40

Table 8 - Standard Deviation for Pressure Depletion Model Parameters......................41

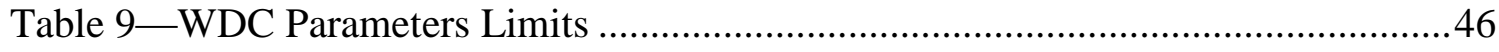

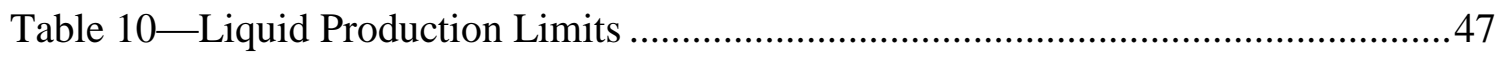

Table 11-WDC Parameters Proposal Distributions...............................................47

Table 12 — Liquid Production Rate Proposal Distribution .......................................48

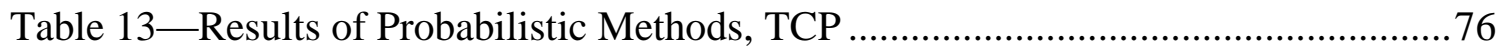

Table 14-Results of Probabilistic Methods, CPOHP............................................... 78 


\section{INTRODUCTION}

\subsection{Statement and Significance of the Problem}

Quantifying uncertainty is an important area in the oil and gas industry. Uncertainty will always be present in production forecasts and reserves estimates and it can be quite large early in the production lives of oil and gas wells. Unreliable quantification of uncertainty can yield overconfident and optimistic estimations of reserves and profitability.

According to McVay and Dossary (2014), even moderate overconfidence and optimism can lead to portfolio disappointment of more than $30 \%$. It is also important to evaluate reserves and resources early for optimal development. McKinney et al. (2002) wrote that a suboptimal development plan can result in $50 \%$ of potential losses in the asset value.

Decline Curve Analysis (DCA) is the most frequently used method to forecast production performance and estimate reserves. However, there are some wells that show complex behaviors, and as a result the decline curve does not fit the production history well. Examples are supertight/shale formations and waterflooded oil and gas fields. In these cases the deterministic predictions of future production and reserves can be far from the actual values, so alternative methods are required to quantify uncertainty in production forecasts and reserves estimates.

\subsection{Status of the Question}

Single deterministic forecasts from DCA models can lead to significant error for wells produced from either unconventional formations or waterflooded reservoirs, which prompts the need for either quantifying uncertainty in the production prognosis or application of alternatives to DCA methods. 
Jochen and Spivey (1996) developed bootstrap methods that can generate probabilistic forecasts using DCA and quantify reserves uncertainty for a single well based on production data available. However, this technique was not well calibrated. Based on a data set including 100 conventional oil and gas wells, P90-P10 ranges for reserves from Jochen and Spivey's method covered less than $40 \%$ of the true reserves. The modified bootstrap method introduced by Cheng et al. (2010) covered $80 \%$ of the true reserves, indicating that this technique is well calibrated probabilistically. However, it takes 2.5-4 minutes to calculate probabilistic production forecasts and reserves estimates for each well.

Probabilistic Decline Curve Analysis (PDCA) software was recently developed and introduced by Gong et al. (2011). The methods mentioned above were applied in the software. In addition, Bayesian Markov Chain Monte Carlo (MCMC) methods, previously used to quantify uncertainty in reservoir simulation (e.g., Liu and McVay, 2009; Xie et al., 2011), were applied in the software. This PDCA methodology has been proposed as a reliable probabilistic approach to quantify uncertainty regardless of the DCA models employed and the amount of production data available for forecasting.

However, PDCA uses either oil or gas production rate, does not take into account water production and does not include alternatives to DCA methods for forecasting production performance and estimating reserves in waterflooded reservoirs. Waterflooding is a widely used technique to maintain formation pressure and increase production performance, but it usually results in multiphase production performance.

Alternative methods to DCA in waterflooded oil fields include a number of empirical multiphase methods based on production history, such as Water Displacement Curve (WDC) models. The models were developed by Soviet Union scholars specifically for waterflooded oil fields. These methods are used extensively in Russia and China (Qitai, 
2000). Water Displacement Curve models are empirical relationships between cumulative oil production and either cumulative water or cumulative liquid production. The models represent processes of reservoir depletion reflecting the different behaviors of water injected into formations.

WDC models allow engineers to predict production performance and estimate reserves in waterflooded reservoirs. Compared with decline curve analysis, WDC models are expected to perform better in forecasting oil production in waterflooded oil fields (Russian Federation Ministry of Energy, 2002). However, these models are imperfect deterministic tools and to my knowledge have never been applied probabilistically. This prompts the need for applying the models using probabilistic methodology to quantify uncertainty in the production forecasts and reserves estimates in waterflooded oil fields.

\subsection{Research Objectives}

Research Objectives.

- Develop probabilistic methods for forecasting production performance and estimating reserves in waterflooded oil fields using multiphase empirical methods;

- Assess the reliability of the probabilistic methods using data from actual waterflooded oil fields.

\subsection{Overview of Methodology}

1. Develop a multimodel based on eleven Water Displacement Curve models to assess differences in matches and forecasts provided by each model;

2. Apply Bayesian methodology and Markov Chain Monte Carlo (MCMC) methods to production forecasting with WDC models;

3. Develop a program that includes deterministic and probabilistic methods to forecast production performance and estimate reserves in waterflooded oil reservoirs; 
4. Calibrate and assess reliability of both multimodel and MCMC-based WDC methods using production data from waterflooded oil fields. 


\section{DETERMINISTIC MODELS}

\subsection{Water Displacement Curve (WDC) Models}

Water displacement curves are empirical models based on relationships between $N_{p}$ and either $\mathrm{L}_{\mathrm{p}}$ or $\mathrm{W}_{\mathrm{p}}$, where $\mathrm{L}_{\mathrm{p}}$ is cumulative liquid production, $\mathrm{N}_{\mathrm{p}}$ is cumulative oil production, and $\mathrm{W}_{\mathrm{p}}$ is cumulative water production. WDC models attempt to replicate a process of reservoir depletion and water-cut rise when waterflooding is applied. The quality of the forecast depends on the quality of initial data and selected history matching period. Table 1 shows WDC model selected for this study.

\begin{tabular}{|c|c|c|}
\hline & \multicolumn{2}{|c|}{ Table 1-Selected WDC Models } \\
\hline № & Curve name & Integral form \\
\hline 1 & $\begin{array}{c}\text { Sazonov } \\
\text { (Sazonov et al., 1973) }\end{array}$ & $\begin{array}{c}\ln \left(L_{p}\right)=a * \mathrm{~N}_{\mathrm{p}}-b \\
\text { or } \\
N_{p}=a * \ln \left(L_{p}\right)-b\end{array}$ \\
\hline 2 & $\begin{array}{c}\text { Maksimov } \\
\text { (Maksimov et al., 1959) }\end{array}$ & $\begin{array}{c}\ln \left(W_{p}\right)=a * \mathrm{~N}_{\mathrm{p}}+b \\
\text { or } \\
N_{p}=a * \ln \left(W_{p}\right)+b\end{array}$ \\
\hline 3 & $\begin{array}{c}\text { IFP School } \\
\text { (Burger et al., 1975) }\end{array}$ & $\frac{W_{p}}{N_{p}}=a * N_{p}+b$ \\
\hline 4 & $\begin{array}{c}\text { Nazarov-Sypachev } \\
\text { (Nazarov and Sypachev, } \\
\text { 1972) }\end{array}$ & $\frac{L_{p}}{N_{p}}=a * W_{p}+b$ \\
\hline
\end{tabular}




\begin{tabular}{|c|c|c|}
\hline \multicolumn{3}{|c|}{ Table 1 - continued } \\
\hline № & Curve name & Integral form \\
\hline 5 & $\begin{array}{c}\text { Sypachev-Posevich } \\
\text { ( Sypachev et al., 1980) }\end{array}$ & $\frac{L_{p}}{N_{p}}=a * L_{p}+b$ \\
\hline 6 & $\begin{array}{c}\text { Gaysin } \\
(\text { Gaysin, 1986) }\end{array}$ & $\frac{N_{p}}{L_{p}}=a * \ln \left(N_{p}\right)+b$ \\
\hline 7 & $\begin{array}{c}\text { Pirverdyan } \\
\text { (Pirverdyan et al., 1970) }\end{array}$ & $N_{p}=b-a * L_{p}^{-\frac{1}{2}}$ \\
\hline 8 & $\begin{array}{c}\text { Kambarov } \\
\text { (Kambarov, 1974) }\end{array}$ & $N_{p}=b-a * L_{p}^{-1}$ \\
\hline 9 & $\begin{array}{c}\text { Kazakov } \\
(\text { Kazakov, 1976) }\end{array}$ & $N_{p}=a L_{p}^{c}+b$ \\
\hline 10 & $\begin{array}{c}\text { Abyzbaev } \\
\text { (Abyzbaev et al., 1975) }\end{array}$ & $\ln \left(N_{p}\right)=a * \ln \left(L_{p}\right)+b$ \\
\hline 11 & $\begin{array}{l}\text { Method of constant oil } \\
\text { saturation } \\
\text { (Savelyev et al., 2008) }\end{array}$ & $N_{p}=a * L_{p}+b$ \\
\hline
\end{tabular}

The advantage of WDC model is that we can take into account liquid production rate. If we know (according to our production plan) at which rate the well is going to produce in the future we can use this designed rate in our calculations. Monthly liquid production rate which we use to calculate Lp is arbitrary number. When waterflooding is applied, Electrical Submersible Pumps (ESP) or other types of pumps are used to lift liquid to the surface and engineers can select liquid production rate by changing speed of the pumps. Thus, we can say that liquid production rate is designed. We can also keep production rate as a constant value assuming that we will produce at the same liquid level. 
The methods considered in this section can be applied at certain stages of field development. According to Savelyev et al. (2008), the WDC methods give accurate results when water-cut is more than at least $30 \%$.

However, there are reservoirs that cannot be properly described by using these models, e.g., reservoirs at late stages of development when activities on reducing watercut and some Enhanced Oil Recovery (EOR) methods are performed.

Let's take, as examples, Maksimov and Sazonov methods. Fig. 1 shows reservoir fluids displacement dynamics using Maksimov and Sazonov WDC models.

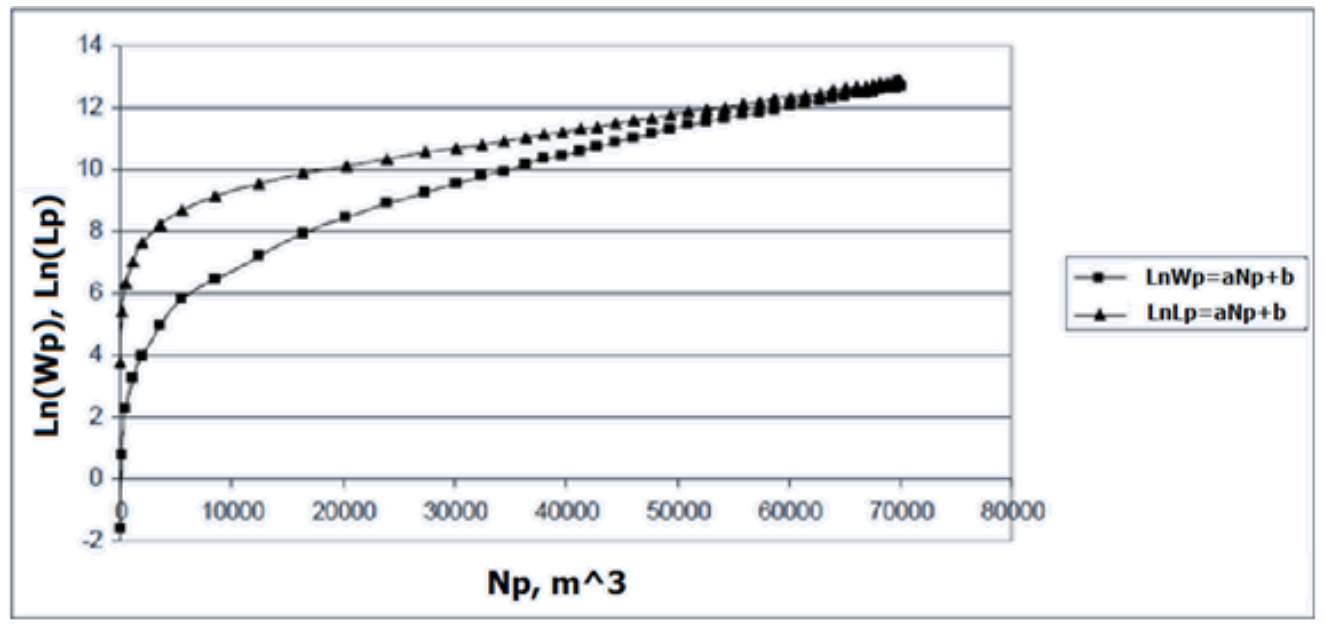

Fig. 1-Comparison of Maksimov and Sazonov Models (Savelyev et al., 2008)

Let's consider the Maksimov method in detail.

Maksimov et al. (1959) established an empirical relationship between cumulative water production and cumulative oil production. He studied the process of oil displacement 
using an artificial reservoir model represented by tube filled in with sand. According to this method, the dependence $W_{p}=f\left(N_{p}\right)$ is described by the following equation

$W_{p}=\beta \times \alpha^{N_{p}}$

where $W_{p}$ is cumulative production of water;

$N_{p}$ is cumulative production of oil;

$\alpha, \beta$ are empirical coefficients determined by means of the least square method.

This equation, $W_{p}=f\left(N_{p}\right)$, can be presented as the following linear equation (2.2)

$\ln \left(W_{p}\right)=a \times N_{p}+b$

where $a=\ln (\alpha)$ and $b=\ln (\beta)$.

In accordance with the described method, the function is plotted on semilog plot, $Y=\ln \left(W_{p}\right)$ and $X=N_{p}$. The plotted function tends to be line which can be defined by calculating the slope $a=\ln (\alpha)$ and intercept $b=\ln (\beta)$. The linear part of the plotted function is used to calculate coefficients $a$ and $b$.

The equation (2.1) can be modified to the following form

$L_{p}=N_{p}+\beta \alpha^{N_{p}}$

By differentiating with respect to the time, we will obtain

$\frac{d L_{p}}{d t}=\frac{N_{p}}{d t}+\frac{d\left(\beta \times \alpha^{N}\right)}{d N_{p}} \frac{d N_{p}}{d t}$ 
$\frac{d L_{p}}{d t}=\left(1+\beta \alpha^{N_{p}} \times \ln (\alpha)\right) \frac{d N_{p}}{d t}$.

Dividing both parts by $\frac{d N_{p}}{d t}$ and taking into account that $\frac{\mathrm{dN}_{\mathrm{p}}}{\mathrm{d \textrm {L } _ { \mathrm { p } }}}$ goes to the minimum value of oil content in the produced liquid, $f_{o}$, it is possible to estimate ultimate recovery, which occurs at minimum $f_{o}$

$1=f_{o}+f_{o} \times \alpha^{N_{p}} \times \beta \times \ln (\alpha)$

$\ln \left(\frac{1-f_{o}}{f_{o} \times \beta \times \ln (\alpha)}\right)=\ln \left(\alpha^{N_{p}}\right)$

$N_{p}=\frac{1}{\ln (\alpha)} \ln \left(\frac{1-f_{o}}{f_{o} \times \beta \times \ln (\alpha)}\right)$

Therefore, EUR for the minimum value of $f_{o}$ will be defined using the formula (2.9)

$E U R\left(f_{o \text { min }}\right)=\frac{1}{a} \ln \left(\frac{1-f_{o}}{f_{o} \times a \times e^{b}}\right)$

Alternatively, EUR for the set maximum value of water content in produced liquid (watercut), $f_{w}$, will be determined from the following formula

$E U R\left(f_{w \max }\right)=\frac{1}{a} \ln \left(\frac{f_{w}}{\left(1-f_{w}\right) \times a \times e^{b}}\right)$

where $a, b$ are coefficients determined by means of the least square method. 
To forecast cumulative production of water corresponding to the value of either $E U R\left(f_{o \text { min }}\right)$ or $E U R\left(f_{w \max }\right)$, the following empirical equation (Maksimov, 1959) can be used

$W_{p}=e^{a N_{p}+b}$

To forecast cumulative production of liquid corresponding to the value of either $E U R\left(f_{o \text { min }}\right)$ or $E U R\left(f_{w \max }\right)$, the following empirical equation (Maksimov, 1959) can be used

$$
L_{p}=N_{p}+e^{a N_{p}+b}
$$

Let's consider the Sazonov method.

The method proposed by Sazonov et al. (1973) is based on the suggestion of strong correlation between cumulative production of oil and liquid, especially at the late stage of field development. In accordance with this method, the dependence $L_{p}=f\left(N_{p}\right)$ can be described by the following exponential equation

$L_{p}=\beta \times \alpha^{N_{p}}$

where $L_{p}$ is the cumulative production of liquid;

$N_{p}$ is the cumulative production of oil;

$\alpha, \beta$ are empirical coefficients.

The equation of dependence, $L_{p}=f\left(N_{p}\right)$, can be represented by the following equation

$$
\ln \left(L_{p}\right)=a \times N_{p}+b
$$


where $a=\ln (\alpha)$ and $b=\ln (\beta)$ are empirical coefficients determined by means of the least square method.

The function is plotted on semilog plot, $Y=\ln \left(W_{p}\right)$ and $X=N_{p}$. By differentiating Eq. 2.13 with respect to the time, the following relationship will be obtained

$\frac{d W_{p}}{d t}=\frac{d\left(\beta \times \alpha^{N} p\right)}{d t}=\frac{d\left(\beta \times \alpha^{N} p\right)}{d N_{p}} \frac{d N_{p}}{d t}$

$\frac{d L_{p}}{d t}=\beta \times \alpha^{N_{p}} \times \ln (\alpha) \frac{d N_{p}}{d t}$

Dividing both parts by $\frac{d N_{p}}{d t}$ and taking into account that $\frac{d N_{p}}{d L_{p}}$ goes to the minimum value of $f_{o}$, it is possible to determine EUR, which occurs at the minimum value of oil content in the produced liquid, $f_{o}$

$1=f_{o} \times \alpha^{N_{p}} \times \beta \times \ln (\alpha)$

$\ln \left(\frac{1}{f_{o} \times \beta \times \ln (\alpha)}\right)=\ln \left(\alpha^{N_{p}}\right)$

$N_{p}=\frac{1}{\ln (\alpha)} \ln \left(\frac{1}{f_{o} \times \beta \times \ln (\alpha)}\right)$

Therefore, the oil reserves for the set minimum value of $f_{o}$ will be calculated based on Eq. 2.20

$E U R\left(f_{o \max }\right)=\frac{1}{a} \ln \left(\frac{1}{f_{o} \times a \times e^{b}}\right)$ 
The EUR for the set maximum value of watercut, $f_{w}$, will be determined using the following equation

$E U R\left(f_{w \max }\right)=\frac{1}{a} \ln \left(\frac{1}{\left(1-f_{w}\right) a \times e^{b}}\right)$

where $a, b$ are empirical coefficients.

To forecast cumulative production of liquid corresponding to the value of either $N_{p}\left(f_{\text {o min }}\right)$ or $N_{p}\left(f_{w \text { max }}\right)$, the following empirical equation (Sazonov, 1973) can be used

$L_{p}=e^{\alpha \times N_{p}+b}$

To forecast cumulative production of water corresponding to the value of either $N_{p}\left(f_{o \text { min }}\right)$ or $N_{p}\left(f_{w \max }\right)$, the following empirical equation (Sazonov, 1973) can be used

$W_{p}=e^{a \times N_{p}+b}-N_{p}$

The Maksimov and Sazonov methods are similar, which is why the areas of their applications almost coincide. However, in certain cases the method of Sazonov is less affected by changes in the field development strategy (Savelyev et al., 2008).

The Maksimov and Sazonov methods cannot be used to estimate reserves assuming endless displacement. However, it is possible to find reserves for the minimum oil content $N_{p}\left(f_{o \text { min }}\right)$ or reserves for the maximum watercut $N_{p}\left(f_{w \text { max }}\right)$. Minimum oil content and maximum watercut values are usually equal to $0.02-0.05\left(f_{o \text { min }}\right)$ and $0.95-0.98$ $\left(f_{w \text { max }}\right)$, respectively (Savelyev et al., 2008). While determining EUR for the specified watercut value, it is also possible to forecast water and liquid production (Table 2). 


\begin{tabular}{|c|c|c|}
\hline \multicolumn{3}{|c|}{$\begin{array}{c}\text { Table 2 - Calculation of Production Parameters } \\
\text { Using Maksimov and Sazonov Models }\end{array}$} \\
\hline Parameter & Maksimov & Sazonov \\
\hline Method & $\ln \left(W_{p}\right)=a \times N_{p}+b$ & $\ln \left(L_{p}\right)=a \times N_{p}-b$ \\
\hline$E U R\left(f_{\text {max }}\right)=$ & $\frac{1}{a} \ln \left(\frac{1-f_{o \text { max }}}{f_{o \text { max }} \times a \times e^{b}}\right)$ & $\frac{1}{a} \ln \left(\frac{1}{f_{o \text { max }} \times a \times e^{b}}\right)$ \\
\hline$E U R\left(f_{w \text { max }}\right)=$ & $\frac{1}{a} \ln \left(\frac{f_{w \max }}{\left(1-f_{w \max }\right) a \times e^{b}}\right)$ & $\frac{1}{a} \ln \left(\frac{1}{\left(1-f_{w \max }\right) a \times e^{b}}\right)$ \\
\hline$L_{p}=$ & $e^{a \times N_{p}+b}$ & $e^{a \times N_{p}+b}$ \\
\hline$W_{p}=$ & $N_{p}+e^{a \times N_{p}+b}$ & $e^{a \times N_{p}+b}-N_{p}$ \\
\hline
\end{tabular}

\subsubsection{Application of WDC Models}

To have better understanding of the methodology, I will execute a forecast based on real production data of well A located in the Kumkol waterflooded oil field, taking as examples Sazonov, $N_{p}=a * \ln \left(L_{p}\right)-b$, and Maksimov, $N_{p}=a * \ln \left(W_{p}\right)+b$, WDC models.

First, I need to have actual monthly production data. Based on the data I can obtain a number of additional parameters such as $\mathrm{L}_{\mathrm{p}}, \mathrm{N}_{\mathrm{p}}, \mathrm{W}_{\mathrm{p}}$ and watercut. After that I plot these parameters vs time to analyze the data (Fig. 2, Fig. 3 and Fig. 4). 


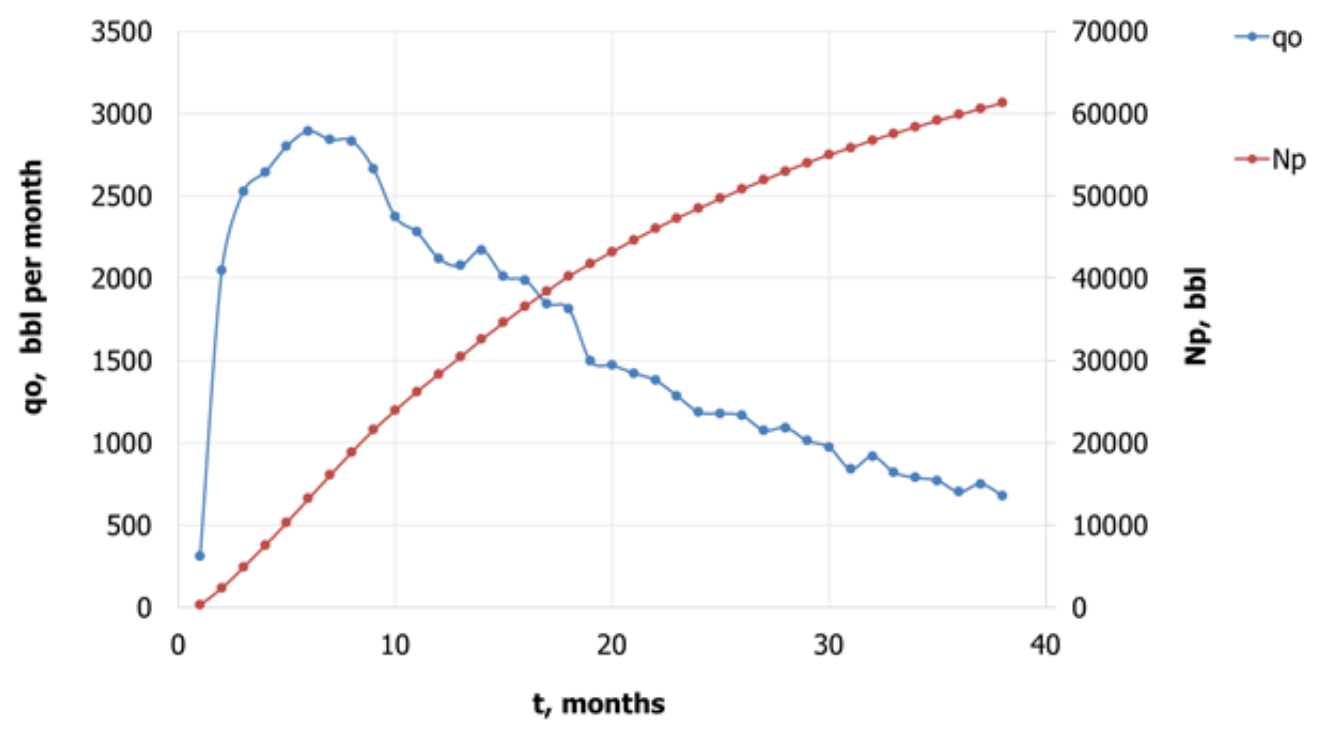

Fig. 2-Monthly and Cumulative Oil Production vs. Time (Well A, Kumkol Oil Field)

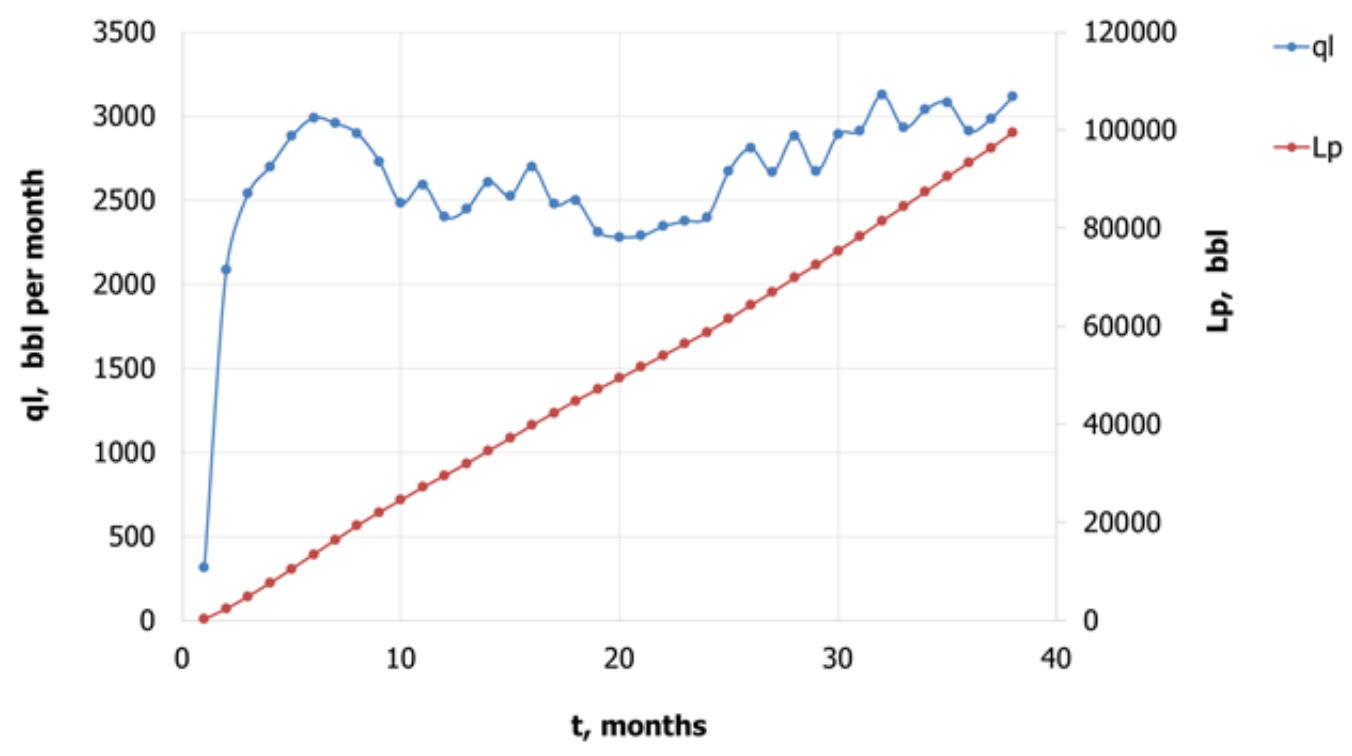

Fig. 3-Monthly and Cumulative Liquid Production vs. Time (Well A, Kumkol Oil Field) 


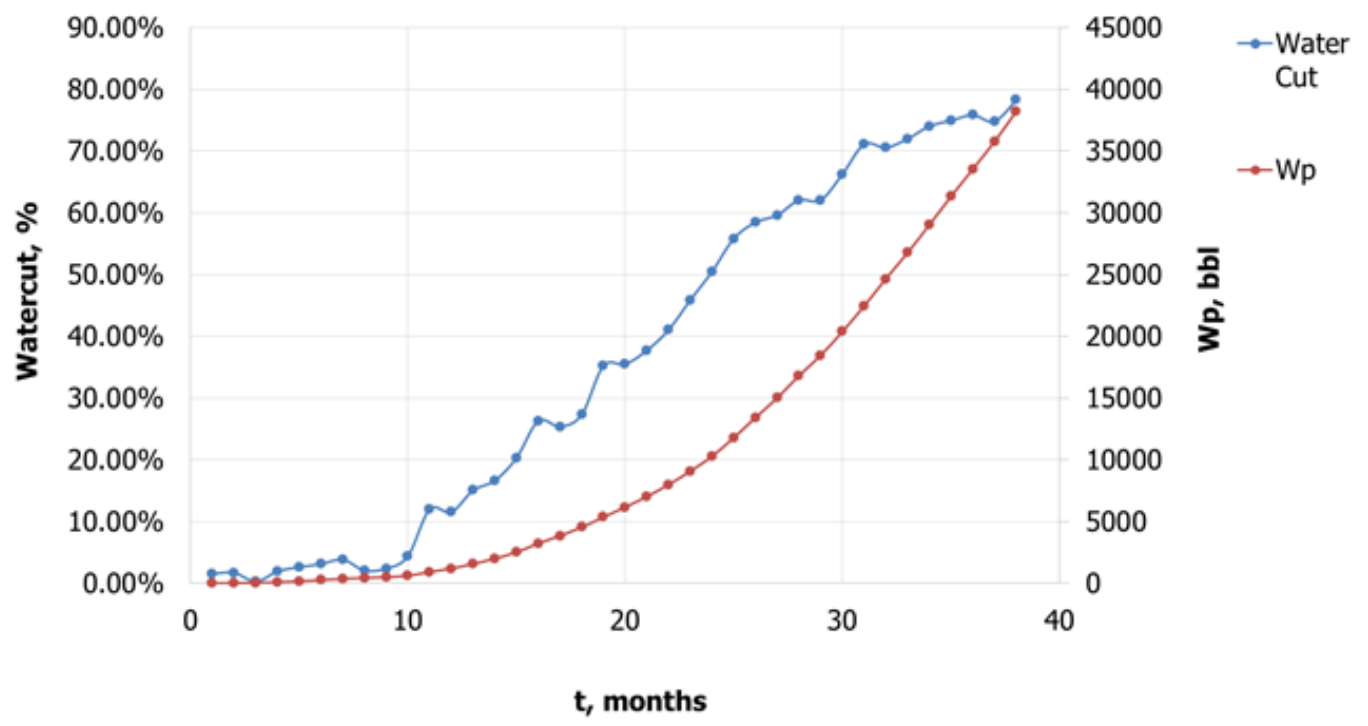

Fig. 4-Watercut and Cumulative Water Production vs. Time (Well A, Kumkol Oil Field)

Now I can verify if WDC methods are applicable for this particular case or not. To apply WDC models, watercut of history matching period must be more than $30 \%$ and it needs to rise during the whole production period (Savelyev et al., 2008). Also, history matching period has to contain at least 6 points. This case meets these criteria, so I can continue the calculations.

Next step is plotting parameters of models; in this case the models are Sazonov, $N_{p}=a *$ $\ln \left(L_{p}\right)-b$, and Maksimov WDC model, $N_{p}=a * \ln \left(W_{p}\right)+b$. Using actual production data I calculate $\ln \left(L_{p}\right)$ and $\ln \left(W_{p}\right)$ parameters and then plot them vs. actual values of $N_{p}$. 
Then I need to select history matching period which best represents the model. According to Mishenko et al. (1998) and Savelyev et al. (2008), the history matching period should be no less than 6 and no more than 24 of the last months of production data. In this case I select 10 last points of the production data and use the least square method (or trend line in Microsoft Excel) to match the data with straight lines and obtain $a$ and $b$ coefficients. Fig. 5 and Fig. 6 show the Sazonov and Maksimov fits, respectively. $\mathrm{R}^{2}$ coefficients (0.9998 and 0.9991) indicate good linearity of the selected history matching periods. It shows that the models fit well to the selected history matching period.

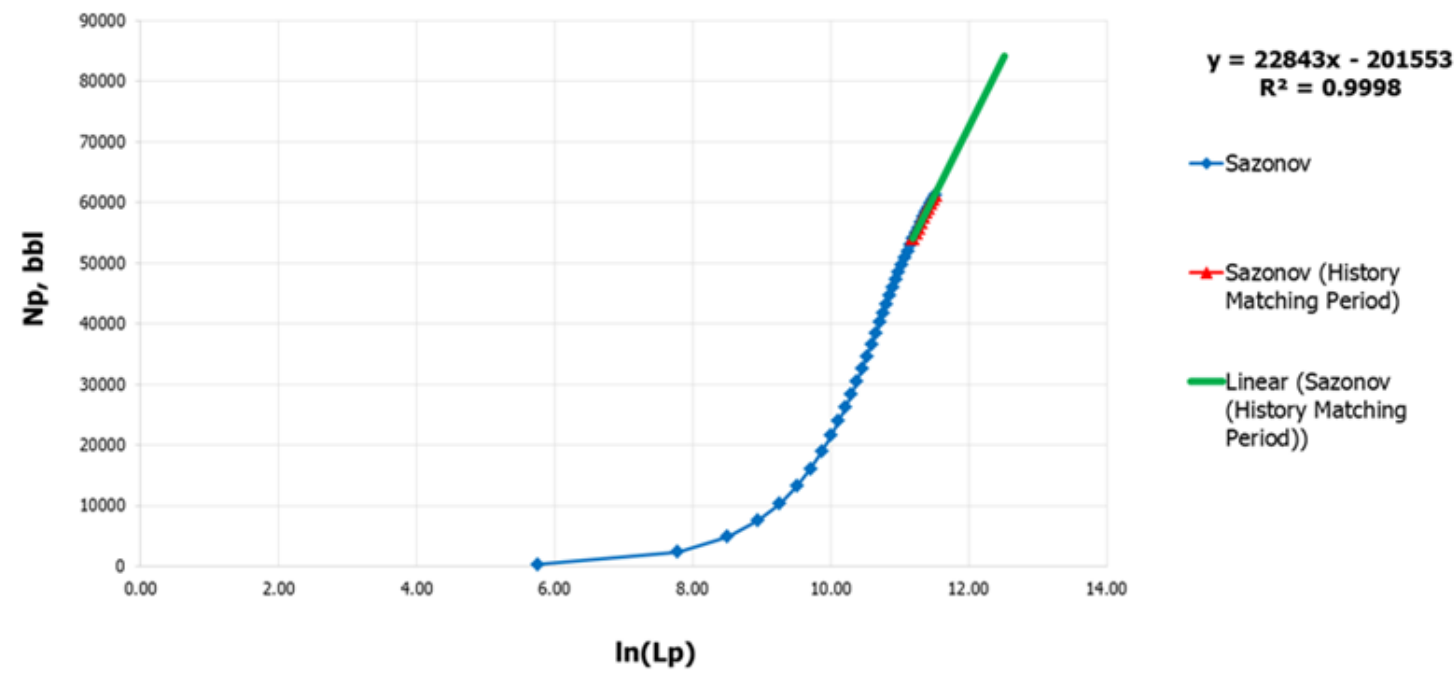

Fig. 5-Sazonov WDC, Cumulative Oil Production vs. Natural Logarithm of Cumulative Liquid Production (Well A, Kumkol Oil Field) 


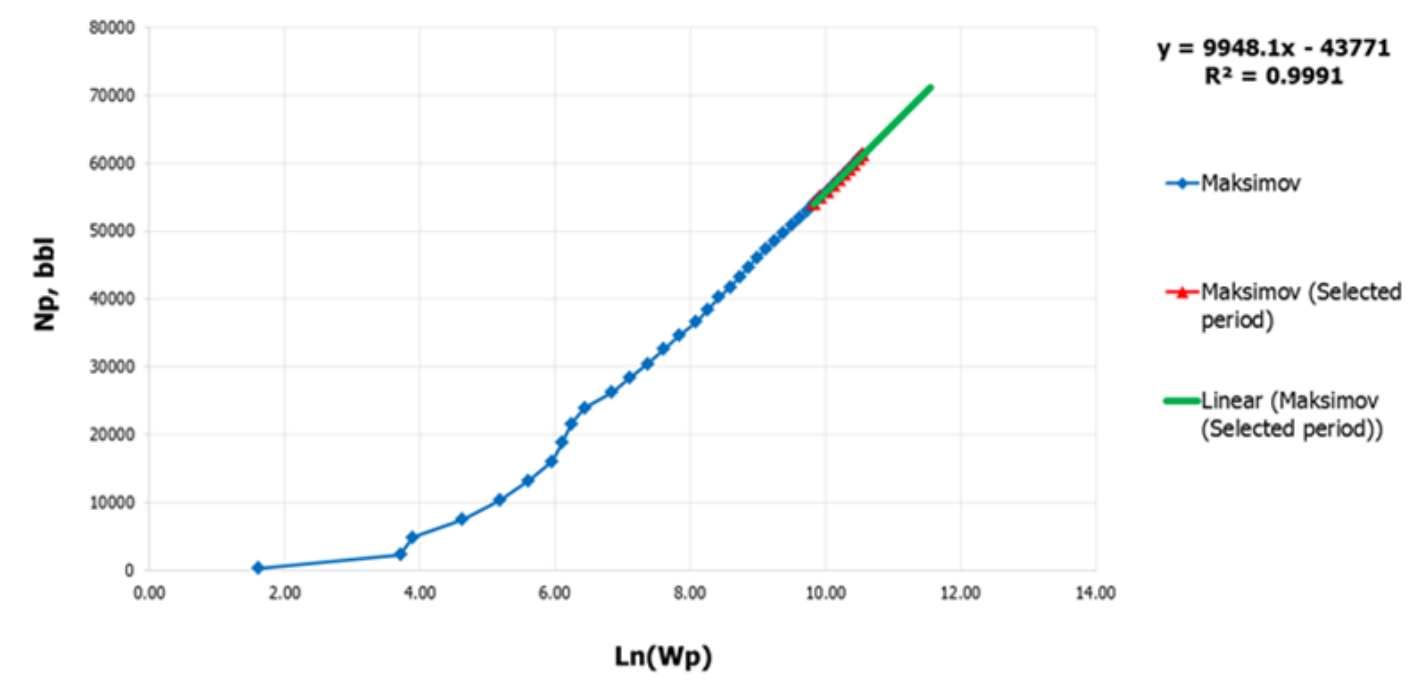

Fig. 6-Maksimov WDC, Cumulative Oil Production vs. Natural Logarithm of Cumulative Water Production (Well A, Kumkol Oil Field)

After fitting the data with the straight lines I have the following equations from the trends, from Fig. 5,

$N_{p}=22843 \times \ln \left(L_{p}\right)-201553$

and from Fig. 6,

$N_{p}=9948.1 \times \ln \left(W_{p}\right)-43771$

At this point I have $a$ and $b$ coefficients for both models, but I also need to extrapolate $L_{p}$ and $W_{p}$ to obtain $\ln \left(L_{P}\right)$ and $\ln \left(W_{P}\right)$ values, and then to calculate $N_{p}$ into the future. When waterflooding is applied, ESP (Electrical Submersible Pump) units are usually used to deliver liquid from the bottoms of wells to the surface, so that liquid production rates of 
the wells are usually designed by engineers. Thus, if values of planned liquid production rates are known I can assume them as future liquid production rates. Otherwise, if I don't have planned liquid production rates I can apply one of the following extrapolation models to forecast $L_{p}$ or $W_{p}$ based on actual values of $L_{p}$ or $W_{p}$.

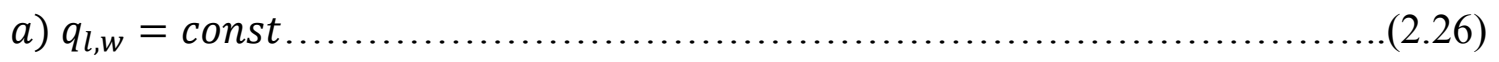

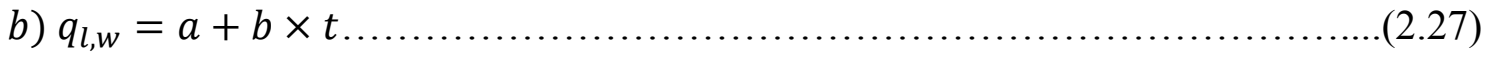

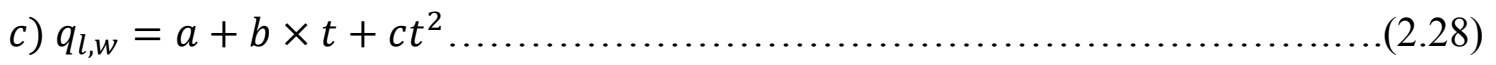

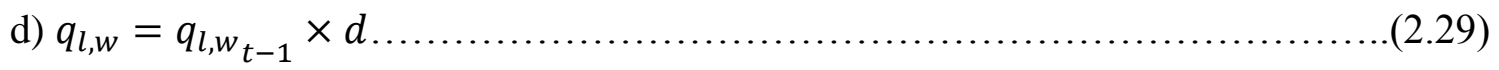

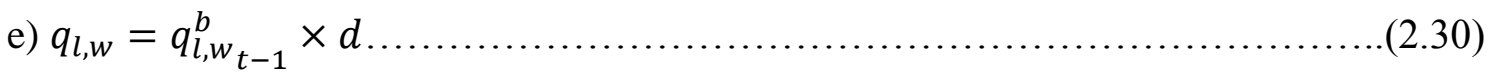

$q_{l, w}$ is either monthly liquid or monthly water production of the current month, $q_{l, w_{t-1}}$ is either monthly liquid or monthly water production of the previous month and parameter $d$ can be calculated using the following equation

$d=\frac{1}{4}\left(\frac{q_{l_{N}}}{q_{l_{N-1}}}+\frac{q_{l_{N-1}}}{q_{l_{N-2}}}+\frac{q_{l_{N-2}}}{q_{l_{N-3}}}+\frac{q_{l_{N-3}}}{q_{l_{N-4}}}\right)$

Monthly instead of cumulative liquid/water production models are used to calculate Wp/Lp values for WDC models because we need to be able to divide calculated cumulative oil production into the equal time periods (month).

To find the best model for liquid production, the relative error can be used,

$\delta_{l}=\sum_{i=1}^{N}\left|\frac{q_{l}-\widehat{q_{l}}}{q_{l}}\right| \frac{100}{N}$ 
where $\mathrm{N}$ is total number of months in the history matching period, $q_{l}$ is actual monthly liquid production in month $\mathrm{i}$ and $\widehat{q}_{l}$ is calculated monthly liquid production in month $\mathrm{i}$. In some cases when there is no information about planned liquid production it is reasonable to assume constant $q_{l}$ (Eq. 2.26) for liquid extrapolation model and linear increase of $q_{w}$ (Eq. 2.27) for water extrapolation model because most of the time in longterm production period the liquid monthly rate is close to a constant value if there is no significant change in development strategy.

In this particular case we can see that liquid production rate is close to constant value (Fig. 3 ) and consequently there is a linear increase in water production (Fig. 6). That is why I assume constant $q_{l}$ to calculate $L_{p}$ and $\ln \left(L_{p}\right)$ for the Sazonov model, and linear increase of $q_{w}$ to calculate $W_{p}$ and $\ln \left(W_{p}\right)$ for the Maksimov model.

Thus, assuming constant $q_{l}$ we need to extrapolate $\mathrm{L}_{\mathrm{p}}$. To do this we plot $\mathrm{L}_{\mathrm{p}}$ versus time and make a linear trend line for the history match period (Fig. 7). In our case, as it was previously determined, the history match period is the last 10 points. Using trend equation, $y=3002.3 x-14657$, and time sequence $(\mathrm{x})$ we can extrapolate $\mathrm{L}_{\mathrm{p}}(\mathrm{y})$.

$L_{p}=3002.3 \times t-14657=102432.7(\mathrm{bbl})$

The $R^{2}$ coefficient shows good linearity of the history matching period, which indicates that the selected model for $\mathrm{L}_{\mathrm{p}}$ extrapolation $\left(q_{l}=\right.$ const $)$ fits well to the history matching period.

To find $\mathrm{W}_{\mathrm{p}}$ assuming linear increase in $q_{w}$ we need to plot $\mathrm{q}_{\mathrm{w}}$ versus time and make a linear trend for the selected history matching period (Fig. 8), which is 10 months. Using trend equation and time sequence (x) we can extrapolate $q_{w}(\mathrm{y})$. 
$q_{w}=3002.3 \times t-14657=102432.7(\mathrm{bbl})$

Where $\mathrm{y}$ is $\mathrm{q}_{\mathrm{w}}$ and $\mathrm{x}$ is a sequent number of month.

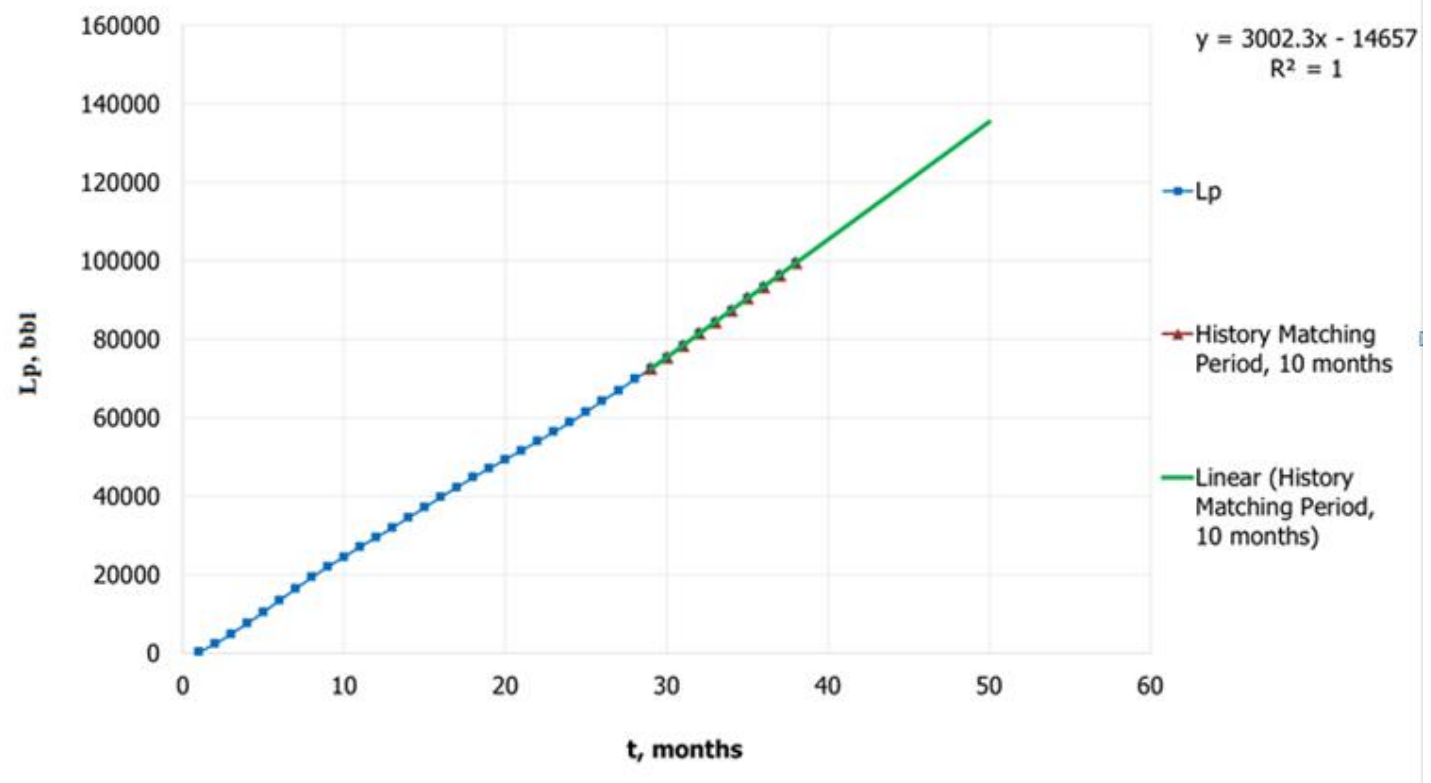

Fig. 7-Cumulative Liquid Production vs. Time (Well A, Kumkol Oil Field) 


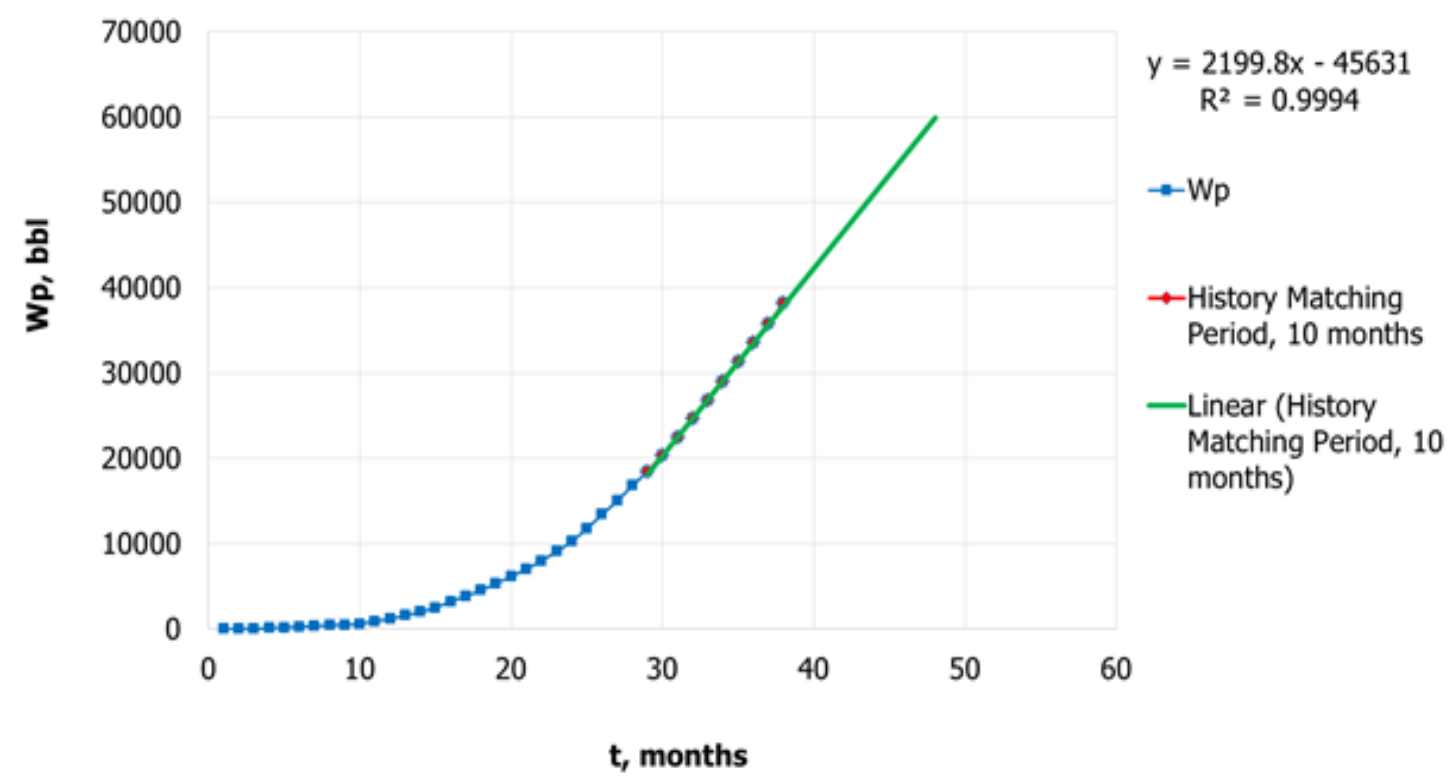

Fig. 8-Cumulative Water Production vs. Time (Well A, Kumkol Oil Field)

Using WDC model, calculated coefficients $a$ and $b$, and extrapolated values of $\mathrm{L}_{\mathrm{p}}$ and $\mathrm{W}_{\mathrm{p}}$ (which are used to calculate $\ln \left(L_{p}\right)$ for the Sazonov model and $\ln \left(\mathrm{W}_{\mathrm{p}}\right)$ for the Maksimov model), I can forecast $\mathrm{N}_{\mathrm{p}}$.

To estimate reserves, one of the following constraints can be set up: minimum monthly production rate, maximum value of watercut or specific time limit. For this case I used 7 years $=84$ months as a time limit (Table 3 ). So in this case 38 months is actual production period used for history matching, 84 months is forecast period and $38+84=122$ months is total time period. 


\begin{tabular}{|l|l|l|}
\hline \multicolumn{2}{|c|}{ Table 3-Results } \\
\hline Input & Sazonov & Maksimov \\
\hline Np (from 0 to 38 month), bbl & 61,288 & 61,288 \\
\hline Forecast time period, month & 84 & 84 \\
\hline Total time period, month & 122 & 122 \\
\hline \multicolumn{2}{|l|}{} \\
\hline Output & Sazonov & Maksimov \\
\hline Np (from 39 to 122 month), bbl & 29,073 & 24,953 \\
\hline Np (from 0 to 122 month), bbl & 90,361 & 86,241 \\
\hline Watercut (122 month), \% & $94 \%$ & $98 \%$ \\
\hline
\end{tabular}

The difference in total $N_{p}$ values (from 0 to 122 month) is approximately $5 \%$ and the difference in forecasted $N_{p}$ values (from 39 to 122 month) is approximately $14 \%$ between the two methods (Table 3). Taking into account the forecast period ( 84 months), it is reasonable to conclude that the difference is acceptable.

Fig. 9 and Fig. 10 show that trends of both models (forecasted cumulative and monthly oil production) look similar. However, the difference in forecasted watercut values (Fig. 2.11) is noticeable. To find best WDC model, engineers can use either one or average of several WDC models with the lowest value of relative error (Eq. 2.35) within history matching period of $N_{p}$. To calculate parameter $\widehat{N p}_{l}$ (calculated cumulative production in month i), we need to calculate $L_{p}$ or $W_{p}$ using selected model for $W_{p}$ or Lp respectively. So the 
better the selected model for $W_{p}$ or $L_{p}$ the closer will be $\widehat{N p}_{\iota}$ to $N_{p}$ and, as a result, the lower will be the relative error, $\delta_{W D C}$.

Another way to find best WDC model is performing hindcast comparing actual and forecasted (hindcasted) values of $N_{p}$.

$\delta_{W D C}=\sum_{i=1}^{N}\left|\frac{N p_{i}-\widehat{N p_{l}}}{N p_{i}}\right| \frac{100}{N}$

where $\mathrm{N}$ is a total number of months in history matching period, $N p_{i}$ is actual cumulative production of oil in month i and $\widehat{N p}_{\iota}$ is calculated cumulative production of oil in month i.

WDC models consist of cumulative values, that is why in the equation of relative error (Eq. 2.35) for these models cumulative production values are used. Liquid/Water production models consist of monthly production values (Eq. 2.32), that is why in the equation of relative error for these models monthly production values are used.

In this case, as we do not have a lot of production data, I used relative error to select the best model (Eq. 2.35). According to relative error, Maksimov model is much more suitable for this case: $\delta_{W D C}($ Sazonov $)=0.2 \%, \delta_{W D C}($ Maksimov $)=0.08 \%$. 


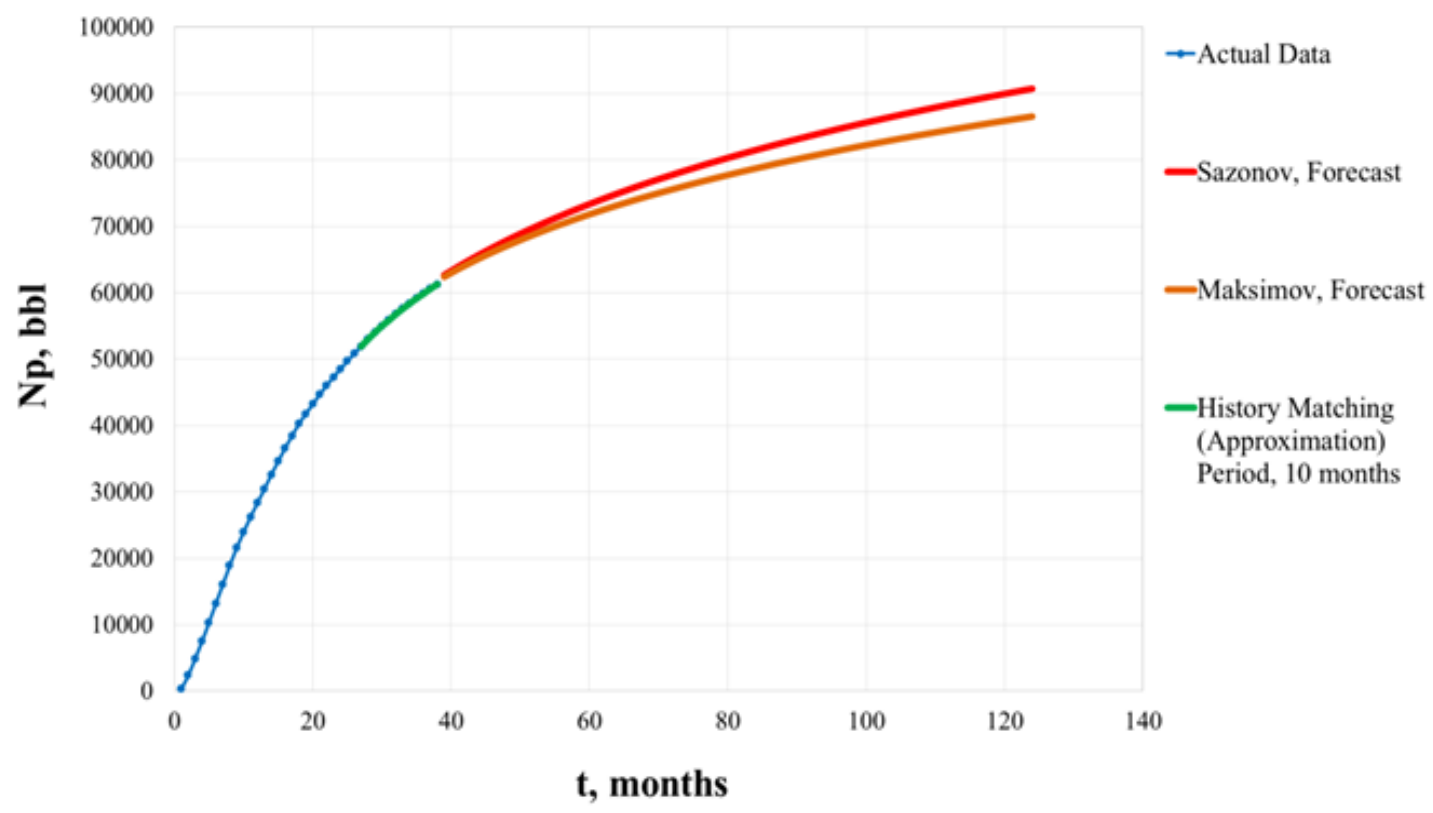

Fig. 9-Reserves Forecast (Well A, Kumkol Oil Field)

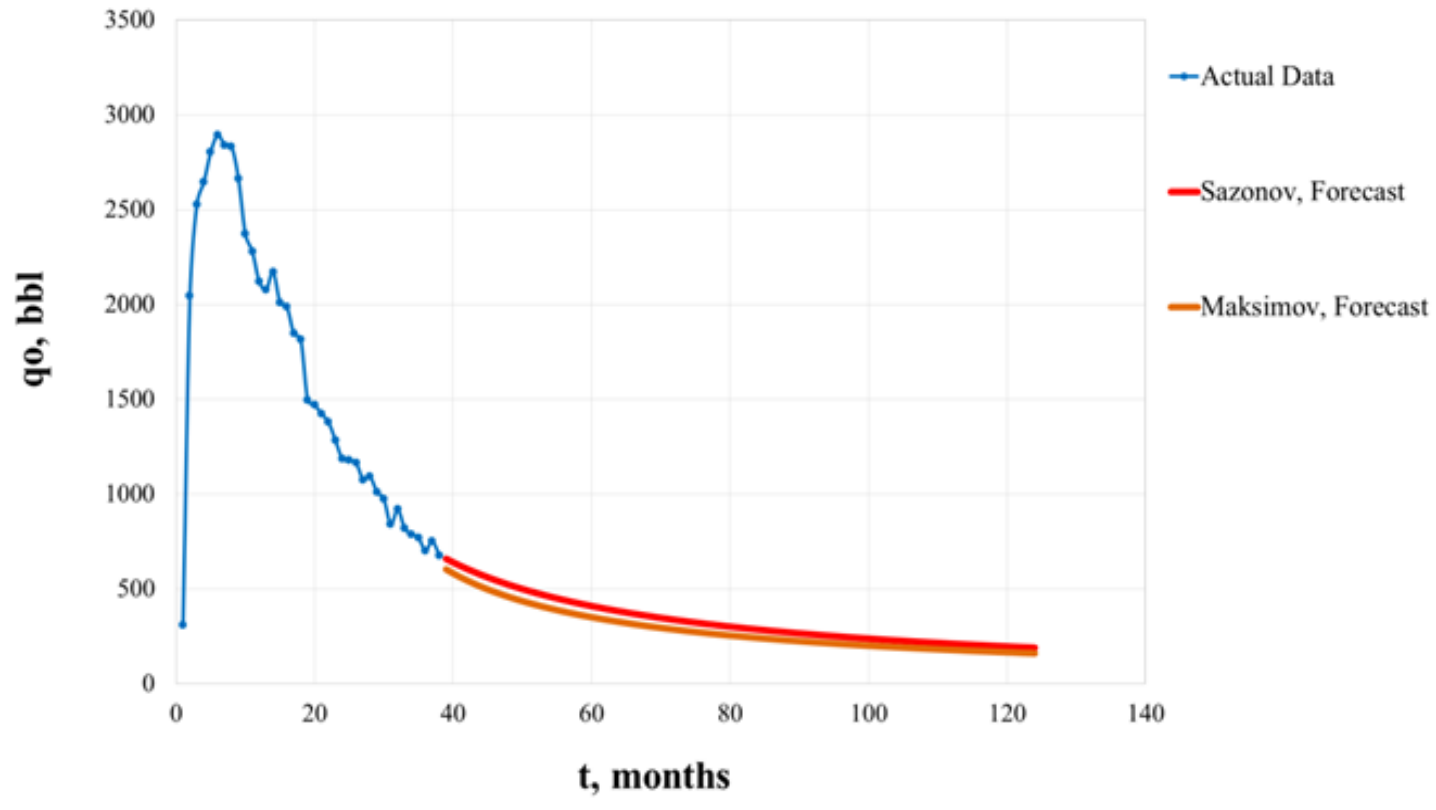

Fig. 10-Monthly Production of Oil (Forecast) (Well A, Kumkol Oil Field) 


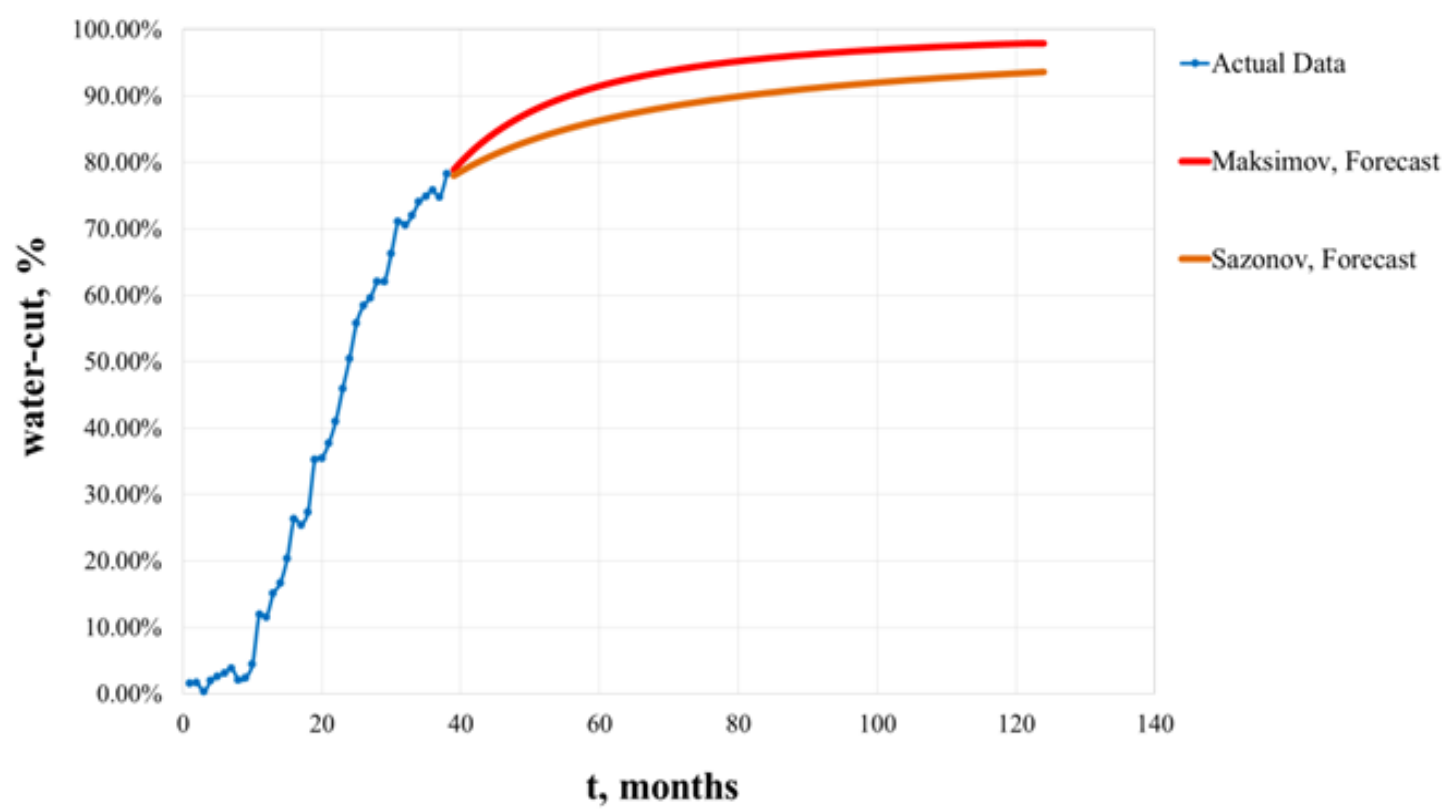

Fig. 11-Monthly Watercut (Forecast) (Well A, Kumkol Oil Field)

\subsubsection{Overall Workflow for Deterministic WDC Modeling}

1. Fit selected model for $q_{l}$ extrapolation to the actual data applying least squares method and find all parameters used in the model.

2. Use designed $q_{l}$ as future monthly liquid production rates. If you do not have designed $q_{l}$, use either $q_{l}$ as a constant (if reasonable) or select one of the models for extrapolating $q_{l}$ (Eq. 2.26 - Eq. 2.30). To select the best model use relative error, $\delta_{l}$, (Eq. 2.32);

3. Calculate $L_{p}$ using selected model for $q_{l}$ extrapolation;

4. Fit WDC models to actual oil production data applying least squares method and find $a$ and $b$ coefficients;

5. Select WDC model. WDC model can be selected according to hindcast or relative error, $\delta_{W D C}$, (Eq. 2.35); 
6. Using computed parameters, forecast production performance for certain period of time or estimate EUR based on selected limits (time, minimum production rate or maximum watercut value).

\subsection{Water-Oil-Ratio Technique}

\subsubsection{Logarithm of Water-Oil Ratio}

One of the most useful and reliable graphing methods for predicting waterflood performance is using the logarithm of producing water-oil-ratio as a function of cumulative production of oil. This method requires only surface production history data over the field development period. Data are graphed in the way such that they can be fitted with a straight line.

The principal value of this approach is derived from the straight-line performance. The theoretical basis was found in the Buckley-Leverett concepts, particularly in the Welge equation for dimensionless cumulative production, and the material balance equation.

The WOR versus $N_{p}$ technique has a physical basis and it ignores an impact of bottomhole pressure (Wolcott, 2009), as rate-time decline methods do. Changes in bottomhole pressure do not have significant impact on the relationship WOR vs. Np; this is a significant advantage of the technique.

For a given line slope, original oil in place (OOIP) must be constant. However, if the slope changes, resulting from field actions, this simply reflects a change in connected OOIP. These actions are easily interpretable by the equations below. 
The initial equation is given by Welge (1959):

$\log (W O R)=\left[b\left(1-S_{w i}\right) / O O I P\right] N_{p}+\log \left(a \times \mu_{o} / \mu_{w}\right)+b \times S_{w i}-\frac{1}{\ln (10)}$

where $S_{w i}$ - initial water saturation, OOIP - oil originally in place, $\mu_{o}$ - oil viscosity, $\mu_{w}$ - water viscosity, $a$ and $b$ are constants.

The slope of the line is

$M=\frac{b\left(1-S_{w i}\right)}{O O I P}$

and the intercept is

$N=\log \left(a \mu_{o} / \mu_{w}\right)+b S_{w i}-1 / \ln (10)$

The only assumption is that the ratio, $k_{r w} / k_{r o}$, can be reasonably represented by

$\frac{k_{r w}}{k_{r o}}=a \times 10^{b \times S_{w}}$

where $a$ and $b$ are constants defining the relative permeability curve.

The use of WOR versus $N_{p}$ graphical technique shows its usefulness in situations with significant changes in liquid rate and bottomhole pressure (Wolcott, 2009). Fig. 12 and Fig. 13 show that even with significant changes in liquid production, which is consequence of changing bottomhole pressure, the WOR line does have some not significant changes in it, but the trend is stable, interpretable and reproducible. Point A (Fig. 12) represents the sharp increase in liquid production and at the same time we can see no changes on the 
graph WOR vs. Np (Fig. 13). The log of WOR is linearly proportional to the cumulative oil production $\left(N_{p}\right)$, as was shown earlier in Eq. 2.36.

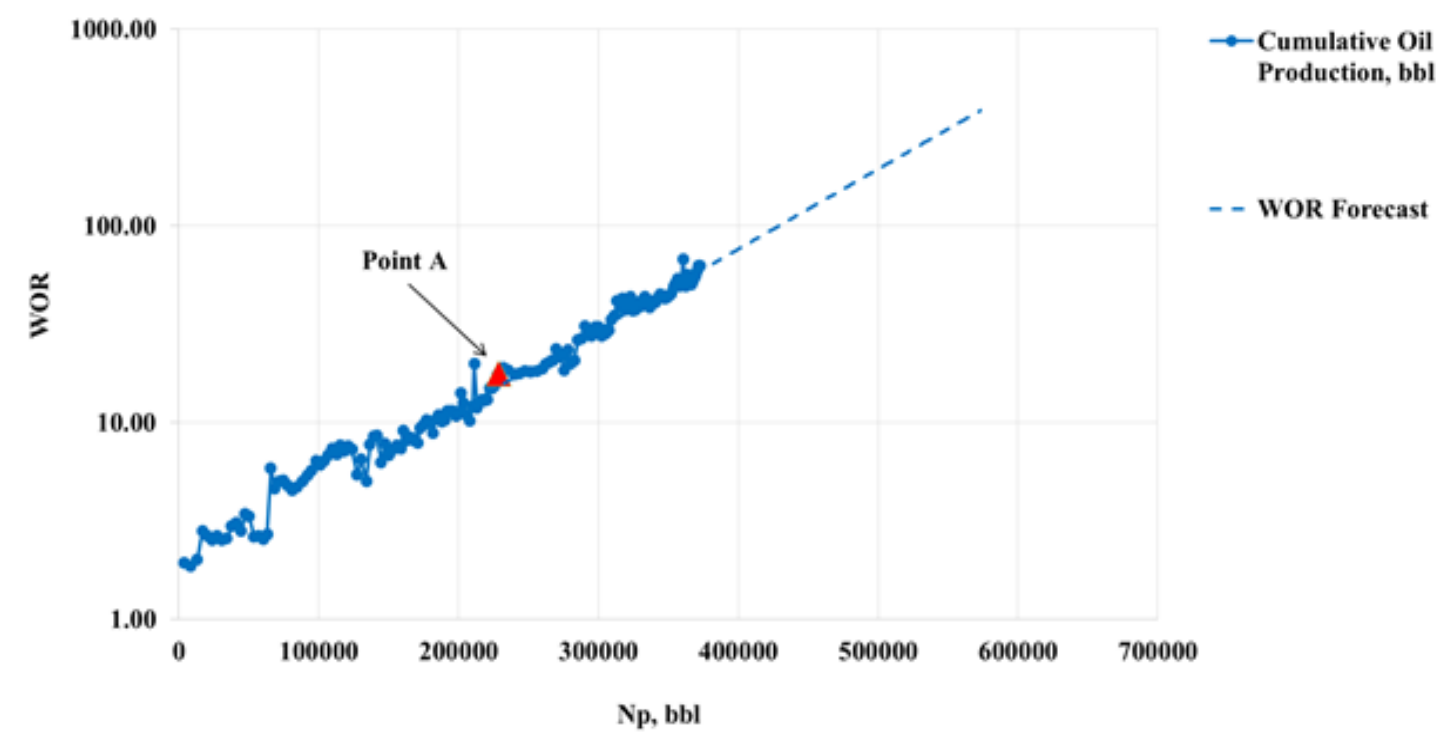

Fig. 12-WOR Technique (Well B, Kumkol Oil Field) 


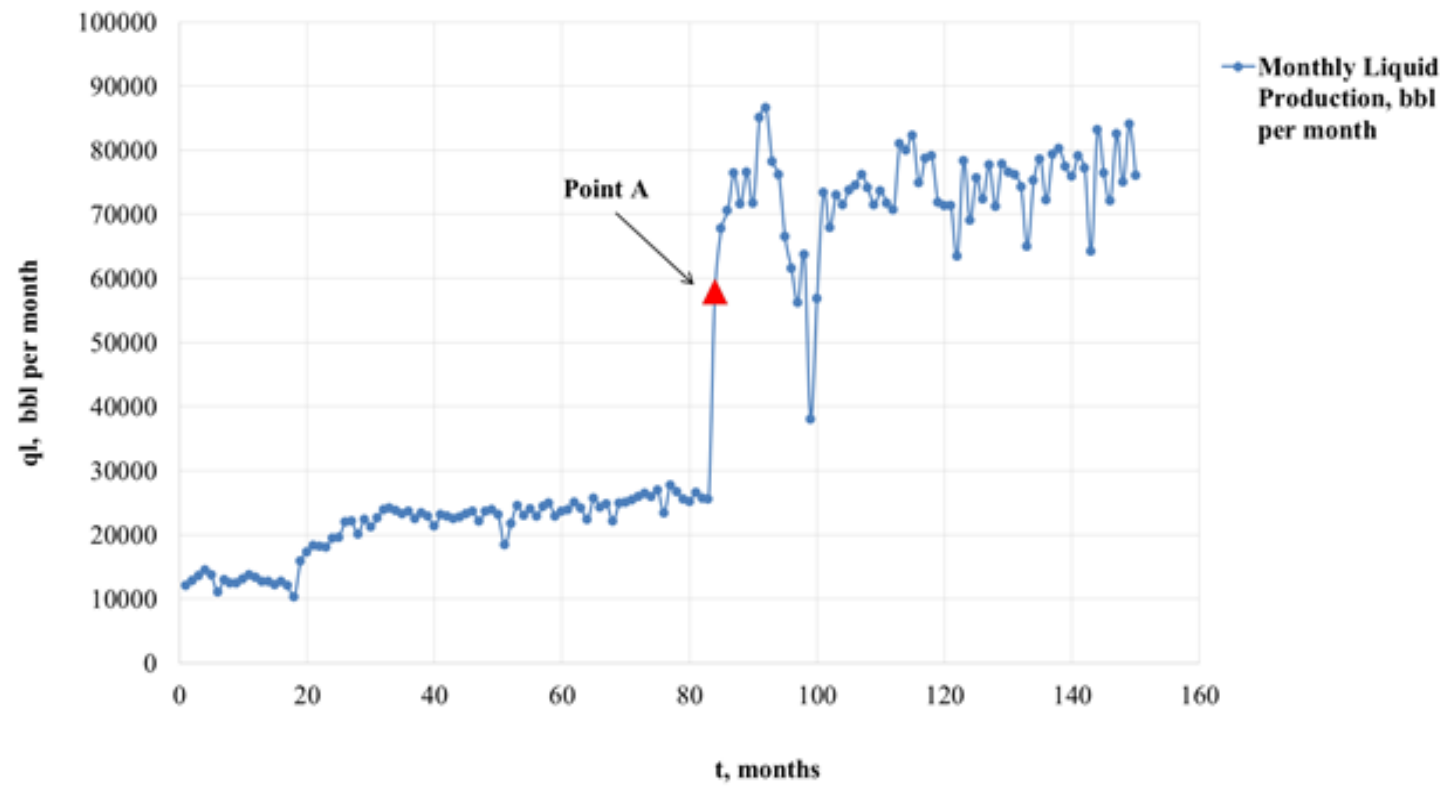

Fig. 13-WOR Technique (Well B, Kumkol Oil Field)

The procedure is as follows:

1. The semilog plot of historical WOR versus cumulative oil production is generated;

2. The plot tends to be linear. The last linear part of the graph is selected for extrapolation;

3. The trend is extrapolated in the future. WOR $=49$ can be used as an economic limit (Wolcott, 2009).

\subsubsection{Mature Waterflood Forecasting}

We can use the WOR vs. $N_{p}$ technique with the algorithm (Fig. 14) introduced by Wolcott (2009) to predict oil production for a given constant liquid monthly rate. The liquid rate can be designed or assumed either as a constant or as an increasing value (Fig. 13). 


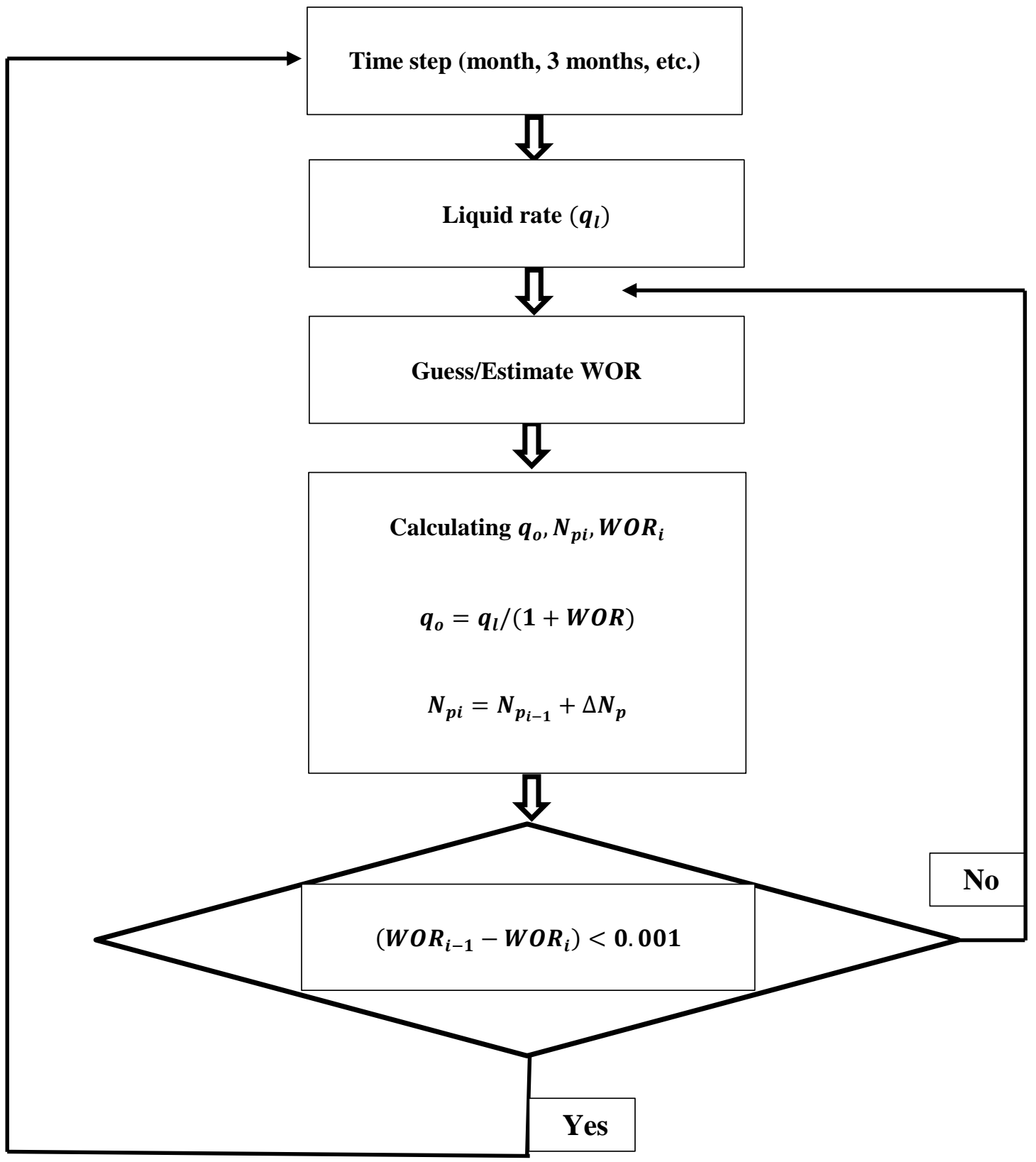

Fig. 14-Iterative Algorithm of the Program Which Can Be Used to Forecast Oil Production Performance 


\subsection{Decline Curve Analysis}

Decline Curve Analysis (DCA) is an empirical method to forecast production performance and estimate ultimate recovery based on historical production data available from oil and gas wells.

When originally presented, Arp's method was essentially empirical; however, Fetkovich (1980) later showed the exponential model represented a constant compressibility depletion of a fixed-volume reservoir. Fetkovich (1994) also superimposed the constant pressure depletion solution of the diffusivity equation into the Arps' equation which resulted in curves useful for integrating early transient and depletion data.

DCA is usually applied on a semilog plot of production rate versus either time or cumulative production. Original Arps' equations are the most widely used technique to estimate reserves and forecast production in oil and gas wells. However, it might not be the best DCA model to forecast production performance and estimate reserves in either shale or waterflooded formations.

\subsubsection{DCA Models}

Arps' equations includes exponential, hyperbolic and harmonic decline models.

$$
\left\{\begin{array}{c}
q(t)=q_{i} \exp \left(-D_{i} t\right) \\
q(t)=\frac{q_{i}}{\left(1+b_{D C A} D_{i} t\right)^{1 / b_{D C A}}}
\end{array}\right.
$$


In Eq. 2.40, $q(t)$ is the production rate as a function of time (Mcf/month), $D_{i}$ is Arps' initial decline rate (1/month), $\mathrm{t}$ is the time (month), $q_{i}$ is initial production rate (Mcf/month), and $b_{D C A}$ is Arp's dimensionless hyperbolic decline constant.

$D=-\frac{d q / d t}{q}$

When $b$ equals to zero, exponential decline is observed. When $b$ is one, the decline is harmonic. Hyperbolic model is applied when $b$ value is between zero and one.

$b=\frac{d}{d t}\left(-\frac{1}{D}\right)$

All the parameters included in conventional DCA are shown in Table 4.

\begin{tabular}{|l|c|c|c|}
\hline \multicolumn{3}{|c|}{ Table 4-DCA, Arps' Models (Fekete, 2014) } \\
\hline Parameter & Exponential & \multicolumn{1}{|c|}{ Hyperbolic } & Harmonic \\
\hline $\boldsymbol{b}_{\boldsymbol{D C A}}$ & $b_{D C A}=0$ & $0<b_{D C A}<1$ & $b_{D C A}=1$ \\
\hline $\begin{array}{l}\boldsymbol{q}(\boldsymbol{t}) \\
\text { (production }\end{array}$ & $q(t)=q_{i} e^{-D_{n} t}$ & $q(t)=\frac{q_{i}}{\left(1+b_{D C A} D_{i} t\right)^{1 / b_{D C A}}}$ & $q(t)=\frac{1}{1+b_{D C A} D_{i} t}$ \\
rate) & $N=\frac{q_{i}-q}{D_{i}}$ & $N=\frac{q_{i}^{b}}{\left(1-b_{D C A}\right) D_{i}}\left(q_{i}^{1-b_{D C A}}-\right.$ & $N=\frac{q_{i}}{D_{i}} \ln \left(\frac{q_{i}}{q}\right)$ \\
\hline $\begin{array}{l}\boldsymbol{N} \\
(\text { cumulative } \\
\text { recovery) }\end{array}$ & $q^{\left.1-b_{D C A}\right)}$ & $D_{i}=\frac{D_{e i}}{1-D_{e i}}$ \\
\hline $\begin{array}{l}\boldsymbol{D}_{\boldsymbol{i}} \\
(\text { nominal } \\
\text { decline } \\
\text { rate) }\end{array}$ & $\begin{array}{l}D_{i}=-\ln (1- \\
\left.\mathrm{D}_{\mathrm{e}}\right)\end{array}$ & $D_{i}=\frac{1}{b_{D C A}}\left[\left(1-D_{e i}\right)^{-b_{D C A}}\right.$ \\
\end{tabular}




\begin{tabular}{|l|c|c|c|}
\hline \multicolumn{3}{|c|}{ Table 4-continued } & Harmonic \\
\hline Parameter & Exponential & Hyperbolic & $D_{e i}=\frac{q_{i}-q}{q_{i}}$ \\
\hline $\begin{array}{l}\boldsymbol{D}_{e} \\
\text { effective } \\
\text { decline } \\
\text { rate) }\end{array}$ & $D_{e}=\frac{q_{i}-q}{q_{i}}$ & $D_{e i}=\frac{q_{i}-q}{q_{i}}$ & \\
\hline $\begin{array}{l}\mathbf{t} \quad(\text { elapsed } \\
\text { time) }\end{array}$ & $t=\frac{\ln \left(\frac{q_{i}}{q}\right)}{D_{n}}$ & $t=\frac{\left(\frac{q_{i}}{q}\right)^{b_{D C A}}-1}{b_{D C A} D_{i}}$ & $t=\frac{q_{i}}{q}-1$ \\
$D_{i}$
\end{tabular}

\subsubsection{Overall Workflow}

1. Fit DCA models to actual data applying least square method and find all parameters used in the models;

2. Select DCA model. DCA model can be selected according to relative error, $\delta$, which is calculated as

$$
\delta_{D C A}=\sum_{i=1}^{N}\left|\frac{q_{i}-\widehat{q}_{l}}{q_{i}}\right| \frac{100}{N} .
$$

where $\mathrm{N}$ is a total number of months in history matching period, $q_{i}$ is actual monthly production in month $\mathrm{i}$ and $\widehat{q}_{l}$ is calculated monthly production in month $\mathrm{i}$;

3. Using computed parameters of selected DCA model, forecast production performance for a certain period of time or estimate EUR based on either economic or time limits. 


\section{PROBABILISTIC / STOCHASTIC METHODOLOGIES}

\subsection{Bayes' Theorem with Markov Chain Monte Carlo Methodology (MCMC)}

\subsubsection{Bayes' Theorem}

Applying Bayes' theorem using MCMC to predict production performance probabilistically based on Arps' equations was first introduced by Gong et al. (2011).

The Bayes' theorem can be expressed as,

$\pi(\theta \mid y)=\frac{f(y \mid \theta) \pi(\theta)}{\int f(y \mid \theta) \pi(\theta) d \theta}$

where $\pi(\theta \mid y)$ is a posterior distribution, $f(y \mid \theta)$ is a likelihood function, $\pi(\theta)$ is a prior distribution of decline curve parameters, $\left(\ln \left(q_{i}\right), \ln \left(D_{i}\right)\right.$ and $\left.b\right), \theta$ is a potential candidate of the parameters and $y$ is the actual production data.

$f(y)=\int f(y \mid \theta) \pi(\theta) d \theta$

The quantity $f(y)$ is a normalizing constant of the posterior distribution.

The important components of Bayesian inference Eq. 3.1 can be characterized using the following statements:

1. $\pi(\theta)$ is called the prior distribution (prior). The prior distribution describes your initial information (beliefs) about parameters before any data have been taken into account; 
2. The likelihood function $f(y \mid \theta)$ is the probability density function of $y$ assuming $\theta$ is the true parameter;

3. Given the observed data $y$, you select a statistical model $f(y \mid \theta)$ to describe the distribution of $Y$ given $\theta$;

4. Updating initial information (beliefs) about $\theta$ by collecting information from the prior and the proposal distributions, $f(y \mid \theta)$;

5. $\pi(\theta \mid y)$ is the posterior distribution which is a distribution of the unknown parameter(s) after all observed data have been collected.

According to Gong et al. (2011), if the error, $\varepsilon$, between $\ln$ (actual production data) and $\ln$ (modeled production data based on selected decline curve model) follows the normal distribution $N(0,1)$, then

$f(y \mid \theta)=\frac{1}{\sqrt{2 \pi}} \exp \left(-\frac{\varepsilon^{2}}{2}\right)$

When the posterior distribution is identified, distribution of either production forecast or EUR can be obtained from the distribution of DCA parameters along with percentiles of the distribution, P10, P50 and P90.

The main purpose of Bayesian methodology is to obtain the posterior distribution of unknown parameter(s). However, there is a problem with calculating the posterior distribution directly. The integral $\int f(y \mid \theta) \pi(\theta) d \theta$ often has to be defined numerically. Gong et al. (2011) used a random walk algorithm for MCMC sampling as a method to deal with this problem. 


\subsubsection{MCMC}

MCMC Markov Chain Monte Carlo (MCMC) methods are a class of algorithms to generate samples from probability distributions (for instance, the posterior distribution of $\ln \left(q_{i}\right), \ln \left(D_{i}\right)$ and $\left.b\right)$.

A Markov chain is a stochastic process that can be expressed as,

$P\left(X_{s}=x_{s} \mid X_{1}=x_{1}, X_{2}=x_{2}, \ldots, X_{s-1}=x_{s-1}\right)=P\left(X_{s}=x_{s} \mid X_{s-1}=x_{s-1}\right)$

Markov chain describes a system under transition, where the next state on the chain depends only on the current one.

Gong et al. (2011) used the Metropolis algorithm for MCMC sampling. Since the posterior distribution is unknown, it is necessary to draw samples from another distribution called the proposal distribution. The proposal distribution is the distribution from which a random candidate is drawn.

There is also probability of the move, $\alpha$ (Eq. 3.5), representing acceptance $\left(\theta_{n}=\right.$ $\left.\theta_{\text {proposal }}\right)$ and probability $(1-\alpha)$ representing reject $\left(\theta_{n}=\theta_{n-1}\right)$.

First, having state $\left(\theta_{S}\right)$, draw a sample candidate $\left(\theta_{s+1}\right)$ from a proposal distribution. Using the current value $\left(\theta_{s}\right)$ and the candidate value $\left(\theta_{s+1}\right)$, the probability of the move, $\alpha$, is calculated. When $\theta_{s+1}$ is accepted, it is collected in the chain and its value is used in defining the next member of the chain. When $\theta_{s+1}$ is rejected, its value is deleted. 
Repeating the previous steps generates a Markov chain that converges to the target distribution.

"The normalized posterior probability of $\theta_{\text {proposal }}$ equals the posterior probability $\pi\left(\theta_{\text {proposal }} \mid y\right)$ divided by the proposal probability of $\theta_{\text {proposal }}$ given $\theta_{s-1}$, while the normalized posterior probability of $\theta_{s-1}$ equals the posterior probability $\pi\left(\theta_{s-1} \mid y\right)$ divided by the proposal probability of $\theta_{s-1}$ given $\theta_{\text {proposal. }}$ "- Gong et al. (2011).

$\alpha=\min \left[1, \frac{\frac{\pi\left(\theta_{\text {proposal }} \mid y\right)}{q\left(\theta_{\text {proposal }} \mid \theta_{s-1}\right)}}{\pi\left(\theta_{S-1} \mid y\right)}=\frac{\pi\left(\theta_{\text {proposal }} \mid y\right) q\left(\theta_{s-1} \mid \theta_{\text {proposal }}\right)}{\pi\left(\theta_{s-1} \mid y\right) q\left(\theta_{\text {proposal }} \mid \theta_{s-1}\right)}\right]$.

$q\left(\theta_{\text {proposal }} \mid \theta_{s-1}\right)=\prod_{\vartheta} \frac{1}{\sqrt{2 \pi}} e^{-\frac{\left(\vartheta_{\text {proposal }}-\vartheta_{s-1}\right)^{2}}{2 \sigma_{\vartheta}^{2}}} \times\left[\Phi\left(\frac{\vartheta_{\text {upper }}-\vartheta_{s-1}}{\sigma_{\vartheta}}\right)-\right.$

$\left.\Phi\left(\frac{\vartheta_{\text {lower }}-\vartheta_{s-1}}{\sigma_{\vartheta}}\right)\right]^{-1}$

where $\vartheta$ is one of either three or four decline curve parameters, depending on the DCA model.

In the Metropolis algorithm, the proposal density function should be symmetric (e.g., a normal distribution), such that $q(x \mid y)=q(y \mid x)$. However, Gong et al. (2011) identified the proposal distribution to be truncated normal distribution (Eq. 3.6),

Combining Eq. 3.5 in Eq. 3.6, the acceptance ratio can be calculated as, 


$$
\begin{aligned}
& \alpha=\min \left[1, \frac{\pi\left(\theta_{\text {proposal }} \mid y\right) q\left(\theta_{s-1} \mid \theta_{\text {proposal }}\right)}{\pi\left(\theta_{s-1} \mid y\right) q\left(\theta_{\text {proposal }} \mid \theta_{s-1}\right)}\right]= \\
& =\min \left[1, \frac{\pi\left(\theta_{\text {proposal }} \mid y\right)}{\pi\left(\theta_{s-1} \mid y\right)} \times \prod_{\vartheta} \frac{\Phi\left(\frac{\vartheta_{\text {upper }}-\vartheta_{s-1}}{\sigma_{\vartheta}}\right)-\Phi\left(\frac{\vartheta_{\text {lower }}-\vartheta_{s-1}}{\sigma_{\vartheta}}\right)}{\Phi\left(\frac{\vartheta_{\text {upper }}-\vartheta_{\text {proposal }}}{\sigma_{\vartheta}}\right)-\Phi\left(\frac{\vartheta_{\text {lower }}-\vartheta_{\text {proposal }}}{\sigma_{\vartheta}}\right)}\right]= \\
& =\min \left[1, \frac{f\left(y \mid \theta_{\text {proposal }}\right) \pi\left(\theta_{\text {proposal }}\right)}{f\left(y \mid \theta_{s-1}\right) \pi\left(\theta_{s-1}\right)} \times \prod_{\vartheta} \frac{\Phi\left(\frac{\vartheta_{\text {upper }}-\vartheta_{s-1}}{\sigma_{\vartheta}}\right)-\Phi\left(\frac{\vartheta_{\text {lower }}-\vartheta_{s-1}}{\sigma_{\vartheta}}\right)}{\Phi\left(\frac{\vartheta_{\text {upper }}-\vartheta_{\text {proposal }}}{\sigma_{\vartheta}}\right)-\Phi\left(\frac{\vartheta_{\text {lower }}-\vartheta_{\text {proposal }}}{\sigma_{\vartheta}}\right)}\right] \ldots . .(3.7)
\end{aligned}
$$

\subsubsection{Application of Bayes Theorem and MCMC with DCA Models}

Gong et al. (2011) applied the MCMC methodology with the Arps' models only; no other models were used in his study. Gong et al. (2011) used the following decline curve parameters: $\ln \left(q_{i}\right), \ln \left(D_{i}\right)$ and $b$ of Arps' equations. He assumed all three parameters to be independent and uniform prior distributions with the following limits: $0.01<q_{i}<1000000$, $0.1<D_{i}<50$, and $0<b_{D C A}<2$, where $q_{i}$ is in Mcf/d and $D_{i}$ is in 1/year. Eq. 3.8 shows density of the prior distribution for DCA parameters: $\ln \left(q_{i}\right), \ln \left(D_{i}\right)$ and $b$.

$\pi\left(\ln \left(q_{i}\right), \ln \left(D_{i}\right), b_{D C A}\right)=\frac{1}{18.41 \times 6.21 \times 2}$

Gonzalez et al. (2011) applied five more DCA models in addition to Arps' equations. These models are: Modified Arps' models, Power-Law, Duong's model, SEPD and Logistic Growth. He suggested the following prior distributions (Table 5) for six decline curve models' parameters in case of gas fields. One additional DCA model, called Pressure Depletion (Blasingame et al., 1991), has been used in this research and prior distribution for this model has been obtained during this research (Table 6). The model is described in details in Section 4.1.6. of this thesis. 


\begin{tabular}{|c|c|c|}
\hline \multicolumn{3}{|c|}{$\begin{array}{c}\text { Table 5-DCA Parameters Limits (Gas), } \\
\text { Suggested by Gonzalez et al. (2012) }\end{array}$} \\
\hline DCA parametes & Lower limit & Upper limit \\
\hline \multicolumn{3}{|c|}{$\underline{\text { Arps' Models }}$} \\
\hline$q_{i}$, Mcf/day & 0.01 & 1000000 \\
\hline$D_{i}, 1 /$ year & 0.1 & 50 \\
\hline$b_{D C A}$ & 0 & 2 \\
\hline \multicolumn{3}{|c|}{$\underline{\text { Modified Arps' Model }}$} \\
\hline$q_{i}$, Mcf/day & 0.01 & 1000000 \\
\hline$D_{i}, 1 /$ year & 0.1 & 50 \\
\hline$b_{D C A}$ & 0 & 2 \\
\hline$T_{0}$, months & 3 & 10000 \\
\hline \multicolumn{3}{|c|}{$\underline{\text { Power-Law Model }}$} \\
\hline$q_{i}, \mathrm{Mcf} / \mathrm{day}$ & 0.01 & 1000000 \\
\hline$D_{i}, 1 /$ year & 0.001 & 10 \\
\hline$D_{\infty}$ & $1 \mathrm{E}-09$ & 1 \\
\hline $\mathrm{n}$ & 0.001 & 2 \\
\hline \multicolumn{3}{|c|}{$\underline{\text { SEPD }}$} \\
\hline$q_{i}, \mathrm{Mcf} / \mathrm{day}$ & 0.01 & 1000000 \\
\hline$\eta$ & 0.01 & 5 \\
\hline$\tau$ & 0.15 & 10 \\
\hline \multicolumn{3}{|c|}{ Duong' Model } \\
\hline$q_{i}, \mathrm{Mcf} / \mathrm{day}$ & 0.01 & 1000000 \\
\hline $\mathrm{a}$ & 0.5 & 5 \\
\hline $\mathrm{m}$ & 0.5 & 2 \\
\hline \multicolumn{3}{|c|}{$\underline{\text { Logistic Growth }}$} \\
\hline$K, \operatorname{Mcf}$ & 1000 & 100000000 \\
\hline$a_{L}$, months & 1 & 1000 \\
\hline$n_{L}$ & 0.01 & 1 \\
\hline
\end{tabular}




\begin{tabular}{|ccl|}
\hline \multicolumn{3}{|c|}{ Table 6-DCA Parameters Limits } \\
\hline DCA parameter & Lower limit & Upper limit \\
\multicolumn{3}{|c|}{ Pressure Depletion } \\
$q_{i}$, bbl/day & 1 & 10000 \\
$D_{i}, 1 /$ year & 0.01 & 50 \\
$b_{D C A}$ & 0 & 1 \\
\hline
\end{tabular}

The proposal distribution is assumed to be $\mathrm{N}(\mu, \sigma)$, where $\mu$ equals value of parameters from the previous step of Markov Chain, for example, $\ln \left(q_{i}\right)_{\text {proposal }}=$ $N\left(\ln \left(q_{i}\right)_{s-1}, 0.2\right)$. The only unknowns are the standard deviations for each of the decline curve parameters. The standards deviations were suggested by Gonzalez et al. (2011) considering good mixing for the MCMC simulation (Table 7). Standard deviation for Pressure Depletion Model was also defined (Table 8).

\begin{tabular}{|cc|}
\hline $\begin{array}{c}\text { Table 7-Standard Deviations for } \\
\text { DCA Models Parameters, } \\
\text { Suggested by Gonzalez et al. (2012) }\end{array}$ \\
\hline \multicolumn{2}{|c|}{ Arps' Models } \\
DCA parameter & SD \\
$\ln \left(q_{i}\right)$ & 0.2 \\
$\ln \left(D_{i}\right)$ & 0.4 \\
$b_{D C A}$ & 0.2 \\
Modified Arps' Model \\
$\ln \left(q_{i}\right)$ & 0.2 \\
$\ln \left(D_{i}\right)$ & 0.4 \\
$b_{D C A}$ & 0.2 \\
$T_{0}$ & 1 \\
\end{tabular}




\begin{tabular}{|c|c|}
\hline \multicolumn{2}{|c|}{ Table 7-continued } \\
DCA parameter & SD \\
Power-Law Model & \\
$\ln \left(q_{i}\right)$ & 0.2 \\
$\ln \left(D_{i}\right)$ & 0.4 \\
$\ln \left(D_{\infty}\right)$ & 0.2 \\
$\mathrm{n} \quad$ SEPD & 0.4 \\
$\ln \left(q_{i}\right)$ & 0.2 \\
$\ln (\eta)$ & 0.4 \\
$\ln (\tau)$ & 0.2 \\
$\underline{\text { Duong Model }}$ & \\
$\ln \left(q_{i}\right)$ & 0.2 \\
$\mathrm{a}$ & 0.2 \\
$\mathrm{~m}$ & 0.2 \\
$\underline{\text { Logistic Growth }}$ & 0.4 \\
$\ln (K)$ & 0.2 \\
$\ln \left(a_{L}\right)$ & 0.3 \\
$n_{L}$ & \\
\hline
\end{tabular}

\begin{tabular}{|cc|}
\hline $\begin{array}{c}\text { Table 8-Standard Deviation for } \\
\text { Pressure Depletion Model } \\
\text { Parameters }\end{array}$ \\
\hline $\begin{array}{c}\text { DCA parameter } \\
\text { Pressure Depletion }\end{array}$ \\
$\ln \left(q_{i}\right)$ & 0.2 \\
$\ln \left(D_{i}\right)$ & 0.4 \\
$b_{D C A}$ & 0.2 \\
\hline
\end{tabular}


After all necessary parameters for DCA models have been defined, the likelihood function needs to be calculated. The decline curve parameters from the best fit (for example, $\ln \left(q_{i}\right), \ln \left(D_{i}\right)$ and $b_{D C A_{i}}$ for Arps' models) are used as the initial values in the Markov Chain.

The standard deviation of residual $(\sigma)$ between best fit and actual data for Arps' models is defined as,

$\sigma=\sqrt{\sum_{i=1}^{t} \frac{\left(y_{i}-\widehat{y}_{l}\right)^{2}}{t-3}}$

where $y_{i}$ is observed production rate in month $\mathrm{i}, \widehat{y}_{l}$ is calculated production rate in month $i$ and $t$ is the number of months in production history. The residual sum of squares (RSS) was divided by $t-3$ or $t-4$ because DCA models have from 3 to 4 parameters depending on the model.

The standard deviation of residual between modeled and actual production data for each iteration (for each set of $\theta_{\text {proposal }}$ ) is calculated using the following expression,

$\sigma_{\text {proposal }}=\sqrt{\sum_{i=1}^{t} \frac{\left(y_{i}-\hat{y}_{t_{\text {proposal }}}\right)^{2}}{t}}$

where $y_{i}$ is observed production rate in month $i, \hat{y}_{t_{\text {proposal }}}$ is calculated production rate in month $i$ using set of DCA parameters $\left(\theta_{\text {proposal }}\right)$ and $t$ is the number of months in production history. The RSS was divided by $t$ because the proposal model is independent of the production. 
Gong et al. (2011) suggested to use the standard deviation of logarithm residuals $\left(\sigma_{\text {proposal }}\right)$ between actual production and calculated production to be normally distributed $\mathrm{N}(0, \sigma)$ for the likelihood function,

$f\left(y \mid \theta_{\text {proposal }}\right)=\frac{1}{\sqrt{2 \pi \sigma}} \exp \left(-\frac{\sigma_{\text {proposal }}^{2}}{\sigma^{2}}\right)$

where $\sigma$ is the standard deviation of logarithm residuals between production data obtained using best fit parameters of DCA and actual production data. $\sigma_{\text {proposal }}$ is the standard deviation of logarithm residuals between production data (obtained using proposal parameters of DCA) and actual production data.

Combining the density of the prior distribution (Eq. 3.8), the likelihood function (Eq. 3.11) and the density of proposal distribution (Eq. 3.6) into the acceptance probability (Eq. 3.7), we have the following

$$
\begin{aligned}
\alpha=\min \left[1, \frac{\exp \left(-\frac{\sigma_{\text {proposal }}^{2}}{\sigma^{2}}\right)}{\exp \left(-\frac{\sigma_{s-1}^{2}}{\sigma^{2}}\right)}\right. & \\
& \left.\times \prod_{\vartheta=\ln \left(q_{i}\right), \ln \left(D_{i}\right), b} \frac{\Phi\left(\frac{\vartheta_{\text {upper }}-\vartheta_{s-1}}{\sigma_{\vartheta}}\right)-\Phi\left(\frac{\vartheta_{\text {lower }}-\vartheta_{s-1}}{\sigma_{\vartheta}}\right)}{\sigma_{\vartheta}}\right)
\end{aligned}
$$


$=\min \left[1, \exp \left(\frac{\sigma_{s-1}^{2}-\sigma_{\text {proposal }}^{2}}{\sigma^{2}}\right) \times\right.$

$\left.\prod_{\vartheta=\ln }\left(q_{i}\right), \ln \left(D_{i}\right), b \frac{\Phi\left(\frac{\vartheta_{\text {upper }} \vartheta_{s-1}}{\sigma_{\vartheta}}\right)-\Phi\left(\frac{\vartheta_{\text {lower }} \vartheta_{s-1}}{\sigma_{\vartheta}}\right)}{\Phi\left(\frac{\vartheta_{\text {upper }}-\vartheta_{\text {proposal }}}{\sigma_{\vartheta}}\right)-\Phi\left(\frac{\vartheta_{\text {lower }}^{-\vartheta_{\text {proposal }}}}{\sigma_{\vartheta}}\right)}\right]$.

When the maximum number of iterations is reached, the obtained sets of decline curve parameters can be used to calculate the distribution of EUR. After that, P90, P50, and P10 can be obtained.

\subsubsection{Overall Workflow}

The overall methodology for Bayes' theorem and MCMC with DCA models is written below,

1. Select DCA model (relative error, $\delta_{D C A}$, in Eq. 2.44 can be used);

2. Obtain set of DCA parameters from best fit;

3. Generate a sample, $\theta_{\text {proposal }}$, of the DCA model parameters from the proposal distribution;

4. Calculate acceptance ratio, $\alpha$;

5. Generate a random number between 0 and 1 ;

6. If the random number is less than $\alpha$, accept $\theta_{\text {proposal }}, \theta_{s}=\theta_{\text {proposal }}$, otherwise, $\theta_{s}=\theta_{s-1}$;

7. If $s$ is more than maximum chain length, then stop MCMC, otherwise go to step 3;

8. Calculate distribution of reserves and obtain P10, P50 and P90 of this distribution. 


\subsubsection{Application of Bayes Theorem and MCMC with WDC Models}

Bayes Theorem and MCMC was applied in previous work only with DCA models taking into account neither watercut nor liquid production rate, $q_{l}$. In case of waterflooded oil fields, both watercut limit and liquid/water production are important parameters and they need to be taken into consideration while forecasting production performance and estimating EUR. Moreover, DCA models might not be the best models to use when watercut is more than $30 \%$.

In this research Bayes Theorem and MCMC methodology was first applied with eleven WDC models. Liquid/water production rate, which is one of the parameters (along with a and $\mathrm{b}$ constants) in all WDC models, was used as the third parameter of all WDC models during MCMC procedure. Methodology of Bayes Theorem with MCMC (Gong et al., 2011) was described in Sections 3.1.1 - 3.1.4.

Based on 100 wells, limits for WDC parameters and liquid production rate have been defined during this research (Table 9, Table 10). The standard deviations for each WDC models' parameters and liquid production rate have been also defined (Table 11, Table 12). The standards deviations were chosen in a way to obtain good mixing during MCMC simulation. 


\begin{tabular}{|c|c|c|}
\hline \multicolumn{3}{|c|}{ Table 9-WDC Parameters Limits } \\
\hline WDC & $\begin{array}{c}\text { Lower limit } \\
\underline{\text { Kambarov }}\end{array}$ & Upper limit \\
\hline a & $-1 \mathrm{E}+14$ & -100 \\
\hline \multicolumn{3}{|c|}{$\underline{\text { Sazonov }}$} \\
\hline a & 100 & $1 \mathrm{E}+7$ \\
\hline \multicolumn{3}{|c|}{$\underline{\text { Pirverdyan }}$} \\
\hline a & $-1 \mathrm{E}+11$ & $-1 \mathrm{E}+4$ \\
\hline $\mathrm{b}$ & 100 & $1 \mathrm{E}+8$ \\
\hline \multicolumn{3}{|c|}{$\underline{\text { Nazarov-Sypachev }}$} \\
\hline a & $1 \mathrm{E}-9$ & $1 \mathrm{E}-4$ \\
\hline \multicolumn{3}{|c|}{$\underline{\text { Maksimov }}$} \\
\hline a & 0.1 & $1 \mathrm{E}+6$ \\
\hline $\mathrm{b}$ & $\begin{array}{c}-1 \mathrm{E}+7 \\
\text { Abyzbaev }\end{array}$ & 0.1 \\
\hline a & 0.01 & 100 \\
\hline \multicolumn{3}{|c|}{$\underline{\text { Gaysin }}$} \\
\hline a & $1 \mathrm{E}-5$ & $1 \mathrm{E}-7$ \\
\hline $\mathrm{b}$ & $\begin{array}{c}\begin{array}{c}1 \mathrm{E}-4 \\
\text { Kazakov }\end{array} \\
\end{array}$ & 5 \\
\hline a & 0.1 & $1 \mathrm{E}+5$ \\
\hline $\mathrm{b}$ & $-1 \mathrm{E}+7$ & 1 \\
\hline $\mathrm{c}$ & $\begin{array}{r}1 \mathrm{E}-5 \\
\underline{\mathrm{IFP}}\end{array}$ & 100 \\
\hline a & $1 \mathrm{E}-9$ & 100 \\
\hline $\mathrm{b}$ & -100 & $-1 \mathrm{E}-4$ \\
\hline \multicolumn{3}{|c|}{$\underline{\text { Constant Oil Saturation }}$} \\
\hline a & $1 \mathrm{E}-6$ & 100 \\
\hline
\end{tabular}




\begin{tabular}{|ccc|}
\hline \multicolumn{3}{c}{ Table 9-continued } \\
WDC & Lower limit & Upper limit \\
b & 0.1 & $1 \mathrm{E}+8$ \\
& Sypachev-Posevich & \\
a & $1 \mathrm{E}-11$ & $1 \mathrm{E}-3$ \\
$\mathrm{~b}$ & $1 \mathrm{E}-4$ & 10 \\
\hline
\end{tabular}

\begin{tabular}{|ccc|}
\hline \multicolumn{3}{|c|}{ Table 10-Liquid Production Limits } \\
Parameter & Lower limit & Upper limit \\
& \multicolumn{3}{|c|}{ Liquid Production Rate } \\
$q_{l}$ & 100 & 500000 \\
\hline
\end{tabular}

\begin{tabular}{|c|c|}
\hline \multicolumn{2}{|c|}{$\begin{array}{l}\text { Table 11-WDC Parameters } \\
\text { Proposal Distributions }\end{array}$} \\
\hline WDC & $S D$ \\
\hline \multicolumn{2}{|c|}{ Kambarov } \\
\hline $\mathrm{a}$ & 0.5 \\
\hline $\mathrm{b}$ & 2 \\
\hline \multicolumn{2}{|c|}{ Sazonov } \\
\hline $\mathrm{a}$ & 0.5 \\
\hline $\mathrm{b}$ & 2 \\
\hline \multicolumn{2}{|c|}{ Pirverdyan } \\
\hline $\mathrm{a}$ & 0.2 \\
\hline $\mathrm{b}$ & 2 \\
\hline \multicolumn{2}{|c|}{ Nazarov-Sypachev } \\
\hline $\mathrm{a}$ & 2 \\
\hline $\mathrm{b}$ & 0.2 \\
\hline \multicolumn{2}{|c|}{ Maksimov } \\
\hline
\end{tabular}




\begin{tabular}{|c|c|}
\hline \multicolumn{2}{|c|}{ Table 11 -continued } \\
\hline WDC & $S D$ \\
\hline $\mathrm{a}$ & 0.2 \\
\hline b & 2.5 \\
\hline \multicolumn{2}{|c|}{ Abyzbaev } \\
\hline $\mathrm{a}$ & 0.3 \\
\hline b & 2 \\
\hline \multicolumn{2}{|c|}{ Gaysin } \\
\hline $\mathrm{a}$ & 1 \\
\hline $\mathrm{b}$ & 1 \\
\hline \multicolumn{2}{|c|}{ Kazakov } \\
\hline $\mathrm{a}$ & 0.2 \\
\hline $\mathrm{b}$ & 0.4 \\
\hline $\mathrm{c}$ & 0.2 \\
\hline \multicolumn{2}{|c|}{ IFP } \\
\hline $\mathrm{a}$ & 2.5 \\
\hline $\mathrm{b}$ & 0.4 \\
\hline \multicolumn{2}{|c|}{ Constant Oil Saturation } \\
\hline $\mathrm{a}$ & 0.2 \\
\hline $\mathrm{b}$ & 3 \\
\hline \multicolumn{2}{|c|}{ Sypachev-Posevich } \\
\hline $\mathrm{a}$ & 3 \\
\hline $\mathrm{b}$ & 0.5 \\
\hline
\end{tabular}

\begin{tabular}{|cc|}
\hline \multicolumn{2}{|c|}{$\begin{array}{c}\text { Table 12-Liquid Production } \\
\text { Rate Proposal Distribution }\end{array}$} \\
\hline Parameter & $S D$ \\
Liquid Production Rate \\
a & 0.2 \\
\hline
\end{tabular}




\subsubsection{Overall Workflow}

The overall methodology for Bayes' theorem and MCMC with WDC models is written below,

1. Fit and select a model for $q_{l}$ extrapolation (relative error, $\delta_{l}$, in Eq. 2.32 can be used);

2. Fit and select WDC model (relative error, $\delta_{W D C}$, can be used);

3. Initial parameters of the WDC model are equal to those obtained from best fit;

4. Generate a sample, $\theta_{\text {proposal }}$, of the WDC model parameters from the proposal distribution;

5. Calculate acceptance ratio, $\alpha$;

6. Generate a random number between 0 and 1 ;

7. If the random number is less than $\alpha$, accept $\theta_{\text {proposal }}, \theta_{s}=\theta_{\text {proposal }}$; otherwise, $\theta_{s}=\theta_{s}-1$;

8. If $s$ is more than maximum chain length, then stop MCMC, otherwise go to step 3;

9. Calculate distribution of reserves and obtain P10, P50 and P90 of this distribution.

\subsection{WDC Multimodel}

The WDC Multimodel is a simple and fast method which has been developed during this research. The method is based on the difference in fits and forecasts obtained by the different WDC models.

In the WDC multimodel method, eleven WDC models have been applied. These models are the following: Kambarov, Sazonov, Pirverdyan, Nazarov-Sypachev, Maksimov, Gaysin, Abyzbaev, Kazakov, IFP, Constant Oil Saturation, Sypachev-Posevich (Fig. 14). 


\begin{tabular}{|l|}
\hline \multicolumn{1}{|c|}{ WDC Models } \\
\hline Select WDC Modd \\
\hline 1. $N_{p}=b-\frac{\alpha}{L_{p}}$ \\
2. $N_{p}=\alpha \ln \left(L_{p}\right)+b$ \\
3. $N_{p}=b-\frac{\alpha}{\sqrt{L_{p}}}$ \\
4. $\frac{L_{p}}{N_{p}}=\alpha W_{p}+b$ \\
5. $W_{O R}=\alpha e^{-b N_{p}}$ \\
6. $N_{p}=\alpha l n\left(W_{p}\right)+b$ \\
7. $\ln \left(N_{p}\right)=\alpha l n\left(L_{p}\right)+b$ \\
8. $\frac{N_{p}}{L_{p}}=\alpha l n\left(N_{p}\right)+b$ \\
9. $N_{p}=\alpha L_{p}^{c}+b$ \\
10. $\frac{W_{p}}{N_{p}}=\alpha N p+b$ \\
11. $N_{p}=\alpha L_{p}+b$ \\
12. $\frac{L_{p}}{N_{p}}=\alpha L_{p}+b$ \\
\hline
\end{tabular}

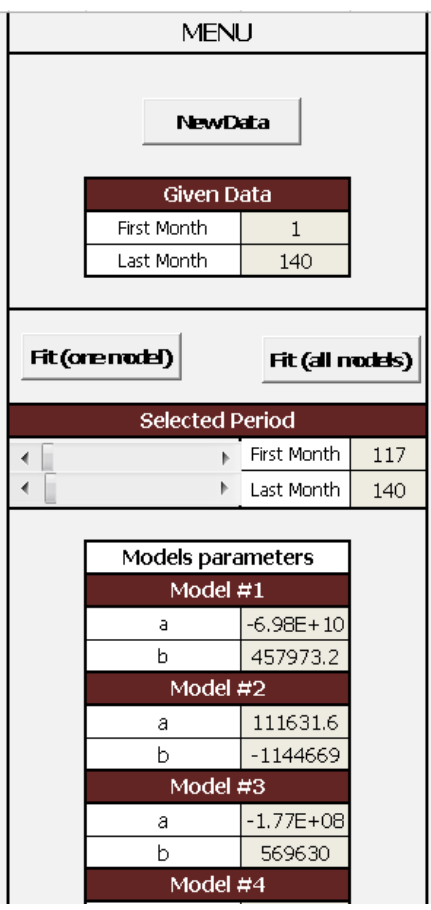

\begin{tabular}{|l|c|c|c|c|}
\hline \multicolumn{5}{|c|}{ Rankings } \\
\hline \multirow{2}{*}{ Model } & \multicolumn{2}{c|}{$\mathrm{R}^{\wedge} 2$} & \multicolumn{2}{c|}{$\delta$ (fIt) } \\
\cline { 2 - 5 } & rank & value & rank & value, \% \\
\hline Kambarov & 3 & 0.9980 & 2 & 0.1699 \\
\hline Sazonov & 6 & 0.9895 & 7 & 0.4105 \\
\hline Pirverdyan & 4 & 0.9949 & 3 & 0.2830 \\
\hline Nazarov-Sipachev & 1 & 0.9999 & 1 & 0.1594 \\
\hline WOR vs. Np & 11 & 0.9573 & 12 & 9.4532 \\
\hline Maksimov & 5 & 0.9918 & 6 & 0.3540 \\
\hline Abyzbaev & 8 & 0.9841 & 9 & 0.5025 \\
\hline Gaysin & 7 & 0.9843 & 5 & 0.3372 \\
\hline Kazakov & & & 8 & 0.4990 \\
\hline IFP & 10 & 0.9591 & 11 & 0.6989 \\
\hline Constant Oil Saturatior & 9 & 0.9722 & 10 & 0.6744 \\
\hline Sipachev-Posevich & 2 & 0.9986 & 4 & 0.3131 \\
\hline
\end{tabular}

Fig. 15-WDC Multimodel

First, the matches of the models are obtained. Second, cumulative production at the end of the hindcast $(\mathrm{CPEOH})$ was calculated and ranked for each of the WDC in the multimodel. The highest value of $\mathrm{CPEOH}$ was considered to be the $\mathrm{P} 10$, the lowest value of CPEOH was considered to be the P90 and the P50 was considered to be the sixth highest value of $\mathrm{CPEOH}$. The choice to use this way of ranking $\mathrm{CPEOH}$ values was obtained empirically (Fig.16 and Fig.17), based on production data of 100 wells. 


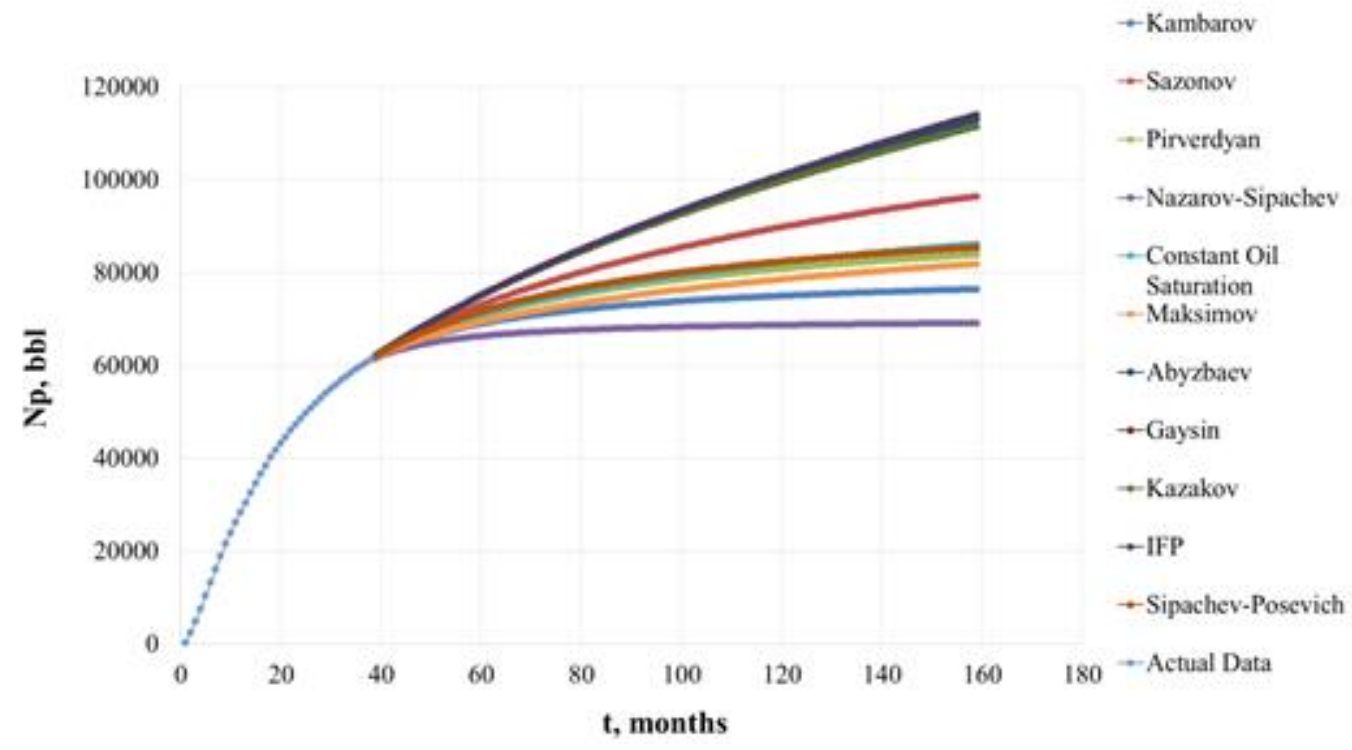

Fig. 16-11 WDC Models (Well C, Kumkol Oil Field)

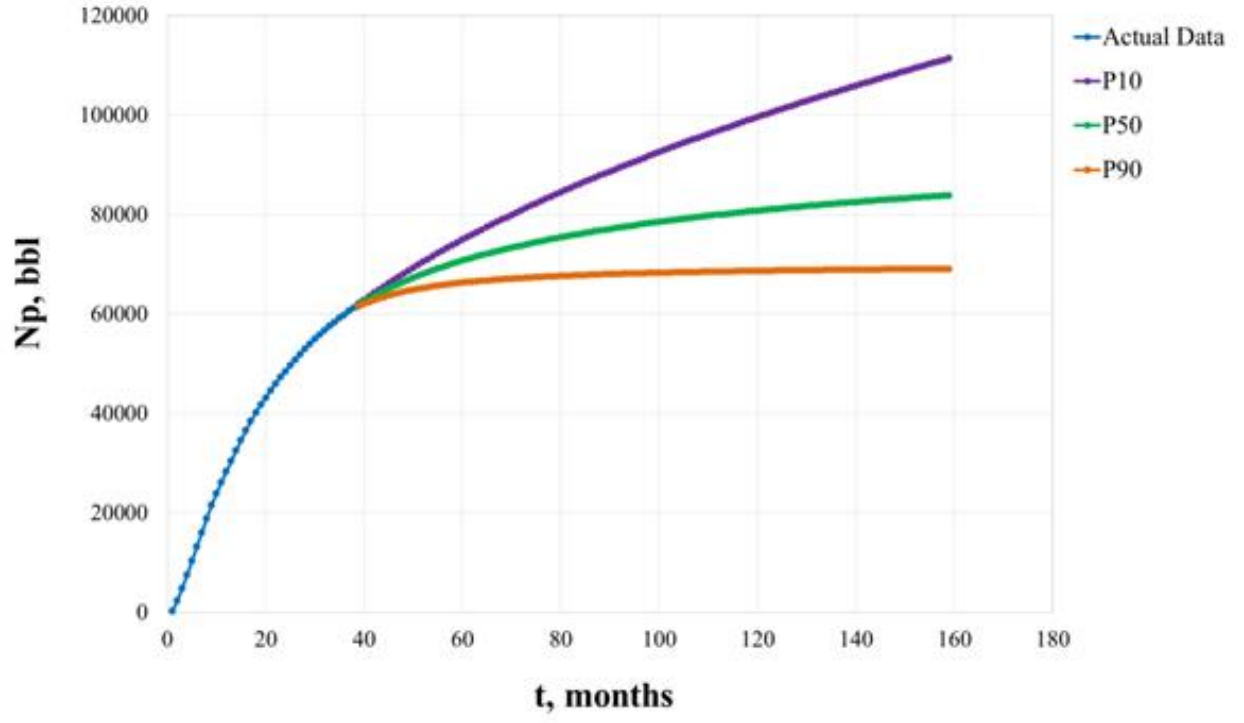

Fig. 17-P10, P50 and P90 Curves (Well C, Kumkol Oil Field) 


\section{THE PROGRAM}

\subsection{Additional Deterministic Methods Applied in the Program}

\subsubsection{Modified Arps' Equations}

When $D_{i}$ becomes too small, production rate no longer declines significantly and reserves can be overestimated. To avoid this problem, the Minimum Decline Rate method was introduced, Eq. (4.1), that imposes a limit $D_{\min }$ below which $D_{i}$ cannot drop.

$\left\{\begin{array}{c}q(t)=\frac{q_{i}}{\left(1+b D_{i} t\right)^{1 / b}}, D_{i}>D_{\text {min }} \\ q(t)=q_{i} \exp \left(-D_{\text {min }} t\right), D_{i} \leq D_{\text {min }}\end{array}\right.$

Once the instantaneous decline reaches $D_{\min }$, Eq. (4.1), it is changed to Exponential Decline.

Although the Minimum Decline Rate method helps to avoid extreme overestimation of reserves, matching the decline curve to transient production data provides no guidance for selecting value of $D_{\min }$. Ultimately, the choice of $D_{\min }$ is based on either experience or mutual agreement between engineer and reserves assessors.

The Modified Arps' model Eq. (4.2) is based on original Arps' equations and a fourth parameter determined as the time at which hyperbolic decline changes to exponential decline. 


$$
\left\{\begin{array}{c}
q(t)=\frac{q_{i}}{\left(1+b D_{i} T_{0}\right)^{1 / b}} \exp \left[\frac{-D_{i}\left(t-T_{0}\right)}{1+b D_{i} T_{0}}\right], t>T_{0} \\
q(t)=\frac{q_{i}}{\left(1+b D_{i} t\right)^{1 / b}}, t \leq T_{0}
\end{array}\right.
$$

In Eq. (4.2), $T_{0}$ is the modified Arps' time when hyperbolic decline switches to exponential decline.

The modified Arps' equation describes both the early and the latest decline of production. For example, if the data initially illustrates a hyperbolic decline, but the last trend is an exponential decline, the model will provide an equation which fits the early hyperbolic decline and the last exponential trend. Otherwise, if the data show an exponential trend the model will apply $T_{0}=0$ and present only an exponential decline.

\subsubsection{Power-Law Exponential Model}

To analyze production data from shale gas reservoirs, several DCA models have been developed recently: Power-Law model (Ilk et al. 2008), Stretched Exponential Production Decline model (Valko and Lee 2010), Duong's model (Duong 2011), and the Logistic Growth model (Clark et al. 2011).

The Power-Law exponential model (Ilk et al. 2008) was the first model developed to improve Arps' model to match production data from unconventional wells. The model is based on a Power-Law loss ratio. The loss ratio was modeled "by a decaying Power-Law function with a constant behavior at large times" (Ilk et al., 2008). 
The constant behavior at large times is described by constant decline parameter, $D_{\infty}$. By having a four-parameter model, the model can describe transient and boundary-dominated flow. The model is defined in Eq. 4.3,

$q(t)=\widehat{q}_{\iota} \exp \left(-D_{\infty} \times t-\widehat{D} \times t^{n}\right)$

where $\widehat{D}$ is the Power-Law decline constant, $1 /$ month, $D_{\infty}$ is the Power-Law decline at infinite time constant, $1 /$ month, and $n$ is dimensionless time exponent.

\subsubsection{Stretched Exponential Production Decline Model}

The stretched exponential production decline (SEPD) model (Eq. 4.4) was developed by Valko and Lee (2010). According to Valko and Lee (2010), the SEPD model offers an

important benefit over the traditional Arps' hyperbolic decline model: that is, more realistic forecasts for low-permeability wells with long-duration transient flow.

$$
q(t)=q_{i} \exp \left[-\left(\frac{t}{\tau}\right)^{\eta}\right]
$$

In Eq. 4.4, $\eta$ is a dimensionless exponent parameter and $\tau$ is the characteristic time parameter, months. 


\subsubsection{Duong's Model}

Duong (2011) introduced a new model specifically for hydraulically fractured horizontal wells based on a plot of inverse material balance time q / Q vs. time, which forms a straight line on a log-log scale (Eq. 4.5). The main point is that this model is limited, the production rate eventually goes to zero. The model is expressed in Eq. 4.6,

$\frac{q}{G_{p}}=a t^{-m}$

$q(t)=q_{i} t^{-m} \exp \left[\frac{a}{1-m}\left(t^{1-m}-1\right)\right]$

where $a$ is the intercept constant, $1 /$ month, and $m$ is the dimensionless slope.

Duong's model works reliably in shale wells even with a short period of production history (Joshi and Lee, 2013). In his study Duong (2011) used several wells types: tight, dry and wet shale gas. Duong (2011) concluded that his model provided more conservative reserves estimates than the Power-Law (Ilk et al., 2008) and Arps' models.

\subsubsection{Logistic Growth Model}

The logistic growth model was developed by Clark et al. (2011). The model is based on the logistic growth curves used to forecast growth (for example cumulative oil or gas production).

$q(t)=\frac{K n_{L} a_{L} t^{n_{L}-1}}{\left(a_{L}+t^{\left.n_{L}\right)^{2}}\right.}$ 
In Eq. 4.7, $K$ is potential EUR without imposing economic limits Mcf, $n_{L}$ is the dimensionless decline exponent parameter, and $a_{L}$ is the time to the power $n_{L}$ at which half of the potential EUR has been produced, months.

Clark et al. (2011) tested the model using 600 wells. They concluded that the logistic model estimates for EUR were more conservative than Arps' equations.

\subsubsection{Pressure Depletion Model}

More recently, Masoner (1996) addressed decline analysis under conditions of changing pressure gradients and variable liquid rates for reservoirs under multiphase flow where the oil relative permeability dominates the decline.

The fundamental assumption relies on the concept that declining oil production relates to the relative permeability for recovery methods involving a depleting oil saturation (for example waterflooding).

Centry and McCray (1978) used simulation to identify that relative permeability predominantly impacts the decline exponent in the hyperbolic equation. These factors indirectly and directly substantiate the physical basis that the hyperbolic form can be applied to the relative permeability-dominated recovery process. When the ultimate reserves do not change, all rate cases reflect an identical WOR as a function of the cumulative fluid produced. The strategy is to calculate WOR at any cumulative fluid value. First calculate the cumulative fluid produced at reservoir conditions at time $t$ using Eq. 4.9. 
$Q_{t}(t)=Q_{t-1}(t)+q_{t}(t) \Delta t$

Next, the effective total elapsed time $t$ since the initial time in days is determined from

$\Delta t_{e}(t)=\frac{Q_{t}(t)}{q_{t}}$

The effective time defines the length of time elapsed had the production rate remained constant. This time corresponds to the cumulative fluid production maturity of the drainage volume. Blasingame et al. (1991) used this same definition of time to provide rate corrections for pressure-depletion type-curve decline analysis.

The effective time allows the calculation of the effective oil production, using either the exponential decline equation,

$q_{o e}(t)=q_{o i} e^{\left\{1+\left[\frac{\ln \left(1-D_{i}\right)}{365}-1\right] \Delta t_{e}(t)\right\}}$

or the hyperbolic form,

$q_{o e}(t)=q_{o i}\left\{1+\left[\left(1-D_{i}\right)^{-b}-1\right]\left(\frac{\Delta t_{e}(t)}{365}\right\}^{\frac{1}{-b}}\right.$

The method can be superior to performing simple decline curve analysis since the effect of variable rate changes can be incorporated. 


\subsection{Additional Probabilistic Methods Applied in the Program}

\subsubsection{Bootstrap Method}

The Bootstrap Method, a special type of Monte Carlo Analysis, was applied by Jochen and Spivey (1996) with DCA models to access uncertainty in production forecasts and reserves estimates. The main advantage of the technique is that it does not require a prior knowledge of probability distributions of parameters used in DCA models. It depends only on the DCA of synthetic data sets.

The bootstrap method makes two assumptions. First, there is a model which can predict production performance. Second, there is a history of production where the data are independently and identically distributed. The second assumption is the same which is normally stated to justify the use of nonlinear regression.

The synthetic data sets of production rate are created by resampling the initial history data. A sample is created by picking production data points at a random time to replace others at a random time. Size of synthetic data set equals to the size of initial data set with some points omitted and some duplicated. From the DCA of the synthetic data sets a distribution of either reserves estimates or production forecast is created.

Bootstrapping as a sampling method requires assumption of no time dependency between the data points. However, this is not true for production rate; production data is time dependent and should not be assumed as independent events. This problem was studied by Cheng et al (2010). 


\subsubsection{Overall Workflow}

1) Generate synthetic data set of production rate by randomly picking values from initial data set taking into account time order with some values omitted and some duplicated;

2) Fit selected DCA model to generated synthetic data set and compute all parameters used in the DCA model;

3) Forecast production performance using computed DCA parameters;

4) Repeat steps 1 to 3 until last iteration (recommended number of iterations is no less than 100);

5) Create distribution of reserves and calculate P10, P50 and P50 of this distribution.

\subsubsection{Modified Bootstrap Method}

The Modified Bootstrap Method (MBM) was introduced by Cheng et al. (2010). Both Bootstrap and Modified Bootstrap methods generate different realizations for decline curves to match. MBM creates synthetic data sets based on blocks of residuals obtained from production data and the best fit from any DCA model, which are not time dependent. The residuals are divided into blocks taking into consideration the difference in production data.

A three-step backward analysis technique have been developed to take into account the analysis of transient data. The backward analysis aims to eliminate data that is considered to be in transient flow from generated data sets.

The first, second and third steps of the backward analysis is applying DCA on 50\%, 30\% and $20 \%$ of the most recent synthetic data sets respectively. The values of percentages applied in the backward analysis were estimated, tested and calibrated using data from 
100 conventional mature wells consisting of oil and gas wells with no dramatic changes in production operations or development strategy.

Each step requires 120 realizations. The three steps of backward analysis generate three probability distributions of either reserves estimates or production forecasts. The P90 of the final cumulative density function of either EUR or production forecasts is the minimum P90 from all three distributions from three steps of backward analysis. The P50 is the mean of three P50 values and the P10 is the maximum of three P10 values from all three distributions from the steps of backward analysis.

The MBM method was shown to be well calibrated for both conventional (Cheng et al. 2010) and unconventional reservoirs (Gong et al., 2011). This approach is explained in detail in the journal paper written by Cheng et al. (2011).

\subsubsection{Overall Workflow}

1) Fit selected DCA model to initial data set of production rate and calculate residuals between the fitted model and observed data;

2) Divide constructed residuals into time blocks using autocorrelation function and confidence band;

3) Generate synthetic data set of blocks by randomly taking them with some blocks omitted and some duplicated;

4) Add generated data set of blocks of residuals to originally regressed decline curve model to obtain a new synthetic data set of production;

5) Fit selected DCA to generated synthetic data set model based on three steps backward analysis technique and compute all parameters used in the DCA model;

6) Forecast either production performance or EUR using computed DCA parameters; 
7) Repeat steps 3 to 6 until the last iteration (recommended number of iterations is 120);

8) Create three distributions of reserves and calculate P10, P50 and P50 of this distribution according to three-step backward analysis technique.

\subsection{The Program Description}

\subsubsection{Introduction}

The Probabilistic Production Forecasting (PPF) Software was developed during this research. The program starts with the following window:

Welcome to Probabilistic Production Forecasting (PPF) Software!

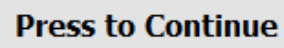

Maksim Nazarenko

Fig. 18-Start Window 
After pressing CONTINUE button, the user sees initial spreadsheet with the MENU table. In this spreadsheet called DATA (Fig. 18) user is able to analyze actual historical data.
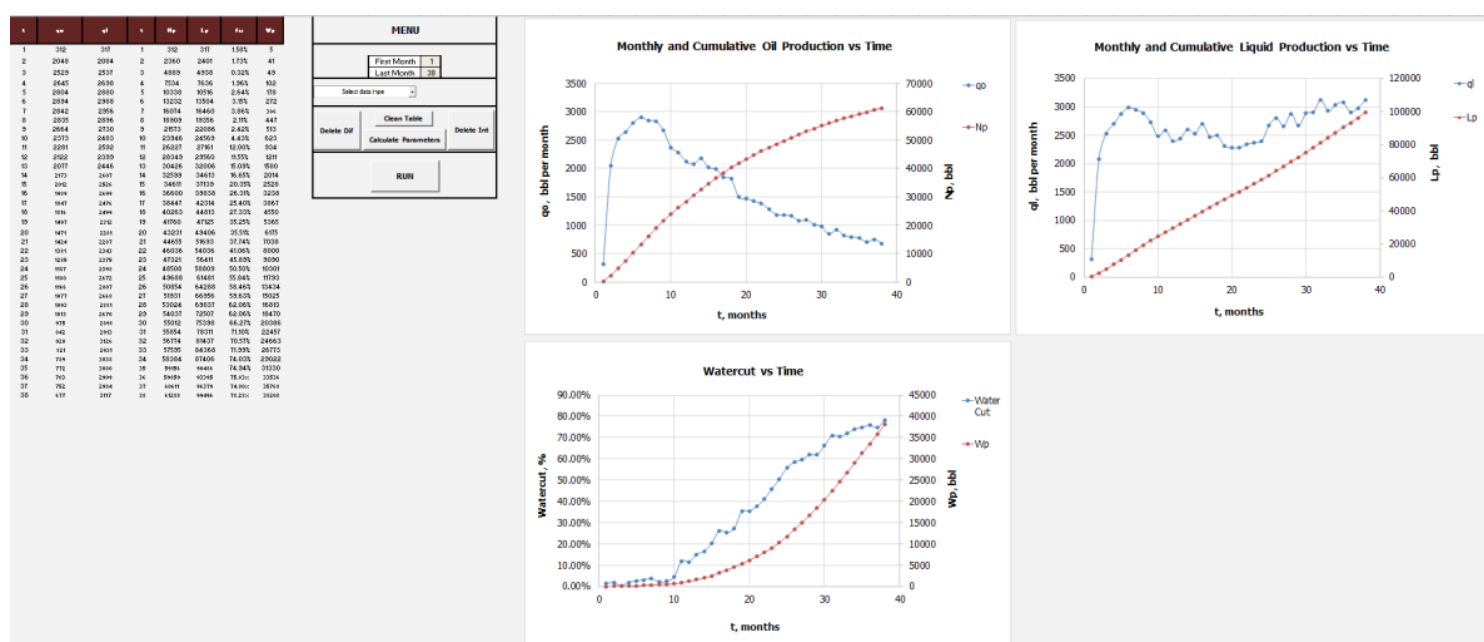

Fig. 19-DATA Spreadsheet (Well A, Wilmington Oil Field)

First, user copies and pastes historical data to the spreadsheet, selects type of the data available (either monthly or cumulative production) and presses CALCULATE PARAMETERS button to calculate the rest of parameters needed for further calculations. Also, three graphs $\left(q_{o}, N_{p}\right.$ or $q_{g}, G_{p}$ vs $\left.t ; q_{l}, L_{p} v s t ; f_{w}, W_{p} v s t\right)$ will be plotted to analyze historical production data.

To get started, RUN button should be pressed. The Initial Information window appears (Fig. 19). There are two main categories: Fluid (Oil or Gas) and Type of Field (Conventional or Shale/Tight Formation), and one subcategory for Conventional Field only (Waterflooding/Aquifer or no Waterflooding/Aquifer). 


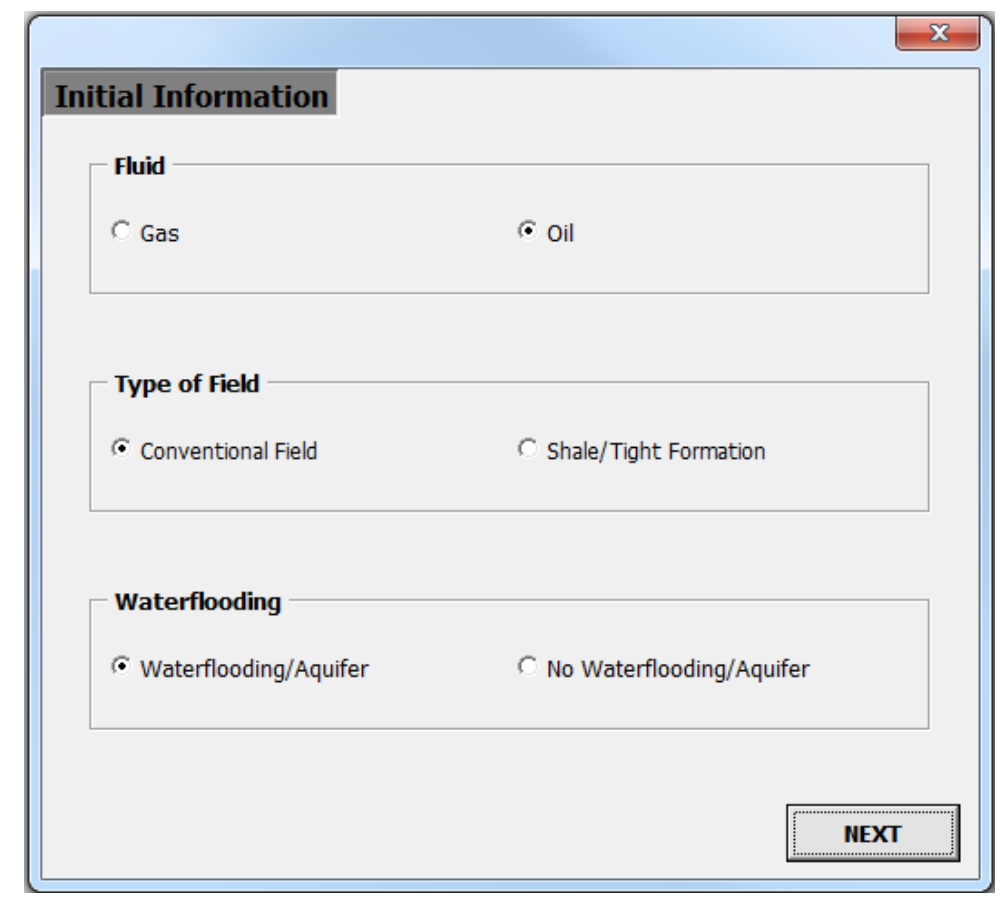

Fig. 20-Initial Information Window

Depending on the selected option, the user goes through one of two possible scenarios. The first scenario is for conventional (no waterflooding) and unconventional fields. The second scenario is for conventional oil fields with either waterflooding or presence of strong aquifer influx.

\subsubsection{First Scenario}

In the first scenario user has INPUTS and DCA OPTIONS windows (Fig. 20). In INPUTS window user selects procedure (Forecast or Hindcast), Interval of unknown history (for Hindcast only) and Period of history matching and Limits (for Forecast only). It is also possible to use production data from either one or more than one well. 


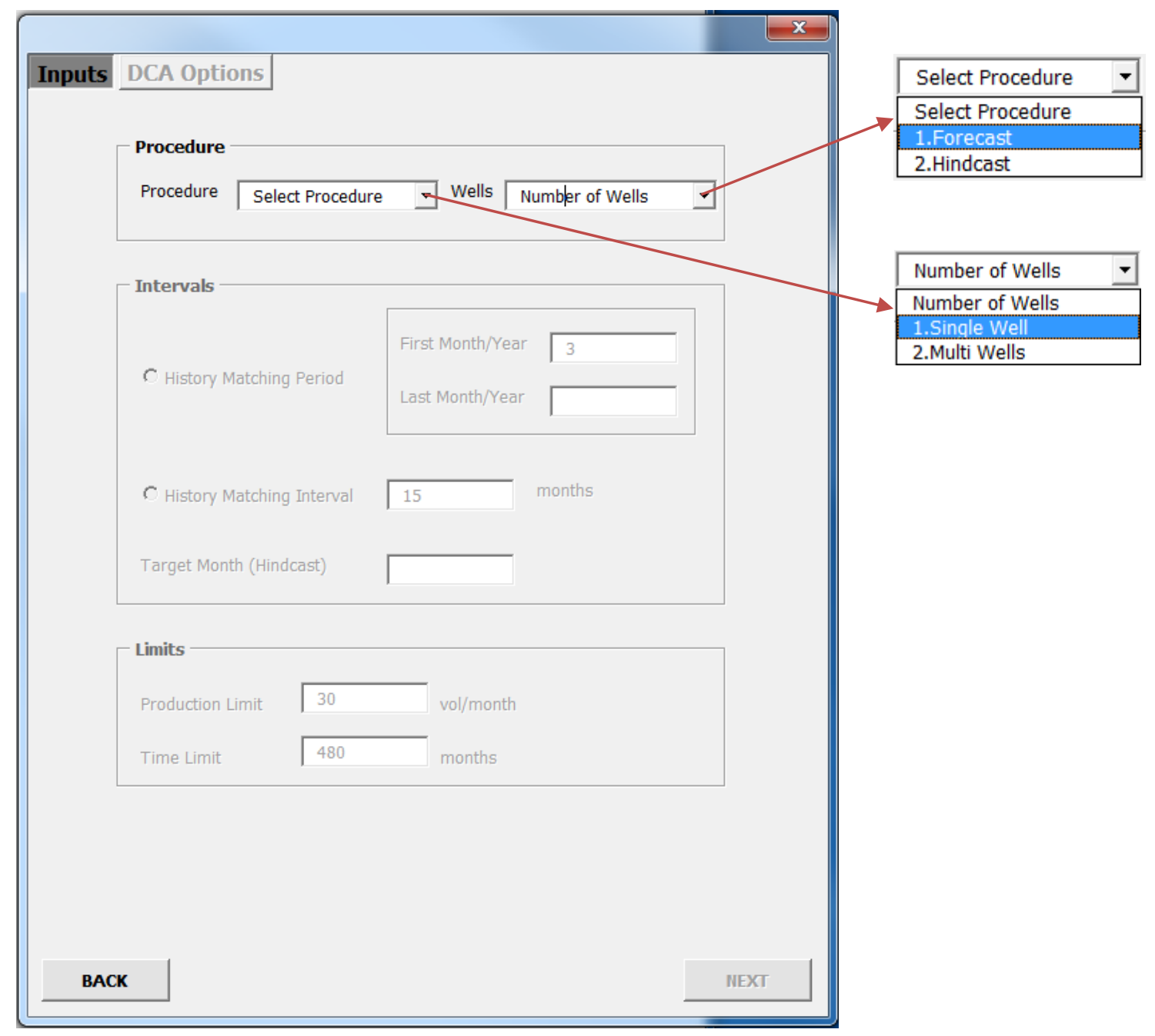

Fig. 21-First Scenario, First Window

In the DCA OPTIONS (Fig. 21) window, the user selects type of methodology (Deterministic or Probabilistic), DCA option (Single or Best Model) and one out of four Probabilistic methods. By selecting Best Model the user tells the program to automatically define best DCA model among all that are applied in the software according to fit error, 
$\delta_{D C A}$ (Eq. 2.44). After that, the program can use the model to do either forecasting or hindcasting using either deterministic or probabilistic methodology.

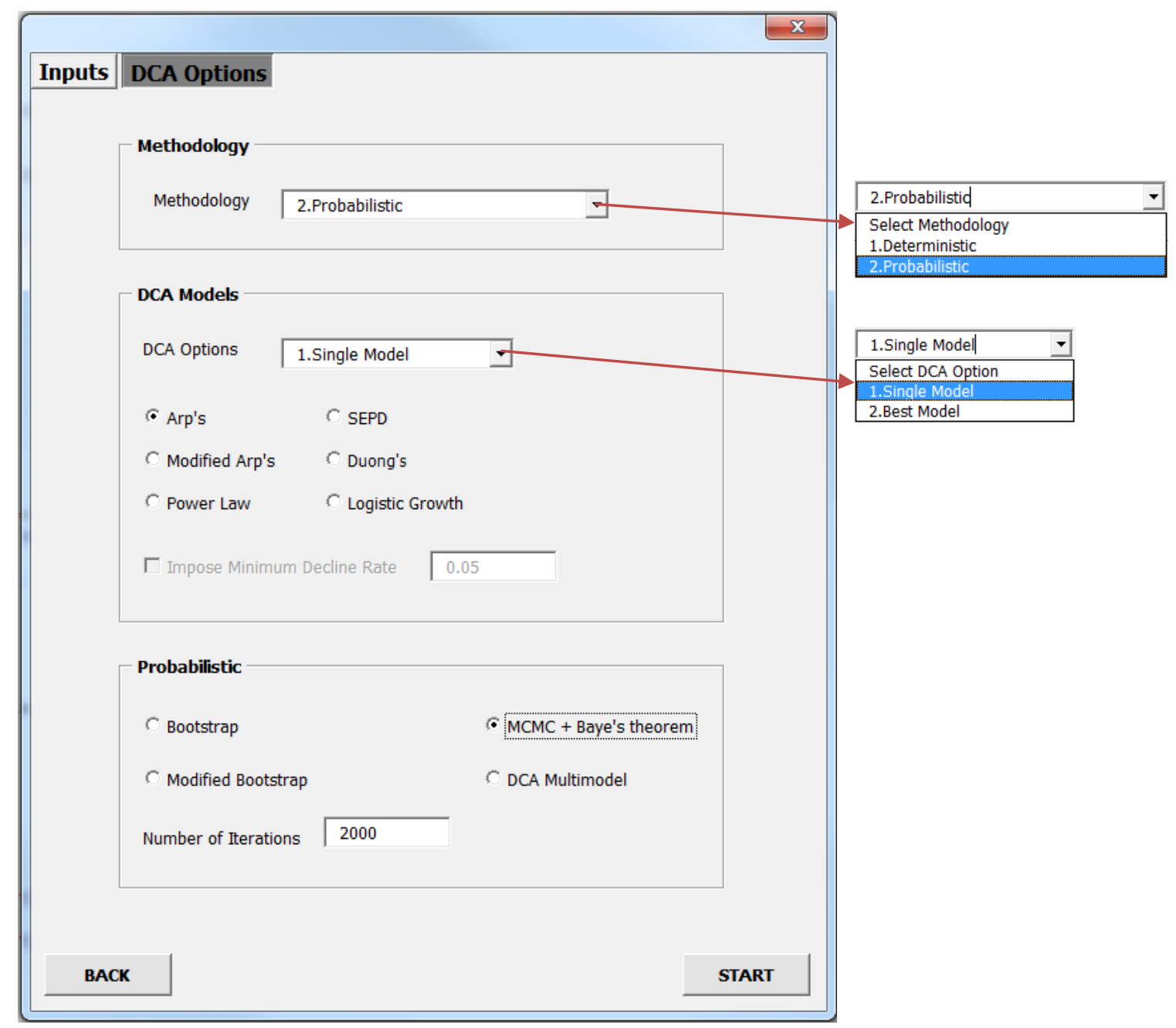

Fig. 22—First Scenario, Second Window 


\subsubsection{Second Scenario}

In the second scenario there are three windows: INPUTS (Fig. 22), DCA OPTIONS (Fig. 23) and WDC OPTIONS (Fig. 24).

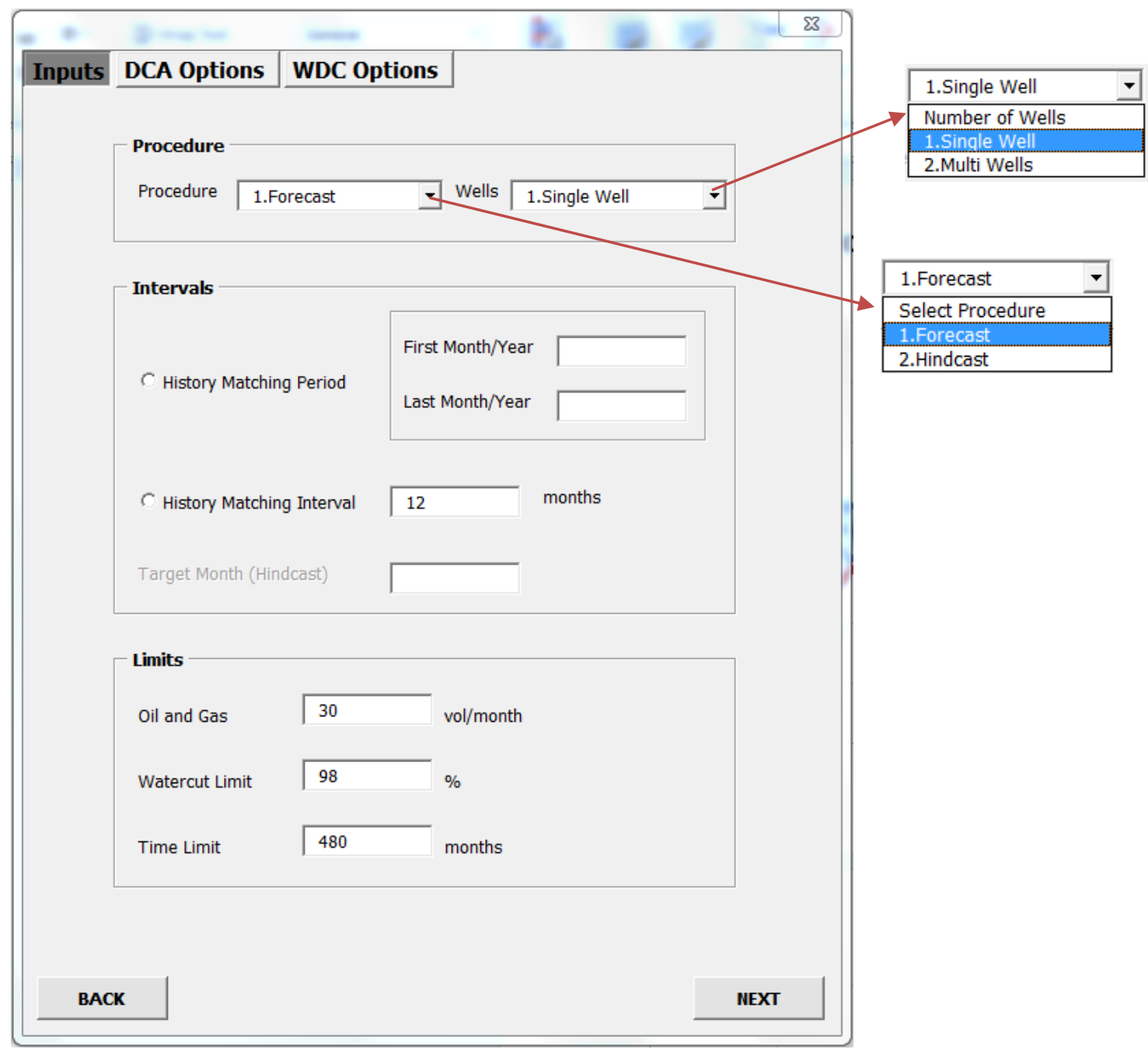

Fig. 23-Second Scenario, First Window 
The only difference between DCA OPTIONS window of the first and second scenarios is that the number of available DCA models are different in each case. Also, in the second scenario watercut limit and liquid production are taken into account during calculations.

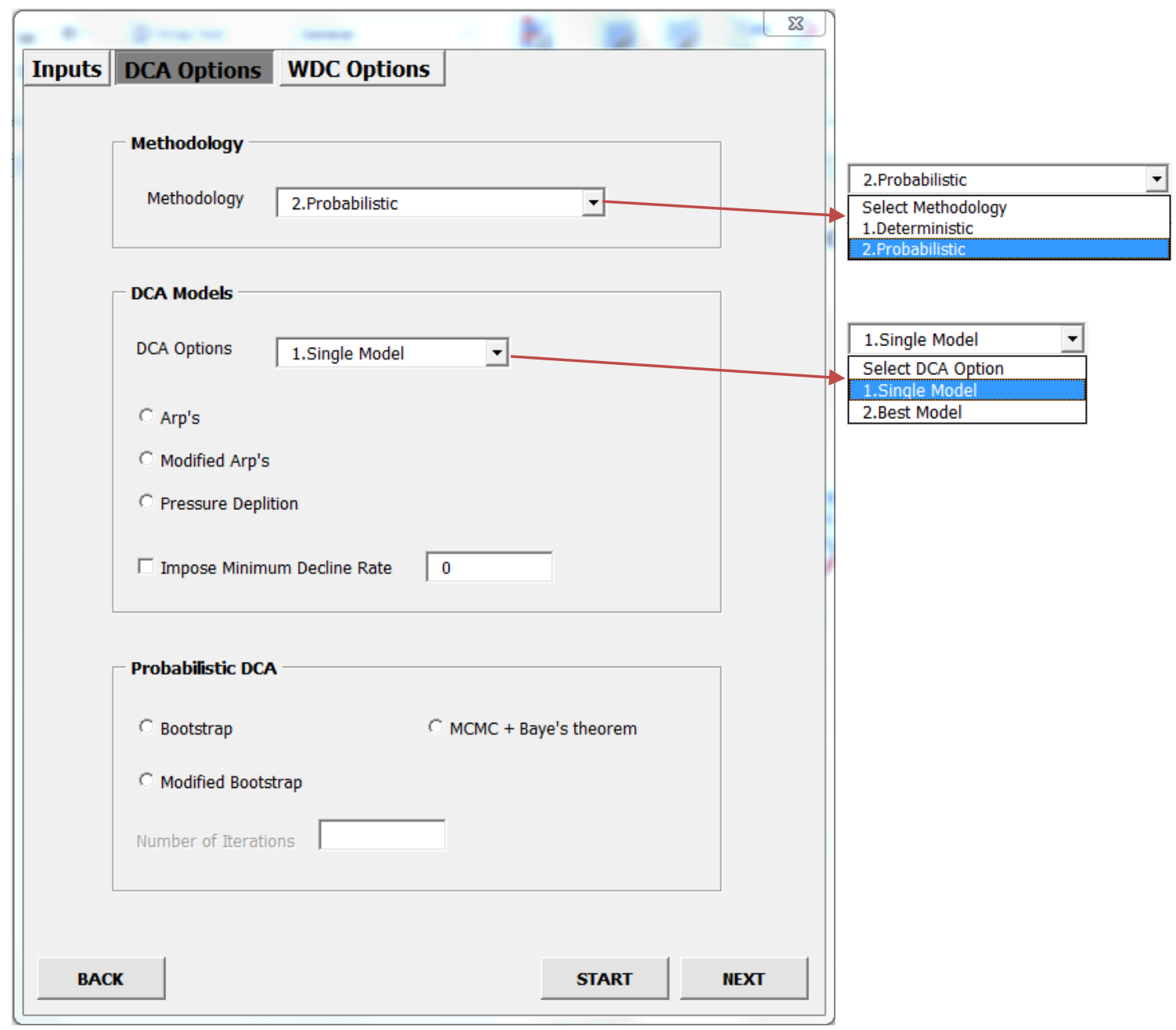

Fig. 24 Second Scenario, Second Window

WDC OPTIONS window allows to use WDC models to forecast production performance and estimate reserves in case of waterflooded oil fields using either a single model or the 
best model defined according to fit error, $\delta_{D C A}$, (Eq. 2.44) with either deterministic or one of two probabilistic methods.

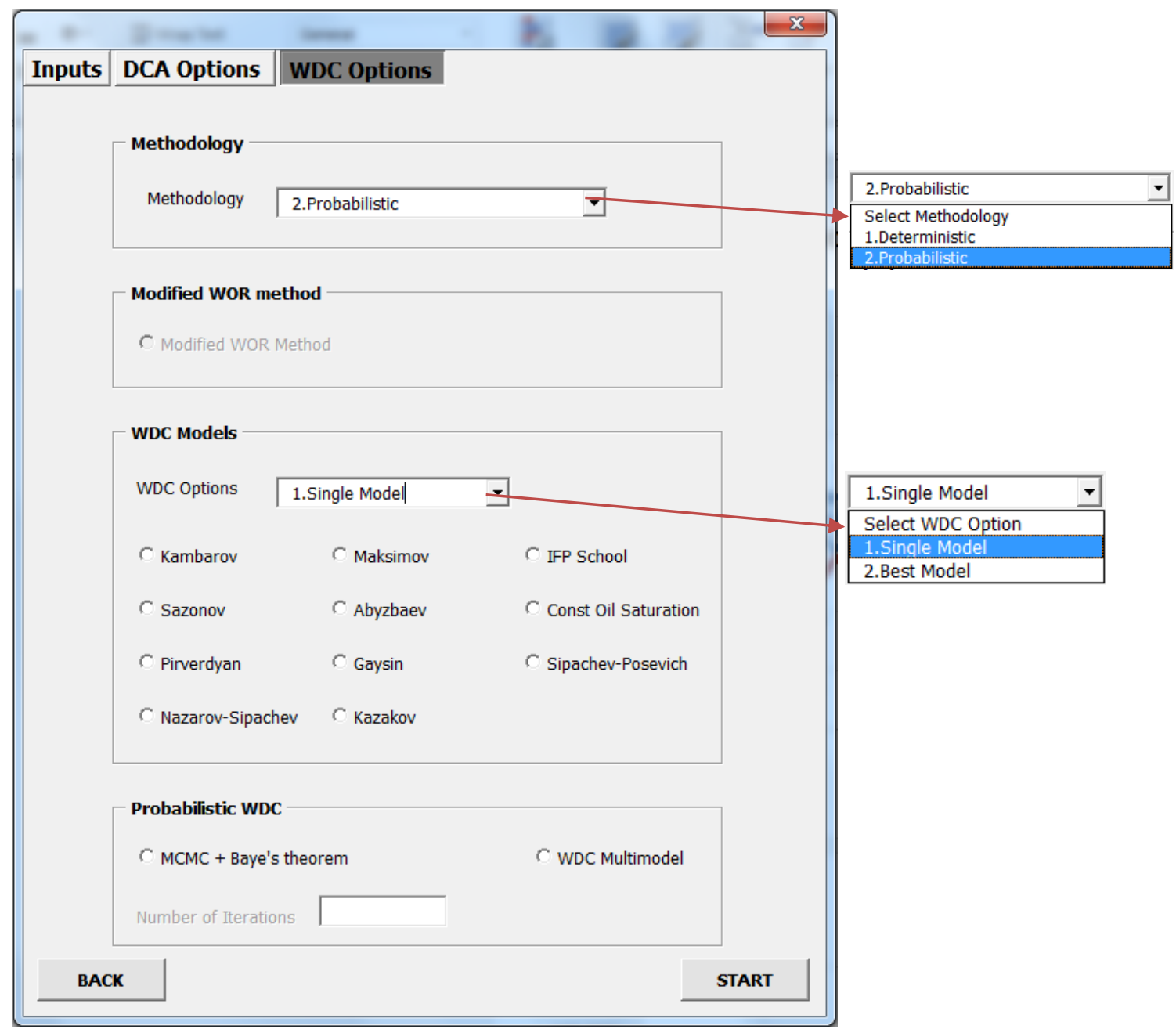

Fig. 25-Second Scenario, Third Window

During the process of calculations the window PROGRESS is shown on the screen (Fig. 25), 


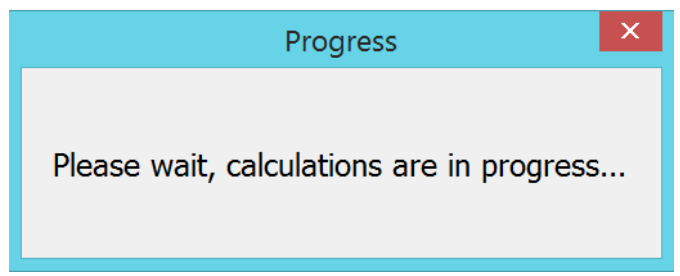

Fig. 26-Progress Window

At the end of the calculations, the user will be informed about ending the procedure by appearance of the following message box (Fig. 26),

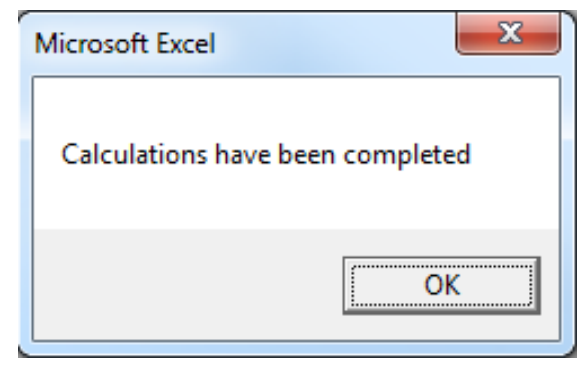

Fig. 27-Message Box

After pressing OK, spreadsheet with the results appears on the screen (Fig. 27). 


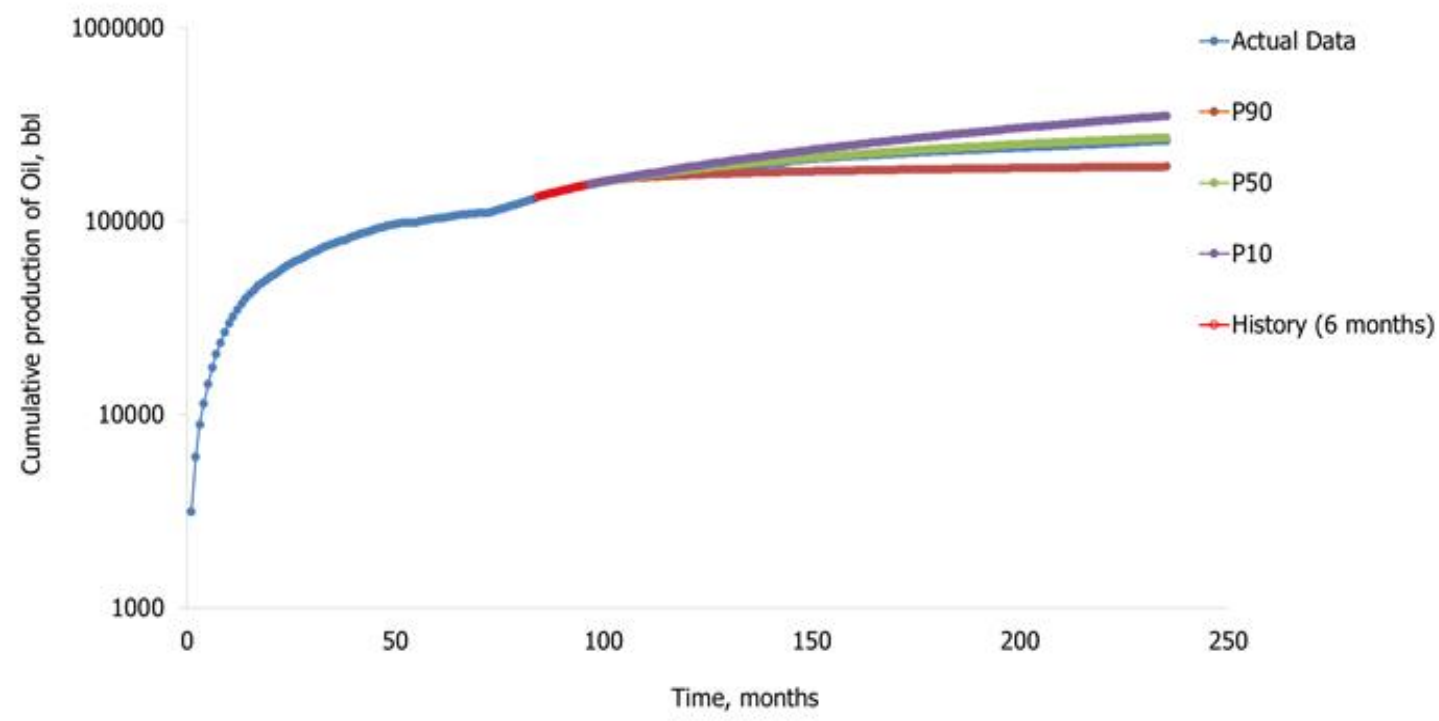

Fig. 28-Example of Result Graph, MCMC with WDC (Hindcast) (Well A, Wilmington Oil Field)

The following schemes (Fig. 28 and Fig. 29) represent all possible options previously described in this section. 


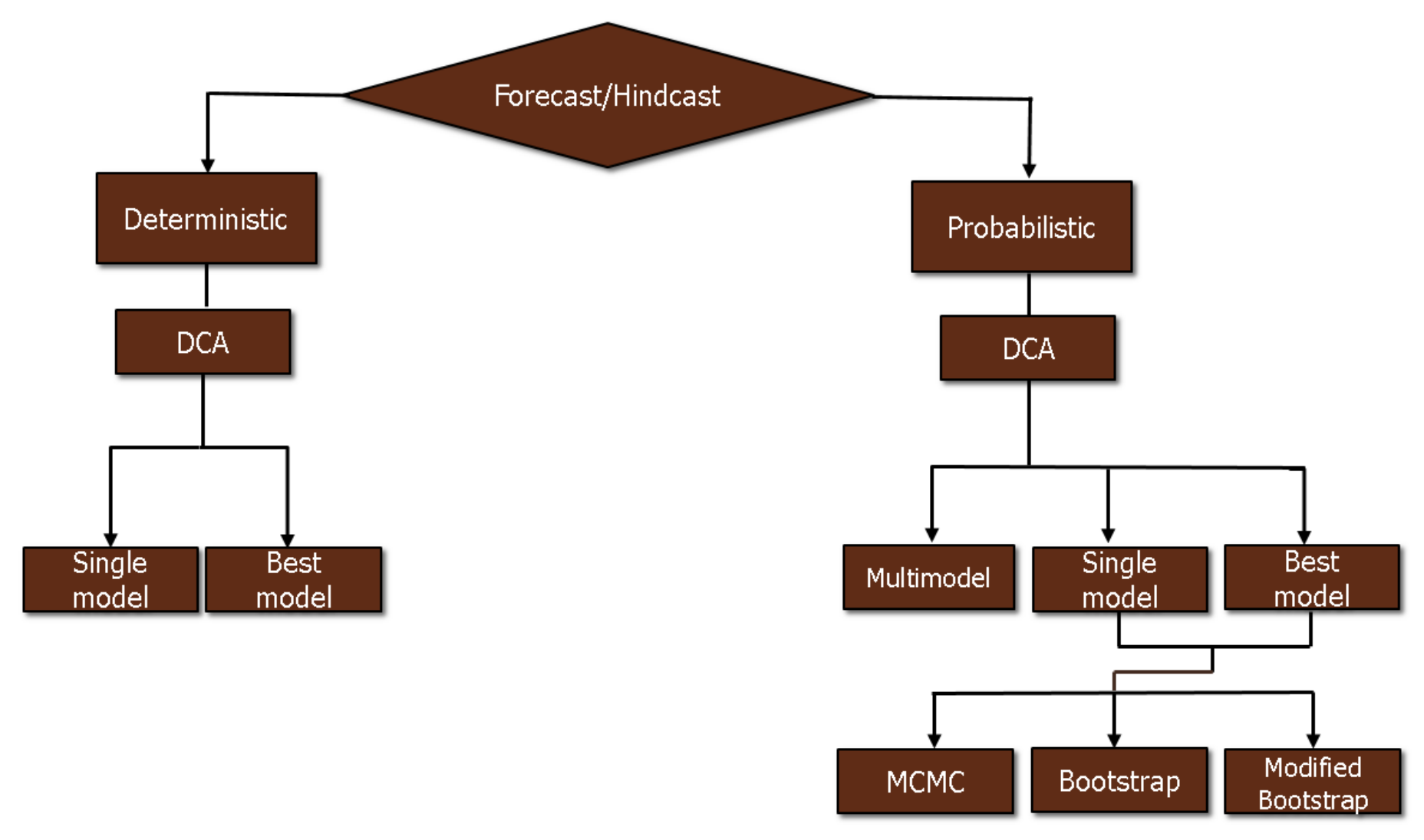

Fig. 29-Scheme of "No Water Production" Scenario 


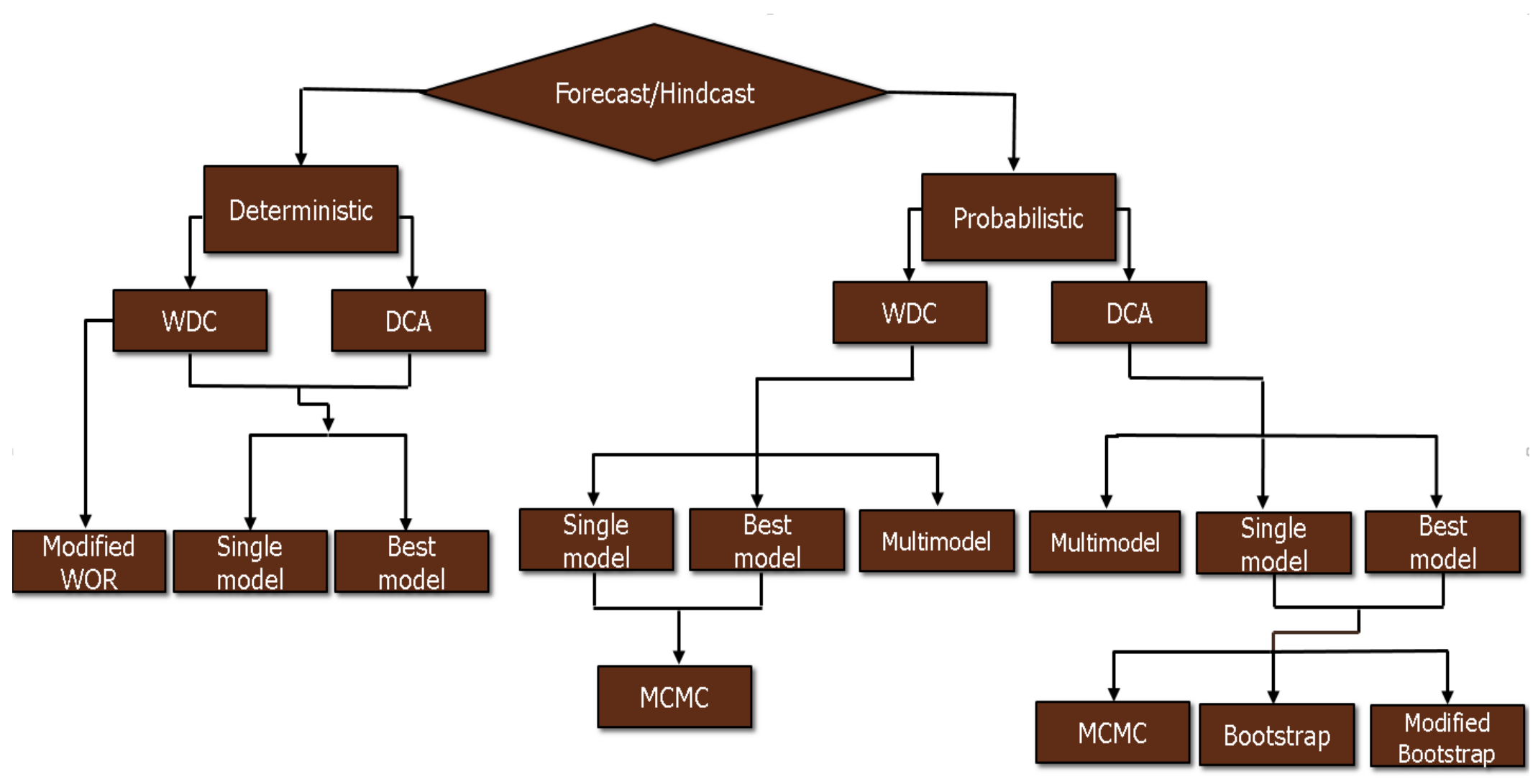

Fig. 30 - Scheme of "Water Production" Scenario 


\section{CASE STUDY}

\subsection{Case Study: Wilmington and Kumkol Waterflooded Oil Fields}

The objective of the study is to calibrate and assess reliability of both multimodel and MCMC-based WDC methods using production data from waterflooded oil fields.

I selected 100 wells for the study. Some wells were restimulated; that is why for these wells the longest production period without any restimulations (the interval starting either from initial production date or from the first date of production after restimulation) was used for the hindcast (Fig. 30). WDC model can be used only when watercut level is more than $30 \%$; thus, all selected wells had at least $30 \%$ of watercut in history matching period (Fig. 31).

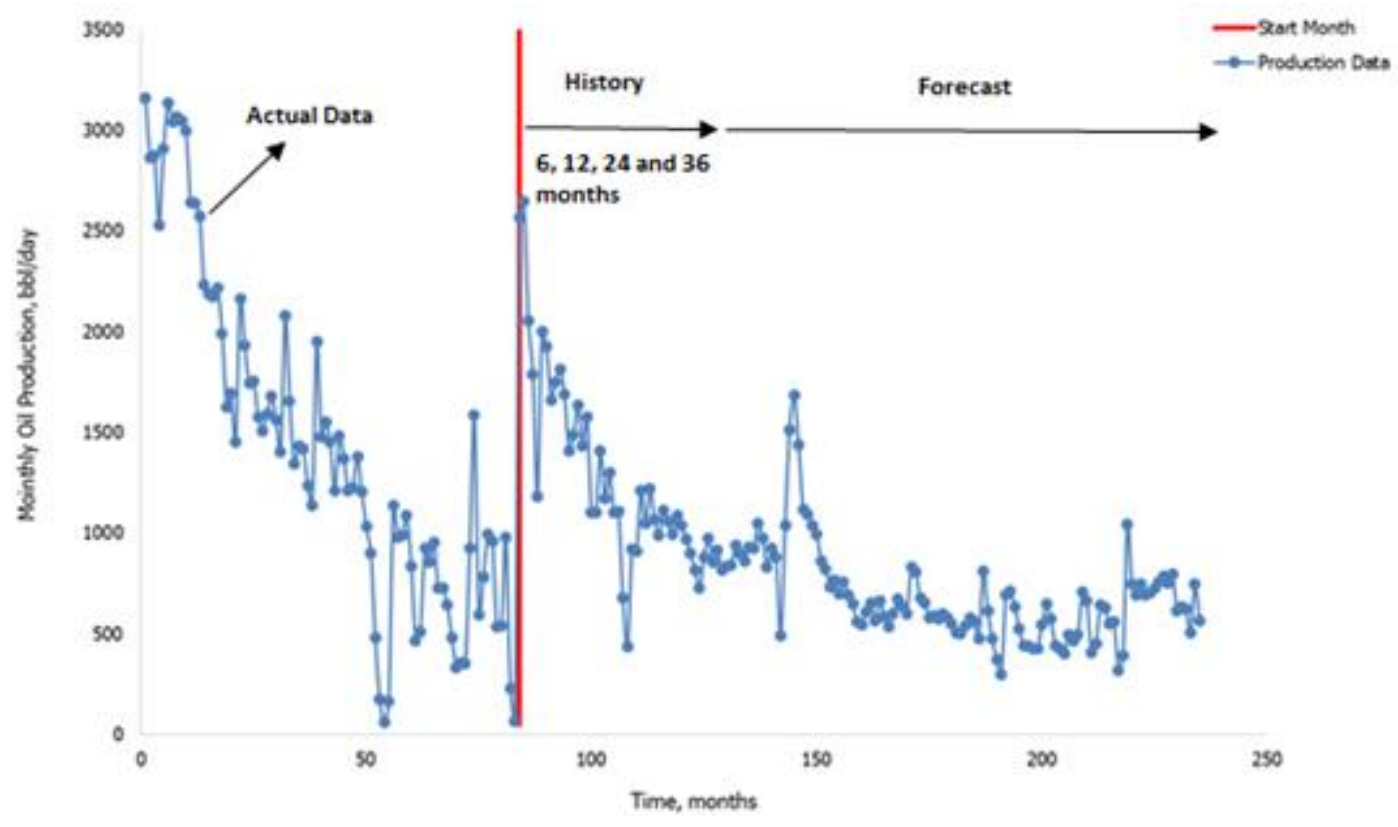

Fig. 31—Monthly Oil Production vs. Time (Well A, Wilmington Oil Field) 


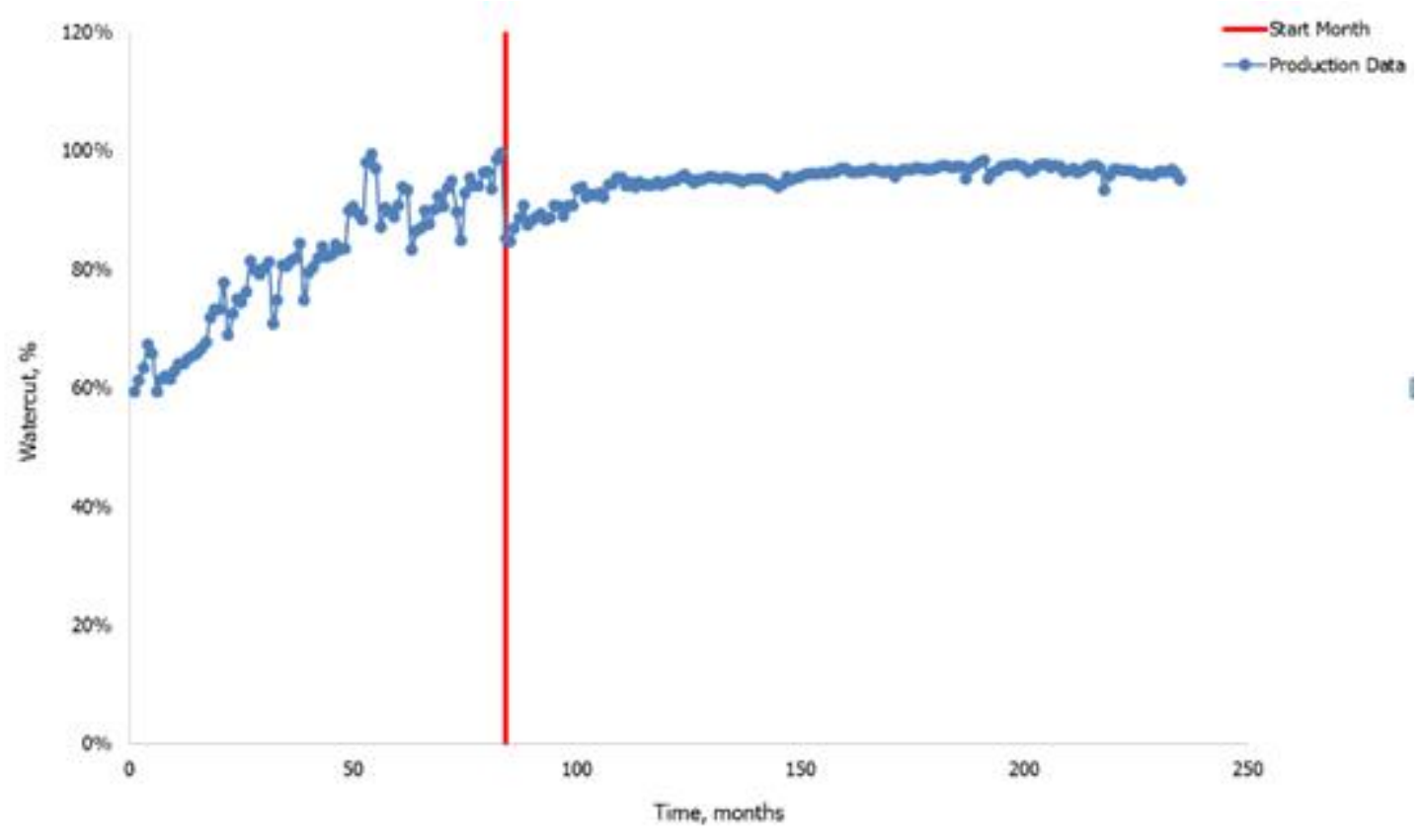

Fig. 32—Watercut vs. Time (Well A, Wilmington Oil Field)

I selected two fields, Wilmington and Kumkol, for this case study because they are mature and have long production histories. I executed a hindcast of 100 wells in which I used four different history matching (approximation) periods: 6, 12, 24 and 36 months, and from five to twelve years of forecast.

I matched assumed-as-known production periods and forecasted production to the last month of the actual history. Both total cumulative production (TCP) at the end of the hindcast and cumulative production of hindcast period (CPOHP) were computed and compared to the actual cumulative production values, verifying reliability of the examined methodologies. TCP includes the whole period from month 1 and CPOHP includes only forecasted cumulative production during hindcast period. 


\subsection{Results}

For each of four history matching periods using each probabilistic method I obtained three scenarios of hindcast: pessimistic (P90), most likely (P50) and optimistic (P10) (Fig. 32, Fig. 33 and Fig. 34).

Table 13 and Table 14 show all parameters involved in testing MCMC with WDC, WDC Multimodel and MCMC with DCA methods.

Fig. 35, Fig. 36 and Fig. 37 show Calibrations Plots which represent Percentages of True values more than or equal to P10, P50 and P90. Fig. 38, Fig. 39 and Fig. 40 show plots which represent Average Relative Error (Eq. 5.1). Fig. 41, Fig. 42 and Fig. 43 show plots which represent Average Relative Range (Eq. 5.2). 
Table 13-Results of Probabilistic Methods, TCP

\begin{tabular}{|c|c|c|c|c|}
\hline $\begin{array}{l}\text { History } \\
\text { Matching } \\
\text { Period, } \\
\text { months }\end{array}$ & Parameters & $\begin{array}{c}\text { WDC } \\
\text { Multimodel }\end{array}$ & $\begin{array}{c}\text { MCMC with } \\
\text { WDC }\end{array}$ & MCMC with DCA \\
\hline 6 & 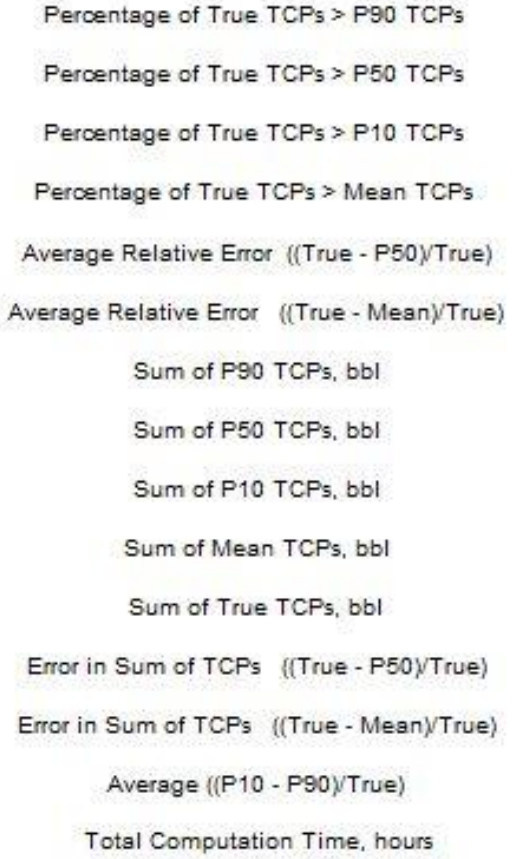 & $\begin{array}{c}5 \% \\
97 \% \\
- \\
4 \% \\
- \\
75678327 \\
150139100 \\
- \\
3 \% \\
0.33\end{array}$ & $\begin{array}{c}14 \% \\
60 \% \\
93 \% \\
51 \% \\
6 \% \\
6 \% \\
77251839 \\
89429221 \\
103389678 \\
89143686 \\
87644588 \\
2 \% \\
2 \% \\
0.26 \\
5\end{array}$ & $\begin{array}{c}42 \% \\
78 \% \\
92 \% \\
81 \% \\
11 \% \\
12 \% \\
84711192 \\
95803853 \\
107985867 \\
98618725 \\
9.24 \\
3.5 \\
13 \% \\
0 \%\end{array}$ \\
\hline 12 & $\begin{array}{c}\text { Percentage of True TCPs > P90 TCPs } \\
\text { Percentage of True TCPs > P50 TCPs } \\
\text { Percentage of True TCPs > P10 TCPs } \\
\text { Percentage of True TCPs > Mean TCPs } \\
\text { Average Relative Error ((True - P50)/True) } \\
\text { Average Relative Error ((True - Mean)/True) } \\
\text { Sum of P90 TCPs, bbl } \\
\text { Sum of P50 TCPs, bbl } \\
\text { Sum of P10 TCPs, bbl } \\
\text { Sum of Mean TCPs, bbl } \\
\text { Sum of True TCPs, bbl } \\
\text { Error in Sum of TCPs ((True - P50yTrue) } \\
\text { Error in Sum of TCPs ((True - Mean } / \text { True) } \\
\text { Total Computation Time, hours }\end{array}$ & $\begin{array}{c}11 \% \\
54 \% \\
95 \% \\
- \\
3 \% \\
- \\
77177230 \\
85139848 \\
104986237 \\
-\end{array}$ & $\begin{array}{l}14 \% \\
95 \% \\
50 \% \\
4 \% \\
4 \% \\
80353981 \\
87467603 \\
98857138 \\
87409358 \\
87644588 \\
0.2 \% \\
0.3 \% \\
0.18 \\
5\end{array}$ & $\begin{array}{c}25 \% \\
84 \% \\
94 \% \\
76 \% \\
6 \% \\
7 \% \\
81980456 \\
91903699 \\
103259591 \\
94528457\end{array}$ \\
\hline
\end{tabular}


Table 13-continued

\begin{tabular}{|c|c|c|c|c|}
\hline $\begin{array}{l}\text { History } \\
\text { Matching } \\
\text { Period, } \\
\text { months }\end{array}$ & Parameters & $\begin{array}{c}\text { WDC } \\
\text { Multimodel }\end{array}$ & $\begin{array}{l}\text { MCMC with } \\
\text { WDC }\end{array}$ & MCMC with DCA \\
\hline 24 & $\begin{array}{c}\text { Percentage of True TCPs > P90 TCPs } \\
\text { Percentage of True TCPs > P50 TCPs } \\
\text { Percentage of True TCPs > P10 TCPs } \\
\text { Percentage of True TCPs > Mean TCPs } \\
\text { Average Relative Error ((True - P50)/True) } \\
\text { Average Relative Error ((True - Mean)/True) } \\
\text { Sum of P90 TCPs, bbl } \\
\text { Sum of P50 TCPs, bbl } \\
\text { Sum of P10 TCPs, bbl } \\
\text { Sum of Mean TCPs, bbl } \\
\text { Sum of True TCPs, bbl } \\
\text { Error in Sum of TCPs ((True - P50)/True) } \\
\text { Arror in Sum of TCPs ((True - Mean)/True) } \\
\text { Total Computation Time, hours }\end{array}$ & $\begin{array}{c}8 \% \\
51 \% \\
93 \% \\
- \\
3 \% \\
- \\
78911673 \\
84559059 \\
95843945 \\
-\end{array}$ & $\begin{array}{c}12 \% \\
48 \% \\
85 \% \\
43 \% \\
2 \% \\
3 \% \\
80894342 \\
84428801 \\
90294018 \\
84230712 \\
87844588 \\
4 \% \\
4 \% \\
0.11 \\
5\end{array}$ & $\begin{array}{c}11 \% \\
54 \% \\
90 \% \\
69 \% \\
2 \% \\
3 \% \\
81316378 \\
88584671 \\
98007758 \\
90863153\end{array}$ \\
\hline 36 & 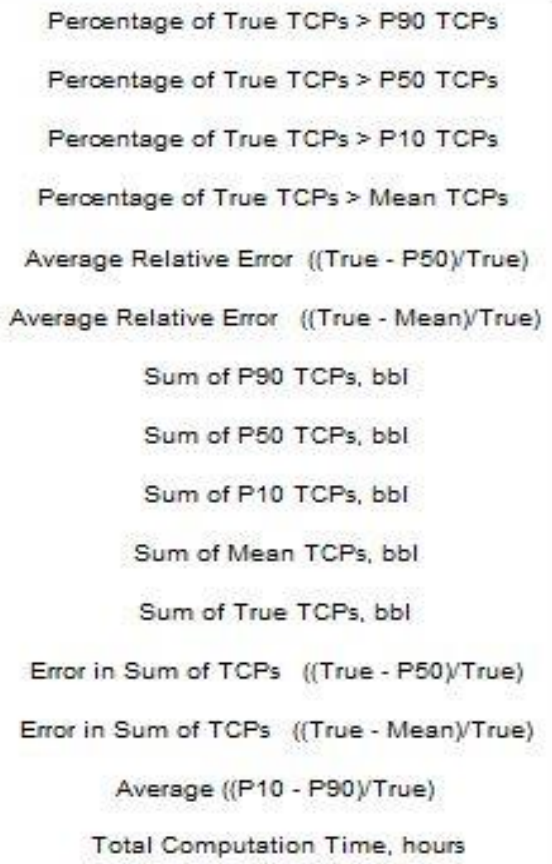 & $\begin{array}{c}13 \% \\
50 \% \\
91 \% \\
- \\
3 \% \\
- \\
80793524 \\
85184245 \\
93540554 \\
-\end{array}$ & $\begin{array}{c}15 \% \\
49 \% \\
81 \% \\
47 \% \\
3 \% \\
2 \% \\
82331709 \\
85293621 \\
92698474 \\
85672332 \\
87644588 \\
3 \% \\
2 \% \\
0.11 \\
5\end{array}$ & $\begin{array}{c}15 \% \\
55 \% \\
88 \% \\
68 \% \\
1 \% \\
1 \% \\
82918798 \\
88417083 \\
96550074 \\
90527705\end{array}$ \\
\hline
\end{tabular}


Table 14-Results of Probabilistic Methods, CPOHP

\begin{tabular}{|c|c|c|c|c|}
\hline $\begin{array}{l}\text { History } \\
\text { Matching } \\
\text { Period, } \\
\text { months }\end{array}$ & Parameters & WDC Multimodel & MCMC with WDC & MCMC with DCA \\
\hline 6 & $\begin{array}{c}\text { Percentage of True CPOHPs > P90 CPOHPs } \\
\text { Percentage of True CPOHPs > P50 CPOHPs } \\
\text { Percentage of True CPOHPs > P10 CPOHPs } \\
\text { Percentage of True CPOHPs > Mean CPOHPs } \\
\text { Average Relative Error ((True - P50)/ True) } \\
\text { Average Relative Error ((True - Mean) / True) } \\
\text { Sum of P90 CPOHPs, bbl } \\
\text { Sum of P50 CPOHPs, bbl } \\
\text { Sum of P10 CPOHPs, bbl } \\
\text { Sum of Mean CPOHPs, bbl } \\
\text { Sum of True CPOHPs, bbl } \\
\text { Aversge ((P10 - P90)/ True) } \\
\text { Total Computation Time, hours }\end{array}$ & $\begin{array}{c}8 \% \\
54 \% \\
9 \% \\
- \\
11259768 \\
805990 \\
- \\
1122541 \\
1.13\end{array}$ & $\begin{array}{c}14 \% \\
60 \% \\
93 \% \\
51 \% \\
17 \% \\
17 \% \\
12835280 \\
25012882 \\
38973119 \\
24727127 \\
23228029 \\
8 \% \\
6 \% \\
0.97 \\
0.3\end{array}$ & $\begin{array}{c}42 \% \\
78 \% \\
92 \% \\
81 \% \\
31 \% \\
33 \% \\
20294633 \\
31387294 \\
43549308 \\
34200186 \\
\\
35 \% \\
47 \% \\
0.97 \\
3.5\end{array}$ \\
\hline 12 & $\begin{array}{c}\text { Percentage of True CPOHPs > P90 CPOHPs } \\
\text { Percentage of True CPOHPs > P50 CPOHPs } \\
\text { Percentage of True CPOHPs > P10 CPOHPs } \\
\text { Percentage of True CPOHPs > Mean CPOHPs } \\
\text { Average Relative Error ((True - P50)/ True) } \\
\text { Average Relative Error ((True - Mean) / True) } \\
\text { Sum of P90 CPOHPs, bbl } \\
\text { Sum of P50 CPOHPs, bbl } \\
\text { Sum of P10 CPOHPs, bbl } \\
\text { Sum of Mean CPOHPs, bbl } \\
\text { Sum of True CPOHPs, bbl } \\
\text { Error in Sum of CPOHPs ((True - P50)/ True) } \\
\text { Error in Sum of CPOHPs ((True - Mean) / True) } \\
\text { Average ((P10 - P90) / True) }\end{array}$ & $\begin{array}{c}11 \% \\
54 \% \\
95 \% \\
8 \% \\
- \\
9900025 \\
17862643 \\
37689032 \\
-\end{array}$ & $\begin{array}{c}14 \% \\
55 \% \\
50 \% \\
13 \% \\
13 \% \\
13076757 \\
20190398 \\
29579932 \\
20132153 \\
20367383 \\
1 \% \\
1 \% \\
0.83 \\
0.3\end{array}$ & $\begin{array}{c}25 \% \\
64 \% \\
94 \% \\
76 \% \\
19 \% \\
21 \% \\
14703251 \\
24626495 \\
35982386 \\
27251253\end{array}$ \\
\hline
\end{tabular}


Table 14-continued

\begin{tabular}{|c|c|c|c|c|}
\hline $\begin{array}{c}\text { History } \\
\text { Matching } \\
\text { Period, } \\
\text { months }\end{array}$ & Parameters & WDC Multimodel & MCMC with WDC & MCMC with DCA \\
\hline 24 & $\begin{array}{c}\text { Percentage of True CPOHPs > P90 CPOHPs } \\
\text { Percentage of True CPOHPs > P50 CPOHPs } \\
\text { Percentage of True CPOHPs > P10 CPOHPs } \\
\text { Percentage of True CPOHPs > Mean CPOHPs } \\
\text { Average Relative Error ((True - P50)/ True) } \\
\text { Average Relative Error ((True - Mean) / True) } \\
\text { Sum of P90 CPOHPs, bbl } \\
\text { Sum of P50 CPOHPs, bbl } \\
\text { Sum of P10 CPOHPs, bbl } \\
\text { Sum of Mean CPOHPs, bbl } \\
\text { Sum of True CPOHPs, bbl } \\
\text { Error in Sum of CPOHPs ((True - P50)/ True) } \\
\text { Error in Sum of CPOHPs ((True - Mean }) / \text { True) } \\
\text { Total Computation Time, hours }\end{array}$ & $\begin{array}{c}5 \% \\
93 \% \\
- \\
7 \% \\
- \\
7343624 \\
24075898 \\
- \\
12910 \\
0.93\end{array}$ & $\begin{array}{c}12 \% \\
48 \% \\
85 \% \\
43 \% \\
7 \% \\
9 \% \\
9326293 \\
12858752 \\
18725989 \\
12682863 \\
18076539 \\
20 \% \\
21 \% \\
0.79 \\
0.3\end{array}$ & $\begin{array}{c}11 \% \\
54 \% \\
90 \% \\
69 \% \\
8 \% \\
13 \% \\
9748329 \\
16998622 \\
26439706 \\
19295104 \\
6 \% \\
20 \% \\
0.90 \\
3.5\end{array}$ \\
\hline 36 & $\begin{array}{c}\text { Percentage of True CPOHPs > P90 CPOHPs } \\
\text { Percentage of True CPOHPs > P50 CPOHPs } \\
\text { Percentage of True CPOHPs > P10 CPOHPs } \\
\text { Percentage of True CPOHPs > Mean CPOHPs } \\
\text { Average Relative Error ((True - P50)/ True) } \\
\text { Average Relative Error ((True - Mean)/ True) } \\
\text { Sum of P90 CPOHPs, bbl } \\
\text { Sum of P50 CPOHPs, bbl } \\
\text { Sum of P10 CPOHPs, bbl } \\
\text { Sum of Mean CPOHPs, bbl } \\
\text { Sum of True CPOHPs, bbl } \\
\text { Error in Sum of CPOHPs ((True - P50) / True) } \\
\text { Error in Sum of CPOHPs ((True - Mean)/ True) } \\
\text { Total Computation Time, hours }\end{array}$ & $\begin{array}{c}13 \% \\
50 \% \\
91 \% \\
- \\
7 \% \\
5436536 \\
9827257 \\
18183587 \\
- \\
20 \% \\
-\end{array}$ & $\begin{array}{c}15 \% \\
49 \% \\
81 \% \\
47 \% \\
7 \% \\
36 \% \\
6974722 \\
9938634 \\
17341487 \\
10315344 \\
12287601 \\
19 \% \\
16 \% \\
0.79 \\
0.3\end{array}$ & $\begin{array}{c}15 \% \\
55 \% \\
88 \% \\
68 \% \\
5 \% \\
33 \% \\
7561811 \\
13080098 \\
21193087 \\
15170718 \\
6 \% \\
23 \% \\
0.82 \\
3.5\end{array}$ \\
\hline
\end{tabular}




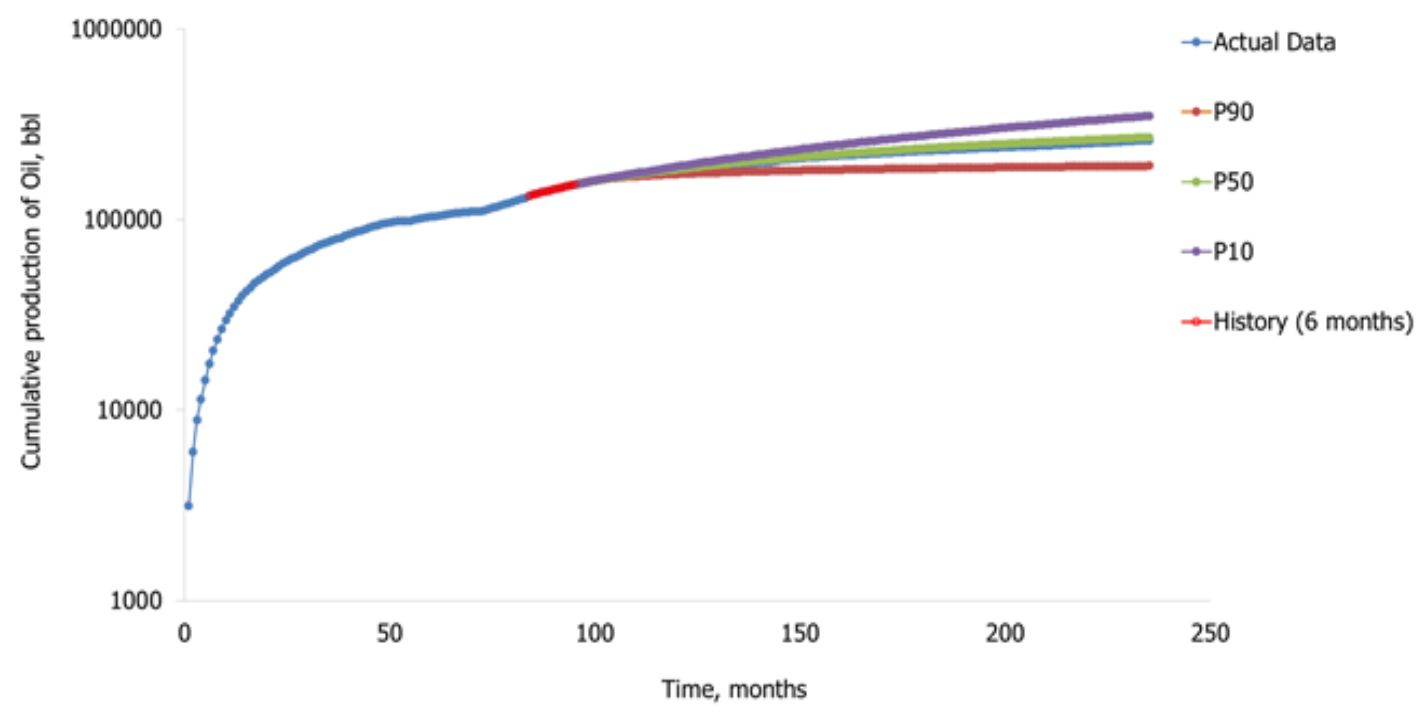

Fig. 33 — Probabilistic Hindcast, MCMC with WDC, Well A (Wilmington Oil Field)

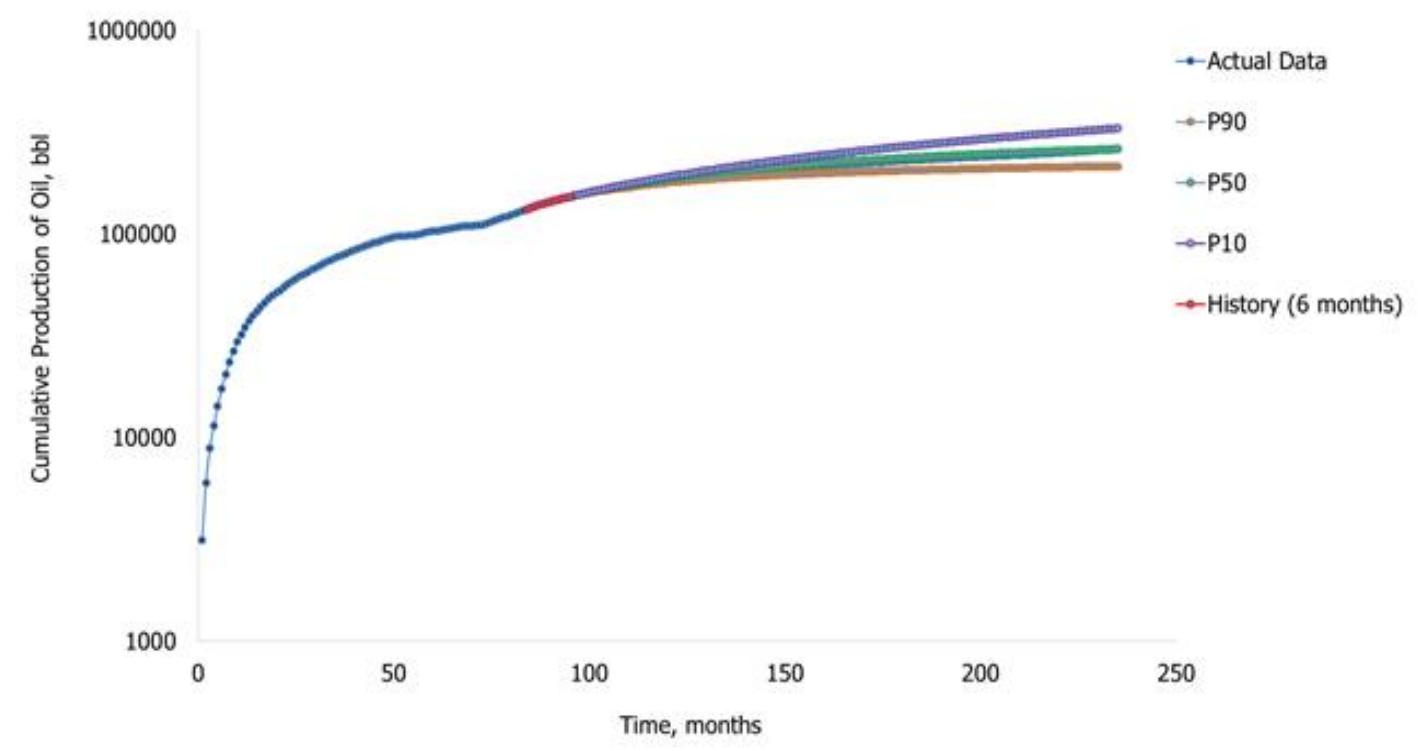

Fig. 34-Probabilistic Hindcast, WDC Multimodel, Well B (Wilmington Oil Field) 


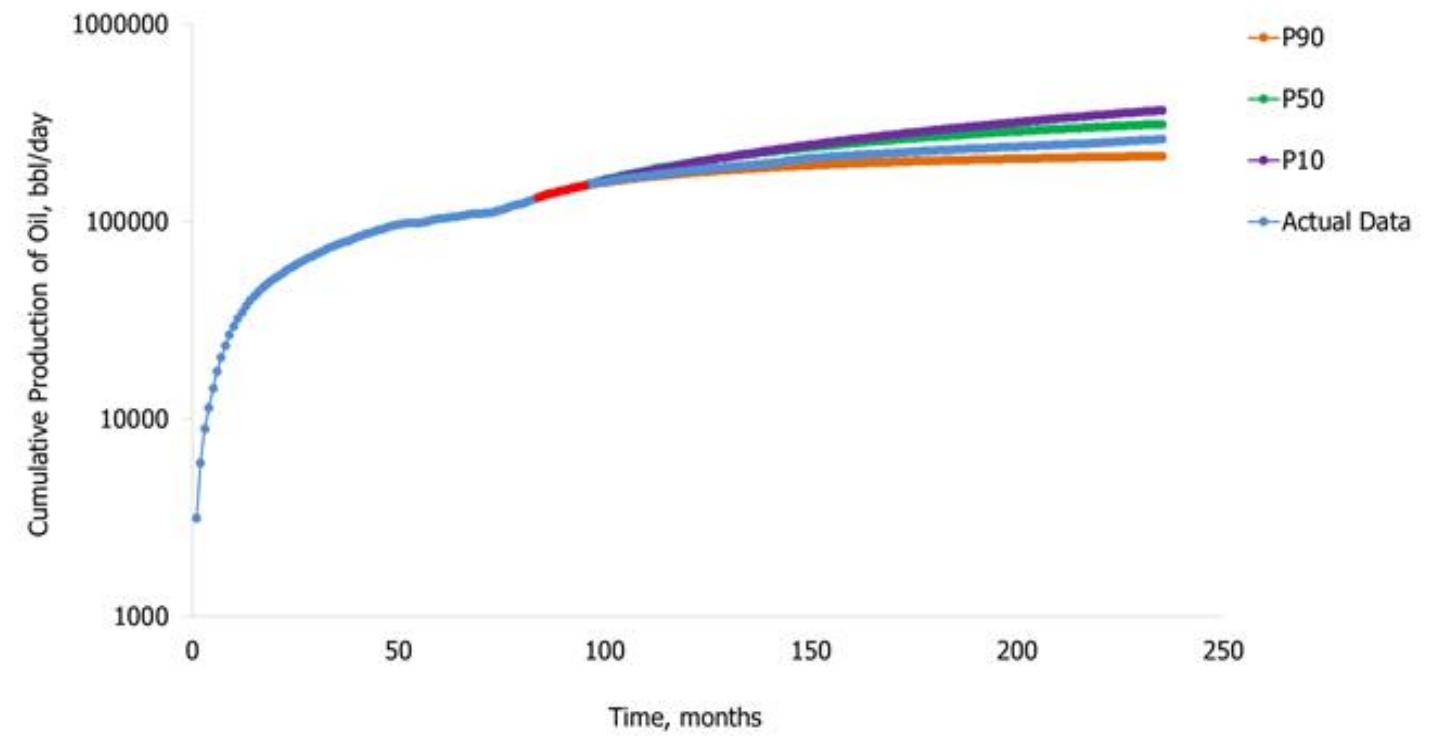

Fig. 35-Probabilistic Hindcast, MCMC with DCA, Well A (Wilmington Oil Field)

Fig. 35, Fig. 36 and Fig. 37 show calibration plots of probabilistic methods used in the study. According to the plots it can be seen that all three methods are well-calibrated; however, the DCA method is noticeably less well calibrated than the others. 


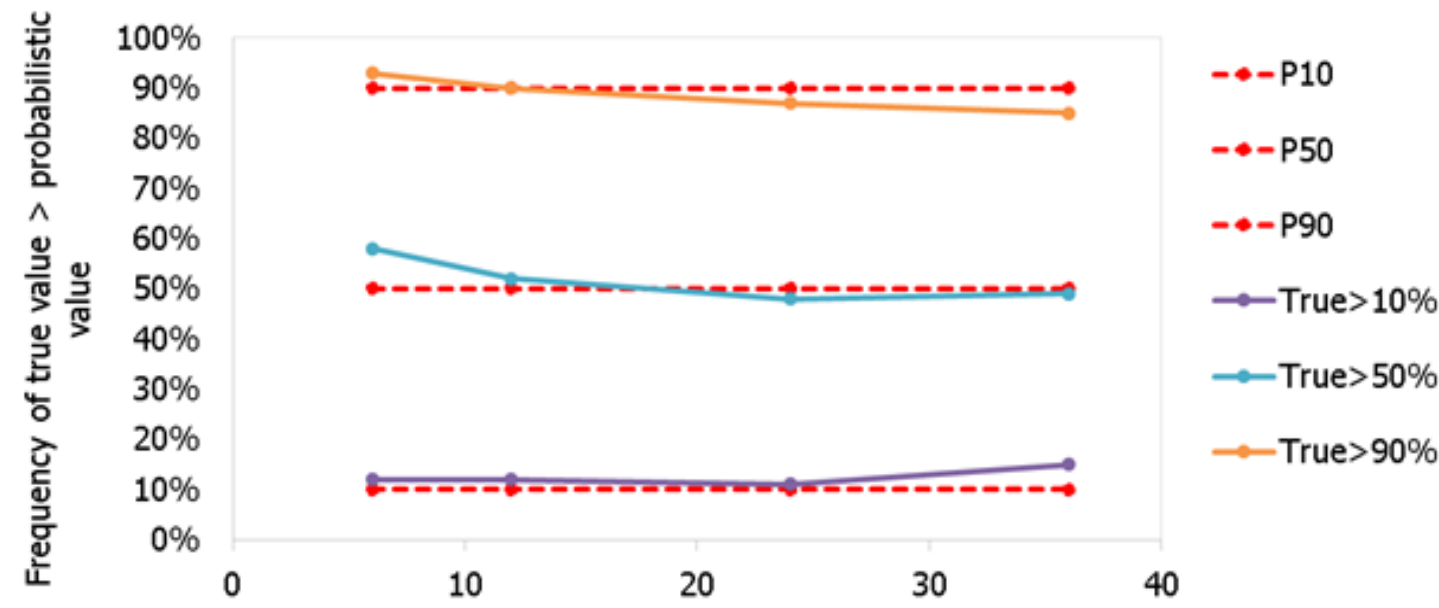

Period of History (months)

Fig. 36 - Calibration Plot, MCMC with WDC

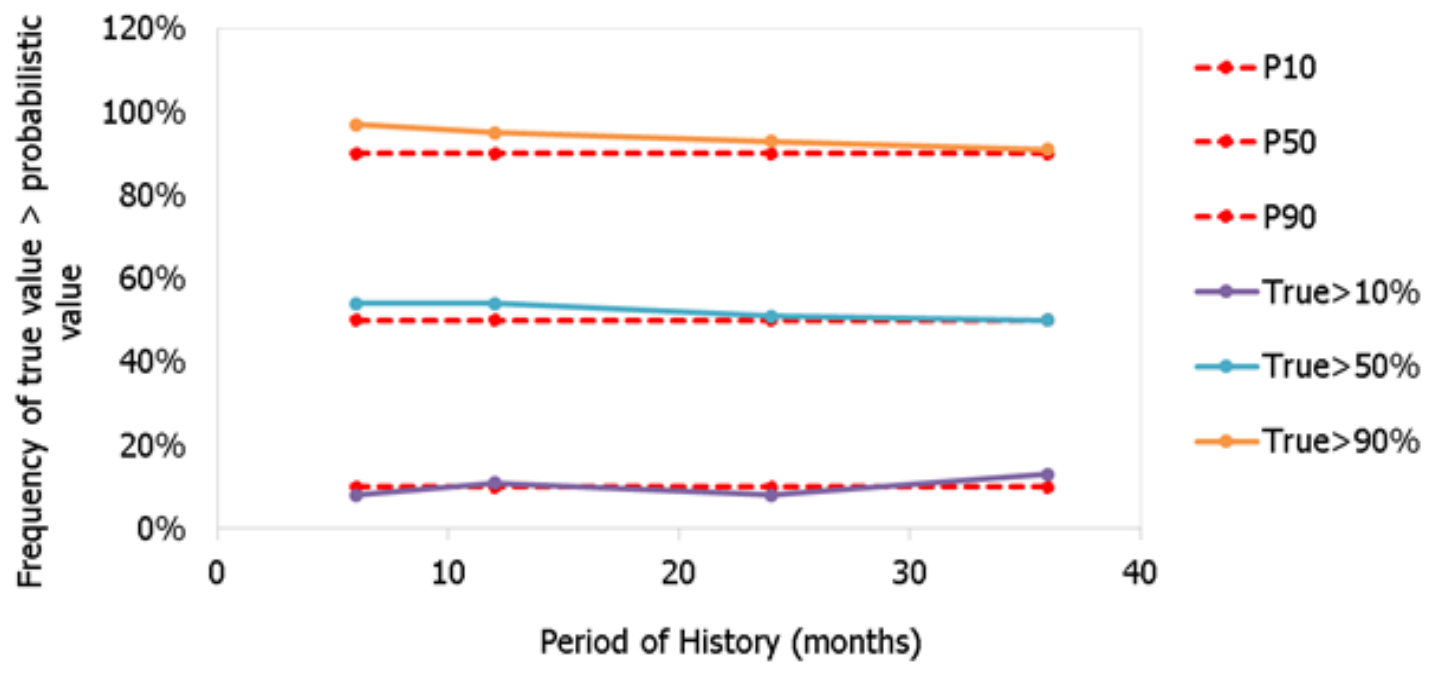

Fig. 37-Calibration Plot, WDC Multimodel 


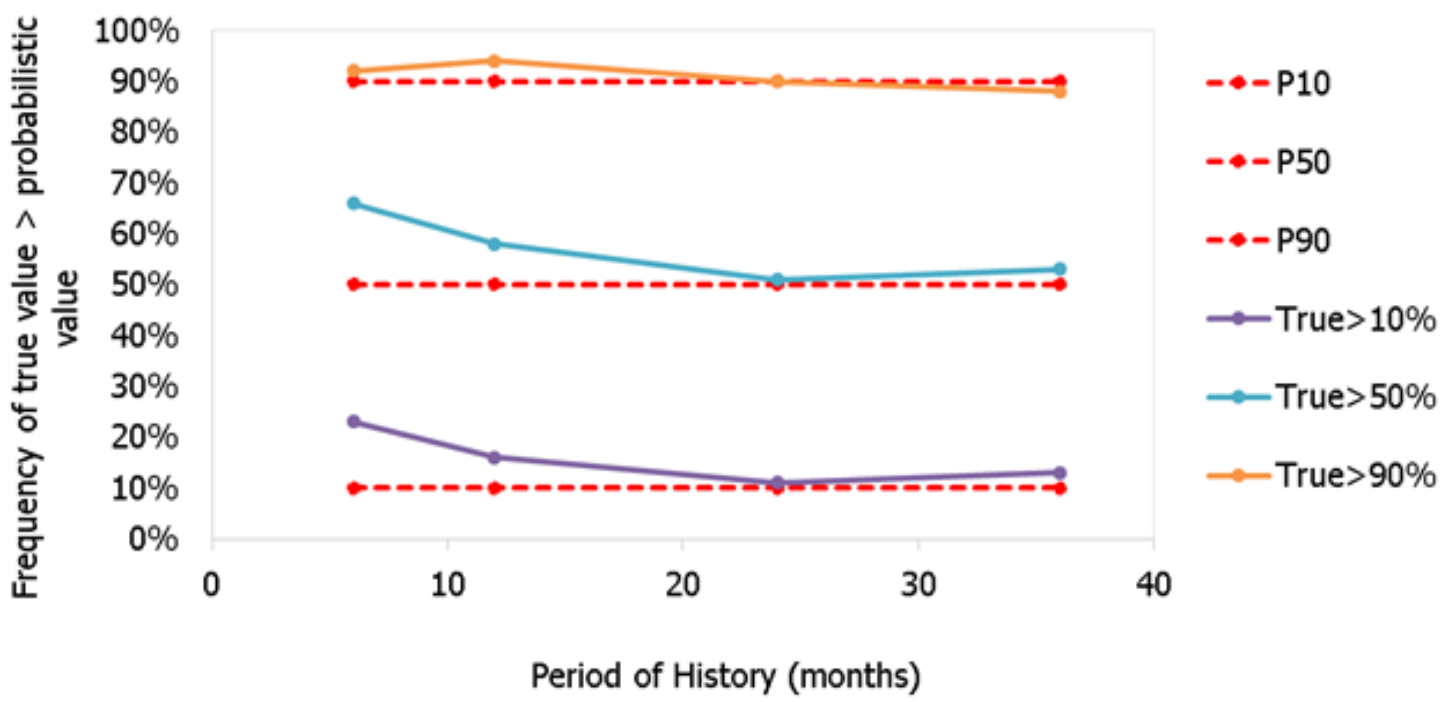

Fig. 38 - Calibration Plot, MCMC with DCA

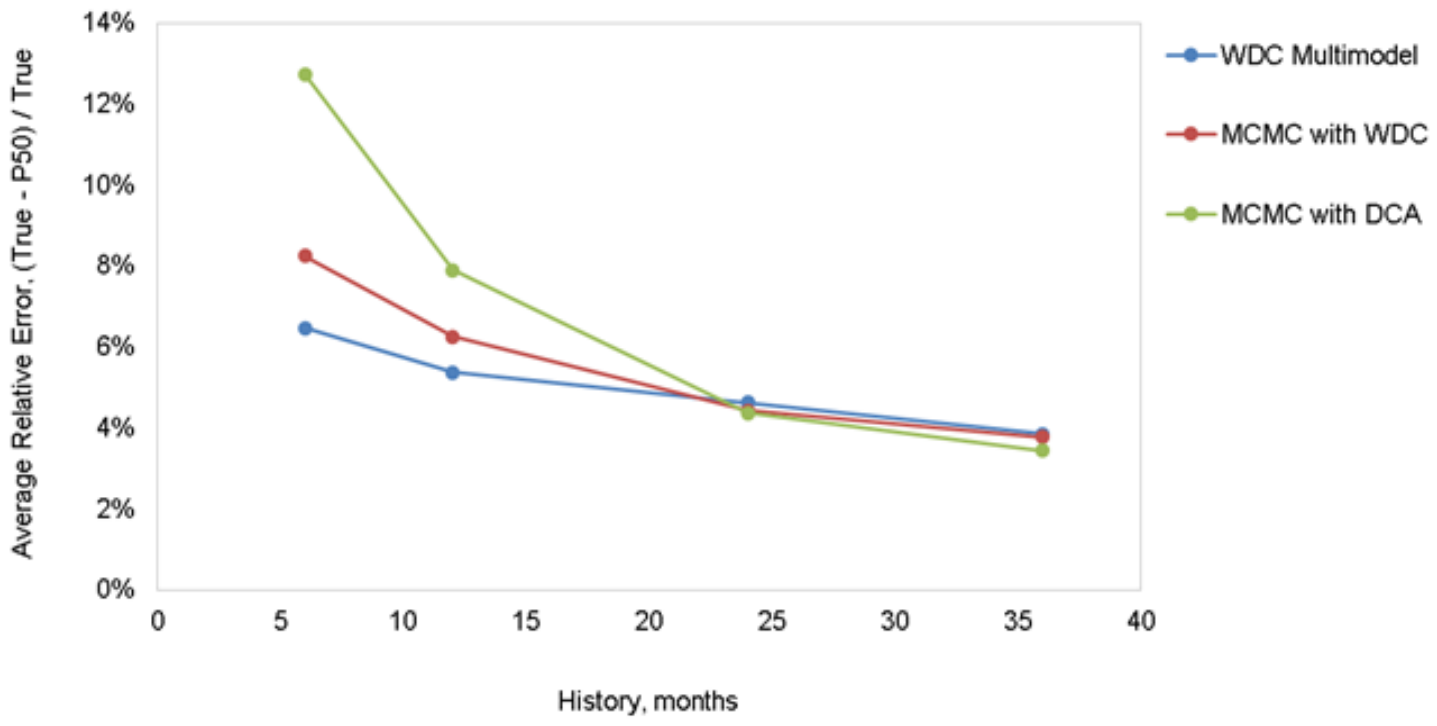

Fig. 39-Average Relative Error (TCP) 


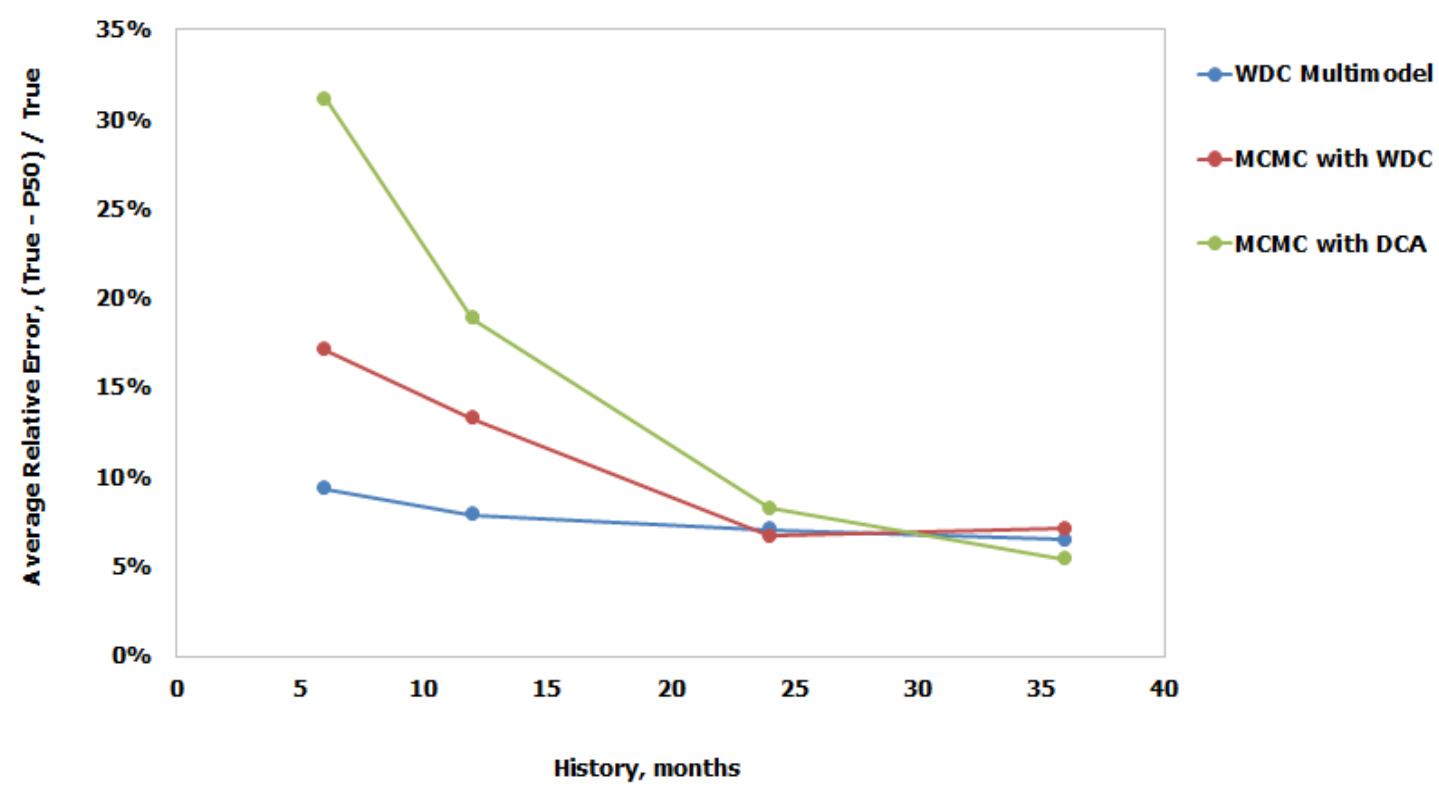

Fig. 40-Average Relative Error (CPOHP)

Fig. 38 and Fig. 39 present Average Relative Error (ARE), Eq. 5.1, using either TCP or $\mathrm{CPOHP}$ of the three probabilistic methods as a function of length of the history matching period. Value of Average Relative Error shows how well the median scenario (P50) of the methodologies match actual oil production. Depending on the methodology and history matching period, ARE varies from $20 \%$ to $45 \%$ for $\mathrm{CPOHP}$ and from $4 \%$ to $13 \%$ for TCP. Compared with MCMC using DCA, WDC Multimodel and MCMC with WDC show more reliable results when the history matching period is less than 24 months.

$\delta_{\mathrm{ARE}}=\sum_{i=1}^{N}\left|\frac{\text { True }_{i}-P 50_{i}}{\text { True }_{i}}\right| \frac{100}{N}$.

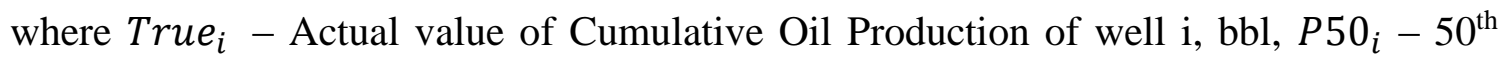
percentile of calculated probability distribution of Cumulative Oil Production of well i, bbl, $\mathrm{N}$ - number of wells. 
Fig. 40 and Fig. 41 present Average Relative Range (ARR), (Eq. 5.2), using either TCP or CPOHP of the three probabilistic methods as a function of length of the history matching period. Depending on the methodology and history matching period, ARR varies from 0.8 to 1.2 for CPOHP and from 0.1 to 0.35 for TCP. The Average Relative Range is decreasing for all methods regardless of history matching period length when we use TCP. When we use CPOHP the ARR is decreasing for MCMC with WDC and WDC Multimodel if the history matching period is less than or equal to 24 months, and relatively constant regardless of history matching period length for MCMC with DCA. Compared with MCMC using DCA and WDC Multimodel, MCMC with WDC shows lower ARR.

$\mathrm{ARR}=\sum_{i=1}^{N}\left|\frac{P 10_{i}-P 90_{i}}{\text { True }_{i}}\right| \frac{1}{N}$

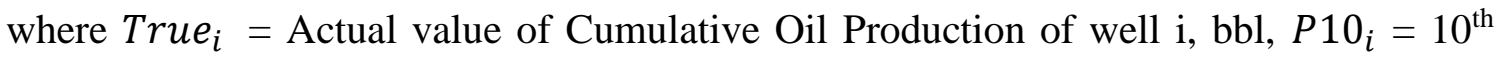
percentile of calculated probability distribution of Cumulative Oil Production of well i, $P 90_{i}=90^{\text {th }}$ percentile of calculated probability distribution of Cumulative Oil Production of well $\mathrm{i}$, bbl, and $\mathrm{N}=$ number of wells. 


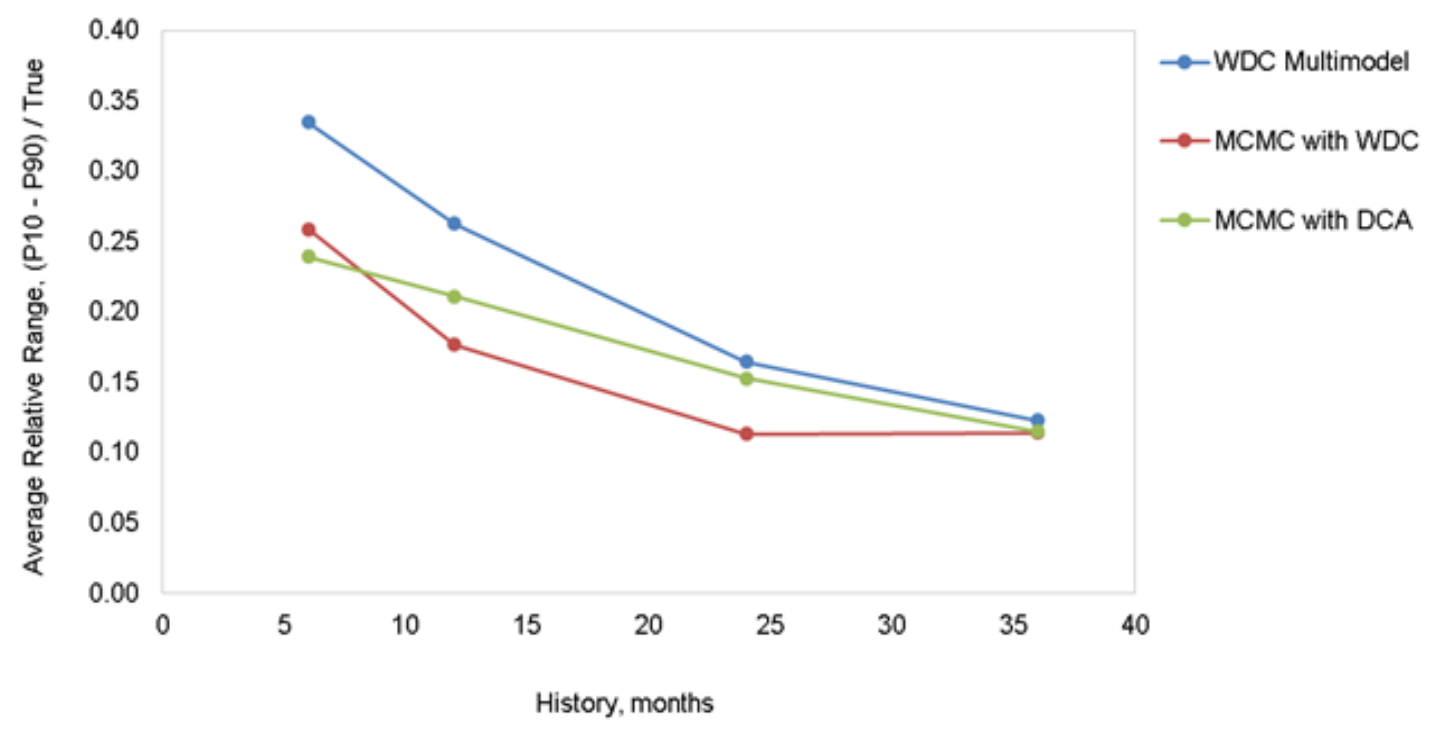

Fig. 41-Average Relative Range (TCP)

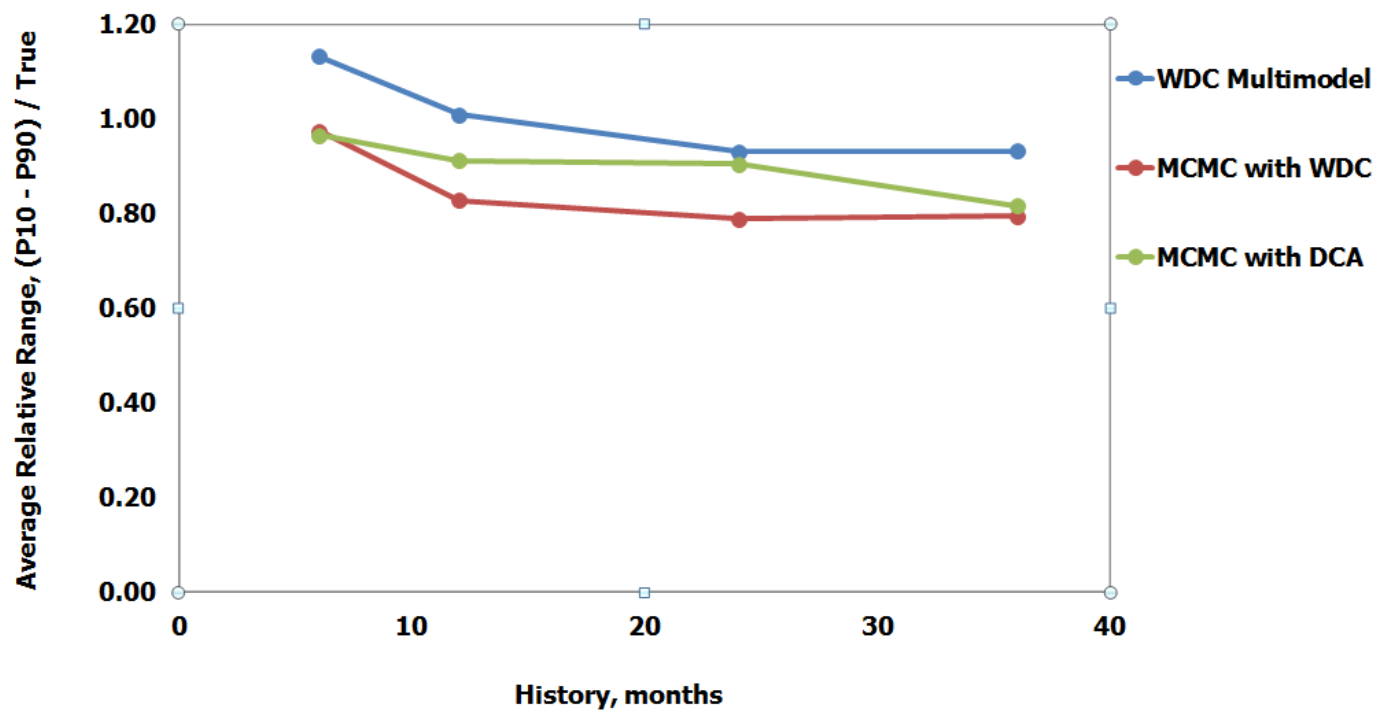

Fig. 42-Average Relative Range (CPOHP) 
In addition, computation time of WDC Multimodel is significantly lower than computation time of MCMC with WDC and MCMC with DCA with a better level of reliability (Fig. 38 and Fig. 39), although it has larger ARR (Fig. 40 and Fig. 41). This is an important advantage for practical application.

Finally, I would like to mention one additional advantage of WDC-based methods as compared to DCA-based methods. The advantage is that they take into account liquid production. When waterflooding is applied, ESP or other types of pumps are used to lift liquid to the surface and engineers can select liquid production rate by changing the speed of the pumps. Thus, we can say that liquid production rate is designed. Also, if the planned rate at which a well is going to produce in the future is known, this rate can be used in the calculations as designed rate. We can also keep production rate as a constant value assuming that we will produce at the same liquid rates. 


\section{CONCLUSIONS}

Based on the hindcast of 100 oil wells from two waterflooded oil fields with 7-12 years of historical data available, the following conclusions have been made:

- WDC Multimodel, MCMC with WDC and MCMC with DCA are overall wellcalibrated probabilistically; however, the DCA method is noticeably less well calibrated than the other two techniques.

- Compared with MCMC using DCA, the WDC Multimodel and MCMC with WDC methods show significantly more reliable results when the history matching period is less than 24 months.

- Compared with MCMC using DCA and WDC Multimodel, the MCMC with WDC shows lower value of ARR.

- The WDC Multimodel method performs more than 20 times faster than the two other techniques, with the same level of reliability but larger ARR.

- An advantage of WDC models over DCA models is that WDC models take into account liquid production. 


\section{LIMITATIONS AND FUTURE WORK}

In this work I applied MCMC with WDC and WDC Multimodel only for two waterflooded oil fields. Thus, for the future work I would propose more testing of MCMC with WDC and WDC Multimodel in different types of reservoirs. 


\section{REFERENCES}

Abyzbaev, Y.Y., Nasyrov, G.G. 1975. Factors that Influence Oil Recovery in Waterflooded Reservoir, The Union of Soviet Socialist Republics, Petroleum Geology Journal, Volume \#2, pp. 60-63.

Anderson, D.M., Nobakht, M., Moghadam, S. and Mattar, L. 2010. Analysis of Production Data from Fractured Shale Gas Wells. Paper presented at the SPE Unconventional Gas Conference, Pittsburgh, Pennsylvania, USA. SPE 131787-MS.

Blasingame, T. A., McCray, T. L., \& Lee, W. J. (1991, January 1). Decline Curve Analysis for Variable Pressure Drop/Variable Flowrate Systems. Society of Petroleum Engineers. Paper presented at the SPE Gas Technology Symposium. Houston, TX. DOI:10.2118/21513-MS

Burger J.G., Combarnous M. 1975. Thermal Methods for Hydrocarbon Production, Journal of Oil \& Gas Science and Technology, IFP, Volume \#30, pp. 551-578.

Cheng, Y., Wang, Y., McVay, D. and Lee, W.J. 2010. Practical Application of a Probabilistic Approach to Estimate Reserves Using Production Decline Data. SPE Economics and Management 2 (1): pp. 1047-1057. DOI: 10.2118/95974pa.

Clark, A.J., Lake, L.W., and Patzek, T.W. 2011. Production Forecasting with Logistic Growth Models. Paper presented at the SPE Annual Technical Conference and Exhibition, Denver, Colorado, USA. SPE 144790-ms. DOI: 10.2118/144790ms.

Dong, Z., Holditch, S.A., and McVay, D.A. 2012. Resource Evaluation for Shale Gas Reservoirs. Paper presented at the SPE Hydraulic Fracturing Technology Conference, The Woodlands, Texas, USA. Society of Petroleum Engineers SPE-152066-MS. DOI: 10.2118/152066-ms.

Drillinginfo. 2014. Drillinginfo.com, http://www.drillinginfo.com/. 
Duong, A.N. 2011. Rate-Decline Analysis for Fracture-Dominated Shale Reservoirs. SPE Reservoir Evaluation \& Engineering 14 (3): pp. 377-387. DOI: 10.2118/137748-pa.

Fetkovich, M.J. 1980. Decline Curve Analysis Using Type Curves. SPE Journal 32 (6): pp. 1065-1077. DOI: 10.2118/4629-pa.

Fetkovich, M.J., Fetkovich, E.J., and Fetkovich, M.D. 1996. Useful Concepts for Decline Curve Forecasting, Reserve Estimation, and Analysis. SPE Reservoir Engineering 11 (1): pp. 13-22. DOI: 10.2118/28628-pa.

Fekete. 2014. Theory and Equations.

http://www.fekete.com/SAN/TheoryAndEquations/HarmonyTheoryEquations /default.htm.

Gaysin, D.K. 1986. Method for Production Performance Forecasting Based on Production Data at the Late Stage of Oil Field Development, The Union of Soviet Socialist Republics, Moscow. Journal of Oil and Gas, Volume \#74, pp. 128-137.

Gentry, R.W., McCray, A.W. 1978. The Effect of Reservoir and Fluid Properties on Production Decline Curves, Journal of Petroleum Technology, Volume \#30, pp. 1327-1341.

Gong, X., Gonzalez, R., McVay, D. 2011. Bayesian Probabilistic Decline Curve Analysis Quantifies Shale Gas Reserves Uncertainty. Paper presented at the Canadian Unconventional Resources Conference, Alberta, Canada. SPE 147588. DOI: $10.2118 / 147588-\mathrm{ms}$

Gonzalez, R., Gong, X., and McVay, D.A. 2012. Probabilistic Decline Curve Analysis Reliably Quantifies Uncertainty in Shale Gas Reserves Regardless of Stage of Depletion. Paper presented at the SPE Eastern Regional Meeting, Lexington, Kentucky, USA. Society of Petroleum Engineers SPE-161300MS. DOI: 10.2118/161300-ms. 
Guidelines for Analyzing Oil and Gas Fields Development Strategies RD 153-39.0110-01. 2002. Moscow. Russian Federation Ministry of Energy.

Ilk, D., Rushing, J.A., Perego, A.D. et al. 2008. Exponential vs. Hyperbolic Decline in Tight Gas Sand: - Understanding the Origin and Implications for Reserve Estimates Using Arps' Decline Curves. Paper presented at the SPE Annual Technical Conference and Exhibition, Denver, Colorado, USA. Society of Petroleum Engineers 116731. DOI: 10.2118/116731-ms.

Jochen, V.A. and Spivey, J.P. 1996. Probabilistic Reserves Estimation Using Decline Curve Analysis with the Bootstrap Method. Paper presented at the SPE Annual Technical Conference and Exhibition, Denver, Colorado. SPE 36633-MS.

Kambarov, G.S., Almamedov, D.G., Mahmudova, T.Y. 1975. Estimated Ultimate Recovery evaluation, The Union of Soviet Socialist Republics, Azerbaijan Republic. Journal of Azerbaijan Oil and Gas, Volume \#3, pp. 800-900.

Kazakov, A.A. 1976. Forecasting production performance using Water Displacement Curves Models, The Union of Soviet Socialist Republics, Journal of Petroleum Engineering, Volume \#8, pp. 5-7.

Liu, C. and McVay, D.A. 2009. Continuous Reservoir Simulation Model Updating and Forecasting Using a Markov Chain Monte Carlo Method. Paper presented at the SPE Reservoir Simulation Symposium, The Woodlands, Texas. 119197MS.

Lo, K.K., Warner, H.R., and Johnson, J.B. 1990. A Study of the Post-Breakthrough Characteristics of Waterflood. 20064-MS SPE Conference Paper. DOI:10.2118/20064-MS.

Maksimov M.I. 1959. Method for Estimating Ultimate Recoverable Reserves of Waterflooded Oil Reservoirs at the Late Stage of Field Development, The Union of Soviet Socialist Republics, Moscow, Journal of Petroleum Geology, Volume \#3, pp. 42-47. 
Masoner, L.O. 1996. A Decline Analysis Technique Incorporating Corrections for Total Fluid Rate Changes, SPE 36695, SPE Annual Tech. Conf., Denver, CO, October 6-9, pp. 171-182.

Mattar, L. 2008. Production Analysis and Forecasting of Shale Gas Reservoirs: Case History-Based Approach. Paper presented at the SPE Shale Gas Production Conference, Fort Worth, Texas, USA. SPE 119897-ms. DOI: 10.2118/119897ms.

McKinney, P.D., Rushing, J.A., and Sanders, L.A. 2002. Applied Reservoir Characterization for Maximizing Reserve Growth and Profitability in Tight Gas Sands: A Paradigm Shift in Development Strategies for Low-Permeability Gas Reservoirs. Paper presented at the SPE Gas Technology Symposium, Calgary, Alberta, Canada. Copyright 2002, Society of Petroleum Engineers Inc. 00075708. DOI: 10.2118/75708-ms.

McVay, D.A., Dossary, M.N. 2014. The Value of Assessing Uncertainty. SPE Journal 6 (2): pp. 100-110. DOI: 10.2118/160189-pa.

Mishenko, I.T., Ibragimov, L.H., Sitnikov, A.A. and Gusev, S.V. 1998. Forecasting Production Performance using Water Displacement Curves. Russia, Moscow. Methodological instructions for Students Majoring in Petroleum Engineering, Gubkin Russian State University of Oil and Gas, Department of Petroleum Engineering.

Nazarov, S.N., Sypachev N.V. 1972. Estimating Recoverable Reserve at the Last Stage of Field Development, The Union of Soviet Socialist Republics. Journal of Oil and Gas, Volume \#10, pp. 41-45.

Pirverdyan, A.M., Nikitin, P.I., Listengarten, L.B., Danelyan, M.G. 1970. Forecasting Oil and Water Production in Heterogeneous Layered Reservoirs, The Union of Soviet Socialist Republics, Azerbaijan Republic. Journal of Azerbaijan Oil and Gas, Volume \#3, pp. 22-23. 
Qitai, Y. 2000. A Generalized Water Displacement Curve of Forecasting Oilfield Development Indexs. Paper presented at SPE International Oil and Gas Conference and Exhibition in China, Beijing, China. Society of Petroleum Engineers SPE 64717.

Sabaev, S. 2006. Application of Analytical Solutions to Improve Economic Efficiency of Oil Production Operations Under Depletion Conditions, Part 1: Optimizing the Number of Wells, Economics and Management in the Oil and Gas Industry, VNIIO-ENG Publisher, Moscow, Russia.

Savelyev, V.A., Tokarev, M.A., Chinarov, A.S. 2008. Practical Methods for Forecasting Oil Production, Russia, Izgevsk. Methodological instructions for Students Majoring in Petroleum Engineering, Udmurtsky University.

Sazonov, B.F. 1973. Improving Recovery Technologies in Waterflooded Oil Fields, The Union of Soviet Socialist Republics, Moscow. NEDRA.

SEC. 2009. Modernization of Oil and Gas Reporting. http://www.sec.gov/rules/final/2008/33-8995.pdf .

SPE, AAPG, WPC et al. 2007. Petroleum Resources Management System. http://www.spe.org/industry/docs/Petroleum_Resources_Management_System _2007.pdf.

Sypachev, A.G., Posevich A.G., Nazarov. S.N., Akramov B.S., Kleverkov V.V., Sidikhodgaev R.K. 1972. Evaluation of Estimated Ultimate Recovery using Water Displacement Curve Models, The Union of Soviet Socialist Republics, Azerbaijan Republic. Journal of edition of Azerbaijan Oil and Gas, Volume \#5, pp. 20-21.

Valko, P.P. and Lee, W.J. 2010. A Better Way to Forecast Production from Unconventional Gas Wells. Paper presented at the SPE Annual Technical Conference and Exhibition, Florence, Italy. Society of Petroleum Engineers 134231. DOI: 10.2118/134231-ms. 
Welge, H.J. 1959. A Simplified Methods for Computing Oil Recovery by Gas or Water Drive, Transactions, AIME, Volume \#195, pp. 91-98.

Wolcott, D. 2009. Applied Waterflood Field Development, Energy Tribune Publishing Inc., Houston, TX.

Zgdanov, S.A., Mishenko, I.T. 1996. Estimating Efficiency of Well Stimulation Techniques using Water Displacement Curves, Russia, Moscow. Methodological Instructions for Students Majoring in Petroleum Engineering, Department of Petroleum Engineering, Gubkin Russian State University of Oil and Gas. 